\title{
1998 Annual Report on the Implementation of Office of Management and Budget (OMB) Circular A-119 and P.L. 104-113
}

Patrick Cooke, Editor Barbara Meigs, Editor

Belinda Collins, Editor

United States Department of Commerce

Technology Administration

National Institute of Standards and Technology

Gaithersburg, MD 20899 
. .

.

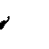




\section{Annual Report on the Implementation of Office of Management and Budget (OMB) Circular A-119 and P.L. 104-113}

Patrick Cooke, Editor Barbara Meigs, Editor Belinda Collins, Editor

March 2000

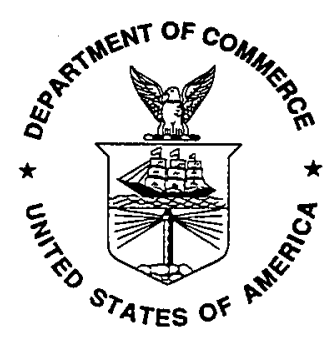

U. S. Department of Commerce

William M. Daley, Secretary

Technology Administration

Dr. Cheryl L. Shavers, Under Secretary of Commerce for Technology

National Institute of Standards and Technology

Raymond G. Kammer, Director 


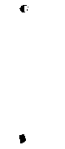

,

.

, 


\title{
ANNUAL REPORT ON THE IMPLEMENTATION OF OMB CIRCULAR A-119 AND P.L. 104-113 COVERING THE PERIOD OCTOBER 1, 1997, THROUGH SEPTEMBER 30, 1998
}

\section{Table of Contents}

Preface $\ldots \ldots \ldots \ldots \ldots \ldots \ldots \ldots \ldots \ldots \ldots \ldots \ldots \ldots \ldots \ldots \ldots \ldots \ldots \ldots \ldots$

OMB Transmittal Letter to Congress $\ldots \ldots \ldots \ldots \ldots \ldots \ldots \ldots \ldots \ldots \ldots \ldots$ vii

\begin{abstract}
ANNUAL REPORT:
\end{abstract}

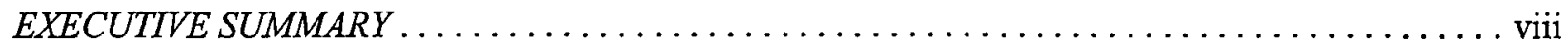

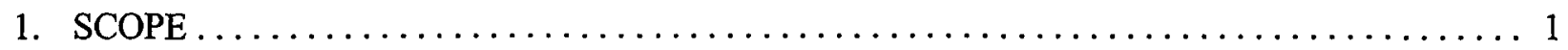

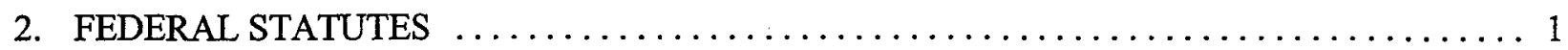

2.1 National Technology Transfer and Advancement Act (Public Law 104-113) . . . . . . . . . 1

$2.2 \mathrm{OMB}$ Circular A119 and Public Law 104-113 $\ldots \ldots \ldots \ldots \ldots \ldots \ldots \ldots \ldots \ldots \ldots$

2.2.1 Agencies' use of voluntary consensus standards versus government-unique standards . . . . 1

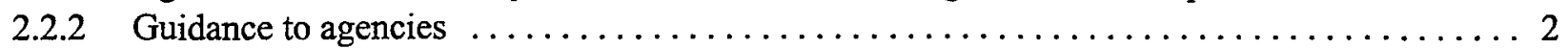

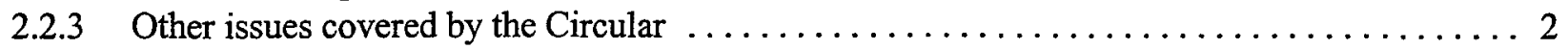

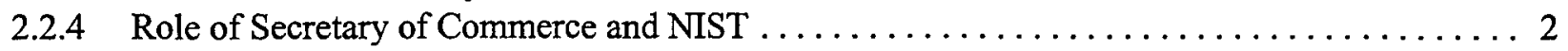

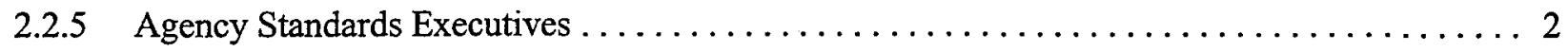

3. INTERAGENCY COMMITTEE ON STANDARDS POLICY (ICSP) $\ldots \ldots \ldots \ldots \ldots \ldots \ldots 2$

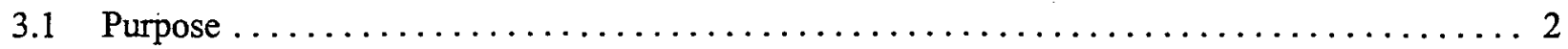

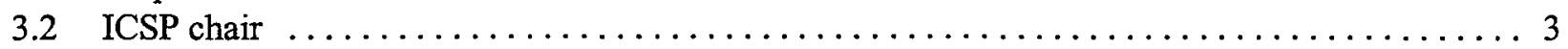

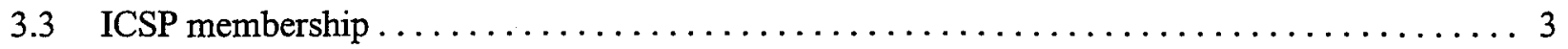

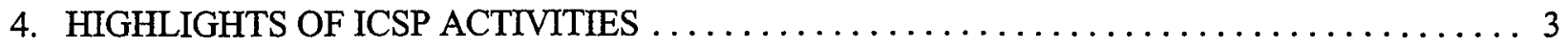

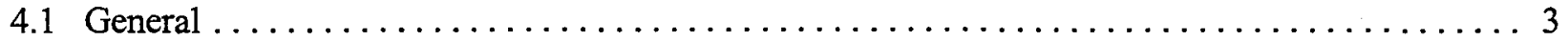

4.2 Interaction with private-sector standards organizations $\ldots \ldots \ldots \ldots \ldots \ldots \ldots \ldots \ldots \ldots \ldots$

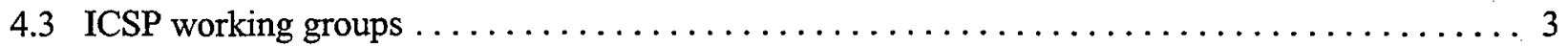

5. HIGHLIGHTS OF FEDERAL AGENCY ACTIVITIES $\ldots \ldots \ldots \ldots \ldots \ldots \ldots \ldots \ldots \ldots \ldots$

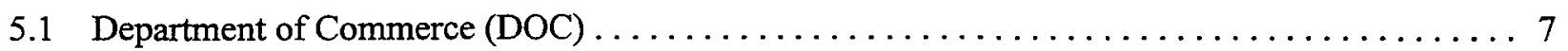

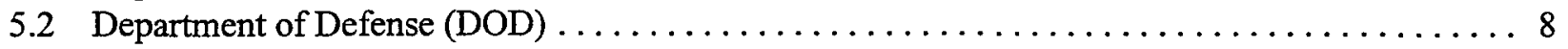

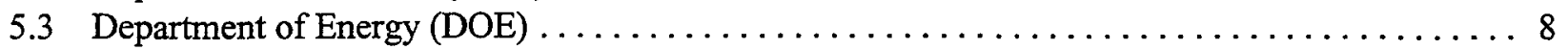

5.4 Department of Health and Human Services (HHS) - Food and

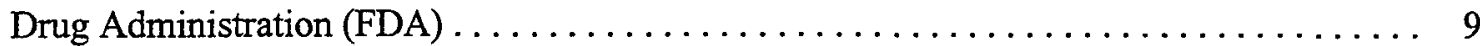

5.5 Department of Housing and Urban Development (HUD) $\ldots \ldots \ldots \ldots \ldots \ldots \ldots \ldots \ldots \ldots$

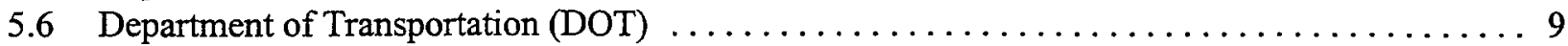

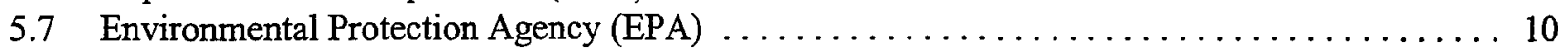

5.8 Federal Communications Commission (FCC) $\ldots \ldots \ldots \ldots \ldots \ldots \ldots \ldots \ldots \ldots \ldots \ldots \ldots \ldots$

5.9 National Aeronautics and Space Administration (NASA) $\ldots \ldots \ldots \ldots \ldots \ldots \ldots \ldots \ldots \ldots$ 
6. AGENCY USE OF GOVERNMENT-UNIQUE STANDARDS IN LIEU OF VOLUNTARY

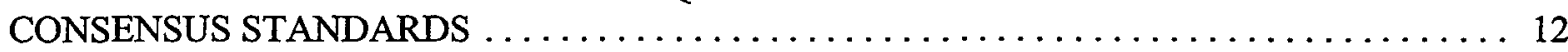

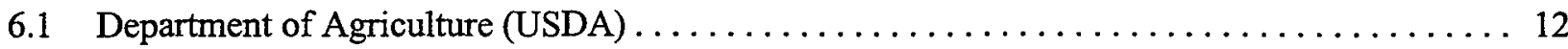

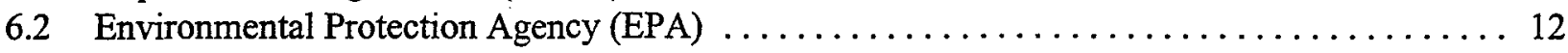

6.3 National Aeronautics and Space Administration (NASA) $\ldots \ldots \ldots \ldots \ldots \ldots \ldots \ldots \ldots \ldots \ldots$

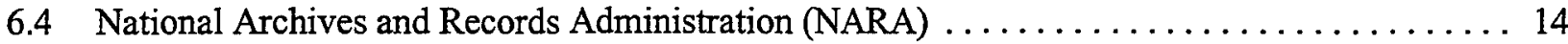

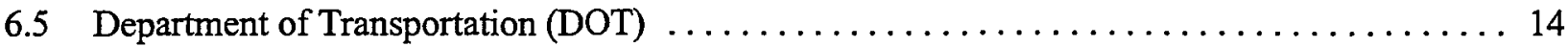

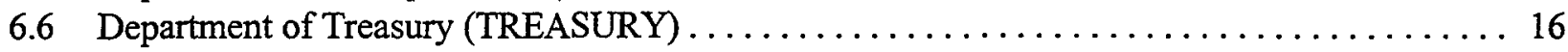

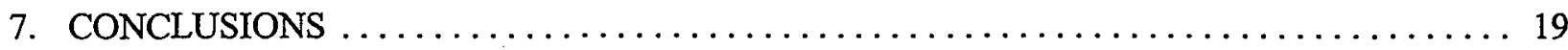

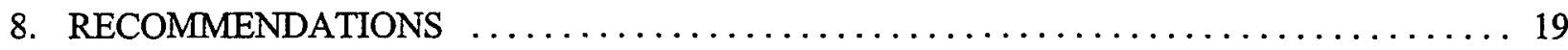

APPENDIX A: CABINET DEPARTMENT REPORTS $\ldots \ldots \ldots \ldots \ldots \ldots \ldots \ldots \ldots \ldots \ldots \ldots \ldots \ldots$

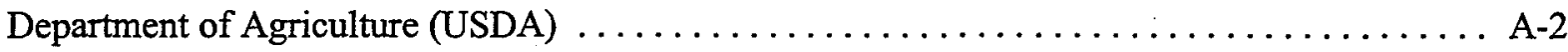

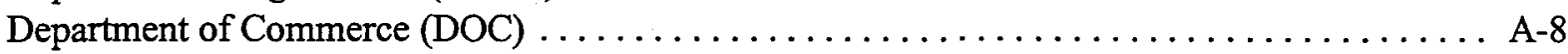

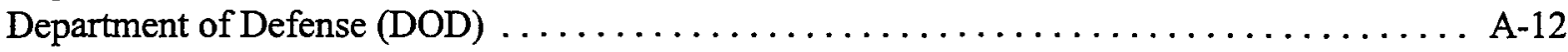

National Communication System (NCS) $\ldots \ldots \ldots \ldots \ldots \ldots \ldots \ldots \ldots \ldots \ldots \ldots \ldots \ldots \ldots \ldots \ldots \ldots \ldots \ldots$

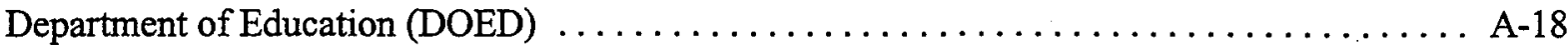

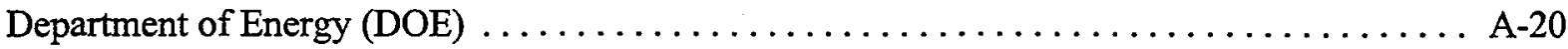

Federal Energy Regulatory Commission (FERC) $\ldots \ldots \ldots \ldots \ldots \ldots \ldots \ldots \ldots \ldots \ldots \ldots \ldots$

Health and Human Services, Department of (HHS)

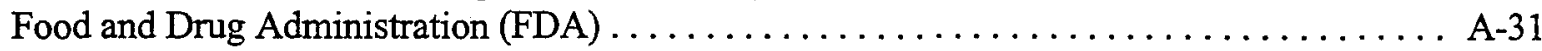

Department of Housing and Urban Development (HUD) $\ldots \ldots \ldots \ldots \ldots \ldots \ldots \ldots \ldots \ldots$ A-37

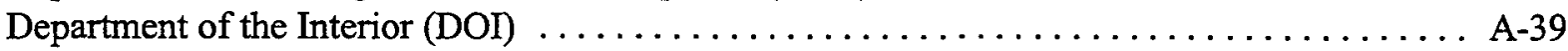

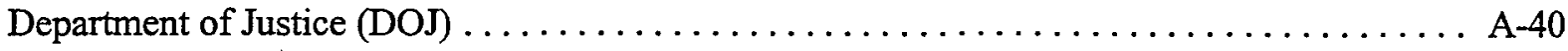

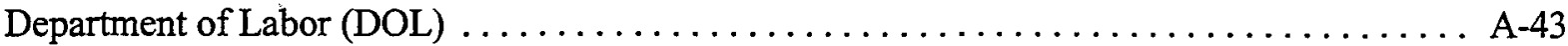

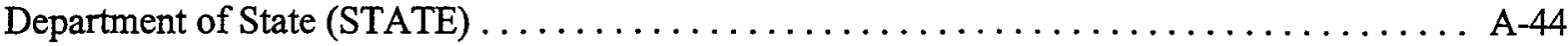

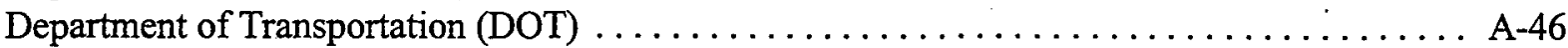

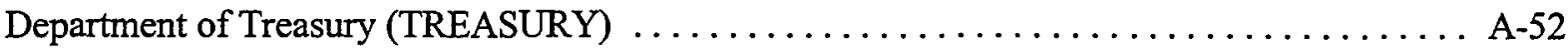

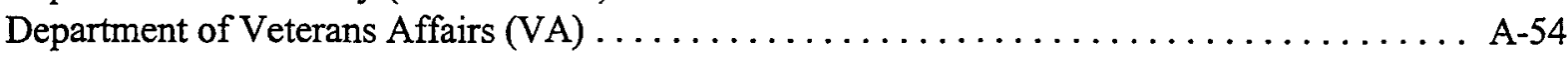

APPENDIX B: OTHER AGENCY REPORTS $\ldots \ldots \ldots \ldots \ldots \ldots \ldots \ldots \ldots \ldots \ldots \ldots \ldots \ldots \ldots \ldots \ldots \ldots$

Consumer Product Safety Commission (CPSC) $\ldots \ldots \ldots \ldots \ldots \ldots \ldots \ldots \ldots \ldots \ldots \ldots \ldots \ldots \ldots \ldots \ldots$

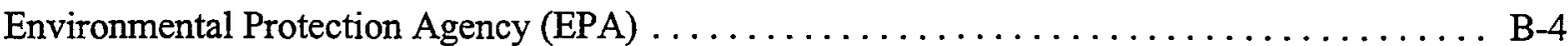

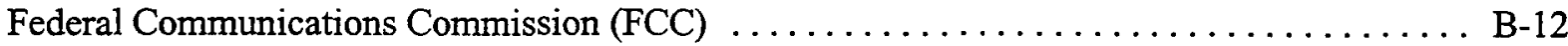

Federal Emergency Management Agency (FEMA) $\ldots \ldots \ldots \ldots \ldots \ldots \ldots \ldots \ldots \ldots \ldots \ldots$

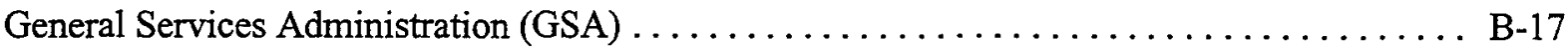

National Aeronautics and Space Administration (NASA) $\ldots \ldots \ldots \ldots \ldots \ldots \ldots \ldots \ldots$ B-18

National Archives and Records Administration (NARA) $\ldots \ldots \ldots \ldots \ldots \ldots \ldots \ldots \ldots \ldots$ B-22

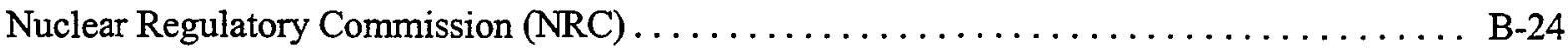

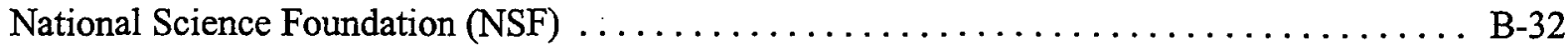

APPENDIX C: CHARTER OF THE INTERAGENCY COMMITTEE ON STANDARDS

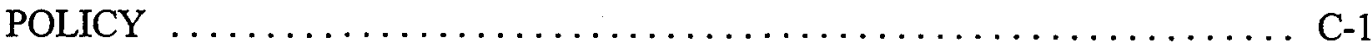


APPENDIX D: MEMBERSHIP OF THE INTERAGENCY COMMITTEE ON STANDARDS

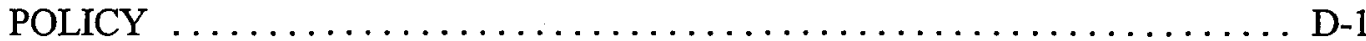

APPENDIX E: LIST OF NIST PUBLICATIONS RELATED TO P.L. $104-113 \ldots \ldots \ldots \ldots \ldots$ E-1

PROTECTED UNDER INTERNATIONAL COPYRIGHT

ALL RIGHTS RESERVED

NATIONAL TECHNICAL INFORMATION SERVICE

U.S. DEPARTMENT OF COMMERCE 


\section{PREFACE}

The Office of Management and Budget (OMB) Circular A-119, "Federal Participation in the Development and use of Voluntary Standards," and Section 12 of P.L. 104-113 (the National Technology Transfer and Advancement Act) direct that the National Institute of Standards and Technology prepare an annual report providing information on Federal use of voluntary consensus standards for OMB to transmit to Congress. The present report provides Federal standards-related information for fiscal year 1998 (FY 98). This FY 98 report also contains material finalized during 1999, including the revised OMB Circular A-119, "Federal Participation in the Development and Use of Voluntary Consensus Standards and in Conformity Assessment Activities," that gives greater guidance for Federal compliance with P.L. 104-113. The FY 99 report will also report against the revised Circular. The full report is also available at http://ts.nist.gov/icsp. 


\section{EXECUTIVE OFFICE OF THE PRESIDENT \\ OFFICE OF MANAGEMENT AND BUDGET \\ WASHINGTON, D.C. 20503 \\ Yarch 9,2000}

The Honorable Constance A. Morella

Chairwoman, Subcommittee on Technology

Committee on Science

U.S. House of Representatives

Washington, D.C. 20515-6301

\section{Dear Madam Chairwoman:}

I am pleased to submit the annual report on the implementation of OMB Circular A-119, "Federal Participation in the Development and Use of Voluntary Consensus Standards," as required by the "National Technology Transfer Act Amendments of 1996" (NTTAA) (P.L. 104 113). This report was prepared by the National Institute of Standards and Technology (NIST) at the Department of Commerce at the request of the Office of Management and Budget. The report contains submissions by affected agencies as well as a summary of Federal activity for the period October 1, 1997 through September 30, 1998. The report also contains recommendations from the Department of Commerce to strengthen and improve Federal agency implementation of the NTTAA and OMB Circular A-119.

The report notes that, during the reporting period, agencies adopted 1,876 voluntary consensus standards in their new procurement and reguiatory activities. During this period, agencies also substituted 146 voluntary consensus standards for government-unique standards in their ongoing procurement and regulatory activities.

The report also describes four instances in which government unique standards were used in lieu of voluntary consensus standards, three at the Environmental Protection Agency and one at the Department of Transportation. Some agencies provided additional information on their use of government unique standards where no voluntary consensus standard alternative existed. .

Thank you for your ongoing interest in and support for policies related to Federal use of voluntary consensus standards.

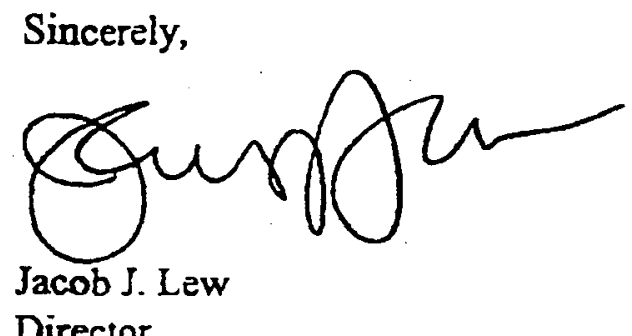

Enclosure

Identical Letter Sent to The Honorable James A. Barcia,

The Honorable F. James Sensenbrenner, Jr., and The Honorable Ralph M. Hall 


\section{EXECUTIVE SUMMARY}

OMB Circular A-119', Federal Participation in the Development and Use of Voluntary

Consensus Standards and in Conformity Assessment Activities, requires the National Institute of Standards and Technology (NIST) to report annually to the Office of Management and Budget (OMB) on the progress that Federal agencies have made toward using voluntary standards rather than agencyunique standards. OMB Circular A-119 also calls for a report on the efforts of NIST in coordinating agencies' use of voluntary standards and their participation in standardization activities. Finally, the Circular also requires NIST to provide summaries of the status of individual agencies' use of standards and of their participation and interaction with private-sector voluntary standards bodies.

Public Law 104-113, the National Technology Transfer and Advancement Act (for which the A-119 Circular provides guidance to Federal agencies) requires Federal agencies to use voluntary standards to the extent practicable, and to report when they have developed agency-specific standards. The present report addresses the development of agency-unique standards, the extent and nature of participation by Federal agencies in the development of voluntary standards, their use of voluntary standards, and an evaluation of the effectiveness of the policy promulgated in the Circular.

This report covers the period from October 1, 1997 through September 30, 1998, fiscal year 1998.

NIST has chosen to rely on and strengthen the Interagency Committee on Standards Policy (ICSP) as the primary means of fulfilling NIST's responsibilities for coordinating Federal standards-related activities. This report describes NIST's coordination activities with special emphasis on implementing the NTTAA and the activities of the ICSP and its working groups, including an overview of standards policy coordination, related external events, compliance with the NTTAA, and future courses of action.

As chair of the ICSP, NST in September 1998 requested that each agency provide information on the status of its implementation of both the OMB Circular A-119 and the NTTAA. The Circular and the NTTAA require that each agency collect specific information regarding the status of its implementation activities: information regarding agency use of government-unique standards, data on the use of voluntary consensus standards, and the number of voluntary standards substituted for governmentunique standards, and the number of individual agency participants in voluntary standards bodies. That information is reported in Table 1 of the report; a summary of the collected data is shown in the following table:

${ }^{1}$ OMB issued a newly-revised Circular A-119 on February 19, 1998. 


\begin{tabular}{|c|c|c|c|c|c|c|}
\hline \multicolumn{7}{|c|}{$\begin{array}{l}\text { FY } 98 \text { Statistics on Federal Agencies' Participation in Development of and Adoption of } \\
\text { Voluntary Consensus Standards }\end{array}$} \\
\hline \multicolumn{2}{|c|}{$\begin{array}{l}\text { Number of Voluntary } \\
\text { Consensus Standards } \\
\text { Bodies in which } \\
\text { Agencies Reported } \\
\text { Participation }\end{array}$} & \multicolumn{2}{|c|}{$\begin{array}{l}\text { Number of Agencies' } \\
\text { Employees Participating } \\
\text { in Voluntary Consensus } \\
\text { Standards Bodies }\end{array}$} & \multirow[t]{2}{*}{$\begin{array}{l}\text { Number of } \\
\text { additional } \\
\text { Voluntary } \\
\text { Consensus } \\
\text { Standards } \\
\text { used in FY } 98\end{array}$} & \multirow{2}{*}{$\begin{array}{l}\text { Number of } \\
\text { Voluntary } \\
\text { Consensus } \\
\text { Standards } \\
\text { substituted in } \\
\text { FY } 98 \text { for } \\
\text { Government- } \\
\text { Unique } \\
\text { Standards }\end{array}$} & \multirow{2}{*}{$\begin{array}{l}\text { Number of } \\
\text { Government- } \\
\text { Unique } \\
\text { Standards Used } \\
\text { in Lieu of } \\
\text { Voluntary } \\
\text { Consensus } \\
\text { Standards in } \\
\text { FY } 98\end{array}$} \\
\hline FY 1998 & $\begin{array}{l}\text { Change } \\
\text { from } \\
\text { FY } 97\end{array}$ & FY 1998 & $\begin{array}{l}\text { Change } \\
\text { from } \\
\text { FY } 97\end{array}$ & & & \\
\hline 869 & -25 & 3242 & -99 & 1876 & 146 & 4 \\
\hline
\end{tabular}

${ }^{1}$ Not reflected in the chart are the total numbers of voluntary consensus standards adopted by Federal agencies and those in the process of being adopted. For example, DOD reported as of FY 98 their total number of adopted voluntary consensus standards was 7,991. DOE reported their total as of FY 98 as 840 . NASA reported that it had an additional 400 voluntary consensus standards that were in the final stages of review as candidates for formal adoption by NASA.

Beyond the simple adoption of voluntary consensus standards, Federal agencies are also continuing to implement P.L. 104-113 and the revised OMB Circular A-119 successfully. Many agencies, including the EPA, DOD, and NASA, have developed procedures for alerting the public about proposed regulations and procurement actions that involve voluntary consensus standards. The EPA has developed wording for inclusion in its notices of proposed rulemaking to draw attention to opportunities for using voluntary consensus standards which allow standards-developing organizations the opportunity to bring possible standards activities to the attention of the agency.

Most agencies have made serious attempts to justify the use of government-unique standards, with only one instance of failure to use an existing standard reported. In most other cases there was no applicable standard. Most agencies are putting procedures into place for identifying existing standards when proposing new regulations or in procurement activities. DOD continues to move Mil-Specs into the voluntary sector on a deliberate basis. Some agencies, notably the NRC, have convened workshops with interested standards-development organizations (SDOs), other agencies, and key stakeholders to address use of voluntary consensus standards in their regulations. Finally, private sector SDOs have also instituted briefing sessions with Federal agencies to address the issue of references to out-of-date standards in regulation.

The decline in agency participation in standards committee activities noted in the FY 97 report appears to have leveled off, but will need to be monitored on an ongoing basis as indicated by the statistics on Federal participation in development of and adoption of voluntary consensus standards. 
Appended to the NIST report are the reports sent to NIST from the Cabinet Departments and Independent Agencies. They are provided in Appendices A and B, with minimal or no editing and formatting. Copies of the ICSP charter, the FY 98 ICSP membership list, and a list of NIST publications related to P.L. 104-113 are provided in Appendices C, D, and E, respectively. 


\section{Annual Report to the Office of Management and Budget on Implementation of OMB Circular A-119}

\section{SCOPE}

This report provides an account of the progress that Federal agencies have made in the use of voluntary consensus standards (VCS) and their participation in standardization activities. It also provides highlights of the status of agencies' interactions with private-sector voluntary consensus standards bodies, agencies' use of government-unique standards, and the activities of the Interagency Committee on Standards Policy (ICSP). It also reports the progress that the National Institute of Standards and Technology (NIST) has made in coordinating Federal agencies' standards-related efforts, including interactions with key private-sector organizations. This report covers the period from October 1, 1997, through September 30, 1998.

Appendices A and B provide copies of the full reports that NIST received from Cabinet Departments and Independent Agencies. Appendices C, D, and E, respectively, provide copies of the ICSP Charter, ICSP membership, and a list of NIST publications related to P.L. 104-113.

\section{FEDERAL STATUTES}

2.1 National Technology Transfer and Advancement Act (NTTAA) - Public Law 104-113, the National Technology Transfer and Advancement Act of 1995, codified existing policies of OMB Circular A-119, established reporting requirements, and authorized NIST to coordinate standards-conformity assessment activities of Federal agencies, and with the private sector.

2.2 OMB Circular A-119 and Public Law 104-113 - On February 19, 1998, the Office of Management and Budget (OMB) issued the newly-revised Circular A-119, Federal Participation in the Development and Use of Voluntary Consensus Standards and in Conformity Assessment Activities, to replace the Circular dated October 20, 1993. The purpose was "to make the terminology of the Circular consistent with Public Law 104-113, to issue guidance to agencies on making their reports to $\mathrm{OMB}$, to direct the Secretary of Commerce to issue policy guidance for conformity assessment, and to make changes for clarity."

\subsubsection{Agencies' use of voluntary consensus standards versus government-unique} standards - Consistent with Section 12(d) of the NTTAA, the Circular directs agencies to use voluntary consensus standards in lieu of government-unique standards except where inconsistent with law or otherwise impractical. It also provides guidance for agencies participating in voluntary consensus standards bodies and describes procedures for satisfying the reporting requirements of the NTTAA. The policies in the Circular are intended to minimize reliance by 
agencies on government-unique standards. These policies do not create the basis for discrimination in agency procurement or regulatory activities among standards developed in the private sector, whether or not they are developed by voluntary consensus standards bodies.

2.2.2 Guidance to agencies - Consistent with Section 12(b) of the NTTAA, the Circular directs the Secretary of Commerce to issue guidance to agencies in order to coordinate conformity assessment activities. The goal is: (1) to eliminate the cost to the Government of developing its own standards and decrease the cost of goods procured and the burden of complying with agency regulation, (2) to provide incentives and opportunities to establish standards that serve national needs, (3) encourage long-term growth for U.S. enterprises and promote efficiency and economic competition through harmonization of standards, and (4) further the policy of reliance upon the private sector to supply Government needs for goods and services.

2.2.3 Other issues covered by the Circular - The Circular states policies with regard to whom is affected, Federal use of standards, Federal participation in voluntary consensus standards bodies, and policy on conformity assessment. It covers the use of standards in regulations and provides the procedures for managing and reporting on agency use of standards in procurement and regulations. It also covers what must be reported and how an agency is to report on its development and use of standards. The Circular also specifies the responsibilities of the Secretary of Commerce, the heads of agencies, and the Standards Executives of agencies.

2.2.4 Role of Secretary of Commerce and NIST - The NTTAA and the Circular assign several policy coordination and implementation tasks to the Secretary of Commerce and specifically to NIST. To carry out these tasks, NIST provides the Chair and Secretariat for the Interagency Committee on Standards Policy (ICSP). NIST must also submit this annual report to $\mathrm{OMB}$ on agency implementation activities, requiring the full cooperation and assistance of all departments and agencies in complying with reporting requirements of the Circular.

2.2.5 Agency Standards Executives - The revised Circular clarifies the role of Agency Standards Executives, particularly regarding agency-wide compliance with the new legal requirements. The Standards Executive must have responsibility for coordinating agency-wide standards-related activities, coordination of implementation of the Circular, and serving on the ICSP. In 1998, at the request of the Secretary of Commerce, each cabinet department and independent agency of the executive branch designated an individual to serve as the Agency Standards Executive for its department or agency.

\section{INTERAGENCY COMMITTEE ON STANDARDS POLICY (ICSP)}

3.1 Purpose - The Interagency Committee on Standards Policy (ICSP) was established in 1968 to encourage coordination and liaison among Federal agencies on matters related to standards. In 1992, the Secretary of Commerce reconstituted the ICSP to provide the required "interagency consultative mechanism to advise the Secretary and agency heads in implementing the policy." 
In October 1997, the Secretary of Commerce approved a new Charter, with similar goals. A copy is provided as Appendix C.

3.2. ICSP chair - The Director of the NIST Office of Standards Services chairs the ICSP on behalf of the NIST Director and the Secretary of Commerce. The ICSP is the primary vehicle for coordinating Federal activities under the NTTAA and the OMB Circular. NIST develops very few agency-unique standards for either procurement or regulation purposes, but plays a major role in standards-related technical and policy-related activities as directed by both the Circular and the NTTAA.

3.3 ICSP membership - The ICSP is currently composed of representatives of the 14 Federal Cabinet departments, 11 independent Federal agencies, and several offices in the Executive Office of the President. The composition of the ICSP is shown in figure 1 on the next page. The ICSP membership is provided in Appendix D.

\section{HIGHLIGHTS OF ICSP ACTIVITIES}

4.1 General - The ICSP met six times in FY 1998. The meetings focused on such main topics as the NTTAA, the revision of the OMB Circular A-119, and the annual report to OMB. There were presentations and discussions of planning activities for implementation of the NTTAA, various agency standards-related policy issues, and proposed guidelines on Federal conformity assessment activities. ICSP members heard presentations from NIST regarding the Government Industry Quality Liaison Panel (GIQLP), the status of the NIST Standards Assistance and Management Information (SAMI) project on-line, and agency ethics guidance and waivers for service on the boards of directors of non-Federal standards organizations. Of paramount interest were three conferences: the September 1997 Open Seminar on Use of and Participation in Voluntary Standards in Government, the March 1998 NIST/OMB seminar on The Revised OMB Circular, and the September 1998 NIST/ANSI Summit: Toward a National Standards Strategy to Meet Global Needs. The ICSP chair reported on the September 1997 Open Seminar at the December 1997 meeting, and the Director of NIST and the President of ANSI (American National Standards Institute) reported on the NIST/ANSI Summit at the 1998 September ICSP meeting.

4.2 Interaction with private-sector standards organizations - Representatives from several private-sector organizations gave presentations on topics of interest. The speakers represented the Council of American Building Officials (CABO), American National Standards Institute (ANSI), National Fire Protection Association (NFPA), the National Cooperation for Laboratory Accreditation (NACLA), and the ICF Kaiser Consulting Group.

4.3 ICSP working groups - During1998 a variety of ICSP activities were carried out by workings groups whose participants were designated by ICSP representatives. The ICSP Working Groups, with their secretariats, are shown in figure 1 on the next page. 


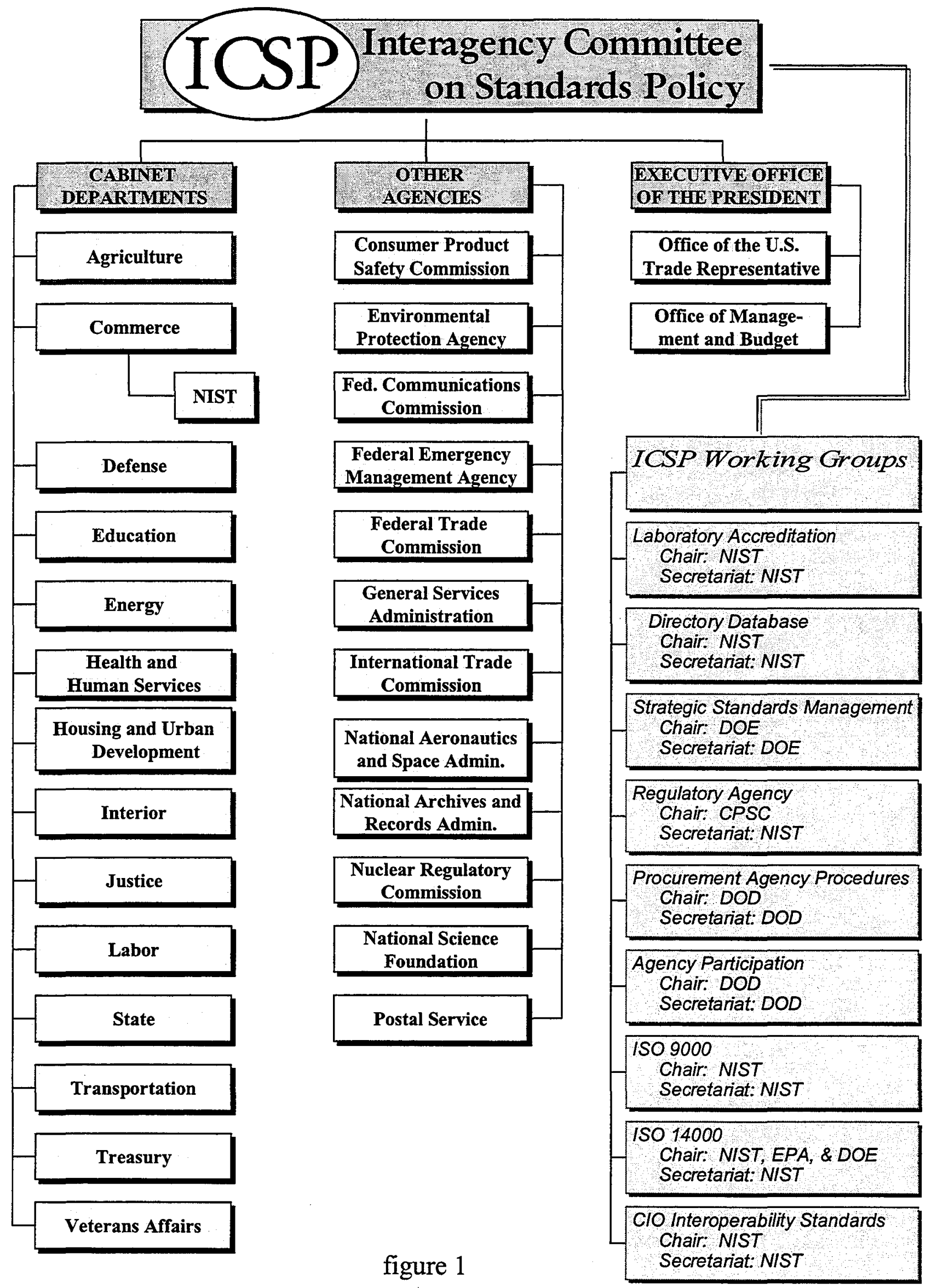


Their activities are described as follows:

- Federal procurement - Dr. Belinda Collins, ICSP chair, asked that a working group be formed to discuss issues shared by Federal Procurement agencies. Representatives from DOD, NASA, and EPA attended the first subcommittee meeting. This meeting focused on NASA's proposed change to the FAR (FAR Case 98-004), which would invite alternatives to government specifications in contracting. At the time of the meeting, language was still being debated in the FAR Council; thus, committee members could not voice a group opinion on the case. The working group did not identify any other pressing needs and decided to meet on an "as required" basis.

- Agency participation in voluntary standards activities - Dr. Collins, requested that a working group look into the extent of "actual" versus "perceived" decline in Federal Government participation in the work of voluntary consensus standards development organizations. Representatives from DOD, AIA, NIST, NRC, ICC, NASA, NFPA, ANSI, and TIA attended the first meeting. The ANSI Organization Member Council was asked to distribute a survey to its members to determine whether there has been a decline in Federal participation and what areas of standards development could benefit from Federal participation in the future. The subcommittee will continue to focus on analyzing survey responses, evaluating reporting procedures, and determining the next course of action. It should be noted that the steep decline in committee memberships reported in the FY 97 Annual Report has not continued.

- The regulatory agencies' working group (ICSP-RAWG) - This working group chaired by Mr. Colin Church, CPSC, helps to develop and implement standards policies of interest to regulatory entities of the Federal Government. Membership includes representatives from CPSC, DOE, DOL, EPA, FCC, FDA, FERC, GSA, HUD, NASA, NHTSA, NIST, NRC, NSA, and USDA. The working group reports to the ICSP and serves as a forum for interagency information exchange and discussion of issues of mutual interest.

During 1998 the working group focused on issues and activities related to the development and implementation of the OMB Circular A-119 dated February 1998. Working group representatives actively participated in discussions of major issues with the ICSP and OMB representatives during the drafting of the document. After the Circular was approved, the working group directed its attention to issues related to implementing its provisions. Other issues that were addressed included: (1) coordination of conformity assessment activities, (2) expediting revision of standards to reflect the most current versions of referenced standards, and (3) on-line standards development.

- Working group on quality management (ISO 9000) - NIST provided material to agencies on the current proposed revisions to the ISO 9000 family of standards, but did not hold any formal working group meetings in FY 98. 
- Working group on ISO 14000 - This working group, chaired by the EPA, met approximately every other month over the past year. Membership in the group now extends to 44 people, representing 14 Federal agencies and the President's Council on Sustainable Development. A strong interest in putting together Federal agencies' issues and perspectives on ISO 14000 continues. However, as the group has matured, its range of activities and interests has expanded. The group continues to invite members to make presentations regarding issues, approaches, and lessons learned by their individual agency or program. These presentations have been very well received and have provided extensive, practical information. Group members also shared ISO 14000 materials and such documents as the EMS (Environmental Management Systems) Primer for Federal Facilities, jointly developed by DOE and EPA, and web sites developed for their programs. Group members also reported on key meetings, such as the TC-207 meeting hosted by the United States in June.

A central feature of the group's effort this year was work toward a "White Paper" on Environmental Management Systems (EMS) issues. The group conducted meetings, including facilitated group discussions and conference calls, to define key elements. This process highlighted the range of ways in which Federal agencies are evaluating and implementing EMSs. The meetings provided a basis for a draft document outlining: (1) an overview of issues and status of EMSs in Federal agencies, (2) trends and key issues to be addressed, and (3) impacts of ISO 14000 on Federal agencies' potential to influence standards.

An index of references and materials is also being developed. This will include policy or position statements by participating agencies on ISO 14001 documents, web sites, and resource directories.

- Working group on laboratory accreditation (WGLA) - This working group, chaired by Mr. James Cigler of NIST, has kept the ICSP current on public- and private-sector activities related to laboratory accreditation throughout the country. The WGLA members attended various government agency meetings, such as the Department of Energy Topical Group on Laboratory Accreditation and the annual meeting of the National Environmental Laboratory Accreditation Conference (NELAC). WGLA members commented on the Draft International Standard, DIS 17025, which is the revision of ISO/IEC Guide 25 General requirements for the competence of testing and calibration laboratories. Several members reported on activities within their agencies related to laboratory accreditation and an attempt will be made to catalog those activities so that members can meet and share experiences that might be of value to each other in their efforts.

Some members of the WGLA also serve on the Government liaison group that works with the private sector National Cooperation for Laboratory Accreditation (NACLA).

Considerable effort has been expended in developing consensus on a Government position regarding the recognition of public- and private-sector laboratory accrediting bodies in the 
United States. This is seen as fulfilling the mandate in the NTTAA for the Government to work with the private sector in the use of national and international consensus standards.

- Working group on directory database - The ICSP working group on directory database did not meet in 1998; however, NIST developed and implemented procedures for on-line registration of staff participation in standards activities which will be made available to all ICSP members. This working group will reconvene in 1999 to review and revise current government-wide guidelines for identifying, collecting and developing directories of Federal Government staff on standards developing committees.

- Working group on standards management - During 1998, the ICSP's Standards Management Working Group, chaired by Mr. Richard Serbu of DOE, coordinated the first Federal Technical Standards Workshop, held at Loews L'Enfant Plaza Hotel in Washington, D.C., on August 4-6, 1998. Sponsors included the Department of Energy (DOE-host), the National Institute of Standards and Technology (NIST), the Environmental Protection Agency (EPA), the Food and Drug Administration (FDA), and the Partnership in Reliability, Maintainability, and Supportability (RMS) Standards (a consortium of professional societies, industrial associations, and Government agencies working together to help implement acquisition and standardization reform). The Workshop supported implementation of the NTTAA (Public Law 104-113) through sharing of standards management success stories, "lessons learned," and discussions of emerging initiatives from within the Federal Government. The Workshop was well-attended by representatives from Federal agencies and their support contractors, standards development organizations, and private industry.

\section{HIGHLIGHTS OF AGENCY ACTIVITIES}

5.1 Department of Commerce (DOC) - Within DOC, NIST has responsibility for the primary activities for implementation of P.L.104-113 and OMB Circular A-119. During FY 98, NIST carried out a number of activities to strengthen coordination between agencies and the private sector. Among these were:

- participating in the September 1997 Open Seminar on Use of and Participation in Voluntary Standards in Government;

- conducting a workshop with OMB in March 1998 on the requirements contained in the revised OMB Circular A119, as a means of acquainting Federal agencies and the private sector with the revised Circular;

- convening a successful summit conference, Toward a National Standards Strategy to Meet Global Needs in September 1998, in cooperation with ANSI;

- revising and signing an ANSI/NIST Memorandum of Understanding on September 24, 1998; 
- promulgating a NIST policy on voluntary consensus standards and a template for strategic standards management that serves as a model for adoption by Federal agencies;

- developing an electronic form for registering NIST/DOC standards participants on-line;

- hosting a public workshop in April 1998 to facilitate establishment and private-sector incorporation of the National Cooperation for Laboratory Accreditation (NACLA) in its mission of providing coordination and worldwide acceptance of competent laboratory accreditation in the United States and to become the U.S. point-of-contact for international laboratory accreditation efforts;

- obtaining international recognition of leadership in laboratory accreditation through the election of the Director of the Office of Standards Services of NIST as Chairman of the International Laboratory Accreditation Cooperation (ILAC).

5.2 Department of Defense (DOD) - A major aspect of the Department's Mil Spec reform initiative continues to be replacement of military specifications and standards with voluntary consensus standards wherever there is a dual-use application. As a result of this initiative, DOD completed a review of its $30,000+$ military specifications and standards to determine whether a replacement voluntary standard already exists or whether one could be developed. DOD reported that as of FY 98 that DOD had adopted 7991 voluntary consensus standards (464 of those were adopted during FY 98). DOD reported that it has identified more than 3000 candidate military specifications and standards with potential to be replaced by voluntary consensus standards. The Department has installed procedures to ensure that proliferation of military documents will not recur.

The Department is also continuing to pro-actively enlist the support of industry associations and voluntary consensus standards-developing organization to help review, identify, and plan for replacement of military specifications and standards with voluntary consensus standards. In situations where a military standardization document is also used by commercial firms, the department is working with the appropriate standards developing organization to create a suitable replacement.

5.3 Department of Energy (DOE) - At DOE, departmental policies on the use of voluntary consensus standards have been implemented by means of a management system established through DOE Order 1300.2A, Department of Energy Technical Standards Program. This Order requires DOE elements to use international and national voluntary consensus standards in preference to Federal and DOE standards, consistent with P.L. 104-113 and OMB Circular A-119. It also establishes an integrated Department-wide Technical Standards Program and supporting infrastructure designed to implement Federal and DOE technical standards' requirements and manage related activities within DOE. The Order encourages and supports staff participation in the planning, development, and coordination activities of voluntary consensus standards committees. 
In October 1998, DOE Order 1300.2A was updated to incorporate references to P.L. 104-113 and the February 1998 revision to OMB Circular A-119. In the interim, the Assistant Secretary for Environment, Safety and Health issued an information memorandum to the Department's cognizant secretarial officers (i.e., senior DOE line managers in Washington, D.C.) describing the new Public Law, its impact upon DOE, and the planned implementation of the law through the Technical Standards Program. The Department had already incorporated the technical standards provisions of P.L. 104-113 and OMB Circular A-119 into its current Technical Standards Program Procedures, and currently manages its technical-standards activities in conformance with the Procedures requirements. In addition, DOE hosted a Federal Technical Standards Workshop with broad participation from Federal agencies in August of 1998 to discuss standards management issues and share experience related to implementing P.L. 104-113 and OMB Circular A-119.

5.4 Department of Health and Human Services (HHS), Food and Drug Administration (FDA) - FDA has conducted standards activities for more than 20 years. In January 1977 the agency promulgated a final regulation, now found at 21 CFR 10.95 , covering participation by FDA employees in standards-developing activities outside the agency. This regulation encourages FDA participation in standards activities that are in the public interest, and specifies the circumstances under which FDA employees can participate in various types of standards bodies.

The agency built upon that rule with a draft policy statement published in the Federal Register on November 28, 1994, and a subsequent final policy published on October 11, 1995. Entitled International Harmonization; Policy on Standards, it provides the agency's overall policy on development and use of standards for all product areas regulated by the agency. In an initiative aimed at furthering harmonization, on January 28, 1995, FDA published in the Federal Register a proposed rule to facilitate the sharing of draft regulations and other pre-decisional documents with State and foreign officials. The final rule, Public Information; Communications with State and Foreign Government Officials, was published on December 8, 1995.

5.5 Department of Housing and Urban Development (HUD) - The Department selected the National Fire Protection Association (NFPA) to function as the secretariat for the Federal Manufactured Home Construction and Safety Standards in 1998. This is the first step in the Department's process to adopt these as consensus-based standards consistent with OMB Circular A-119. The appropriate committees have been established with three members of the HUD staff participating as voting members. The first deliberations were held in December 1998.

5.6 Department of Transportation (DOT) - DOT recognizes the importance and the advantages of using voluntary consensus technical standards since the use of voluntary consensus standards can save both time and money for regulatory agencies. The Department also recognizes the value in participating in standards-developing organizations. For example, NHTSA's participation in standards-developing organizations has helped the agency to be on the 
cutting edge of motor-vehicle related technological innovations and the development of regulatory solutions to vehicle safety problems.

5.7 Environmental Protection Agency (EPA) - EPA implemented the following initiatives to improve its system for promoting compliance with the NTTAA in rulemaking:

- $\quad$ EPA regulators now routinely consider the use of voluntary consensus standards in proposed and final agency regulations. Nearly100 Federal Register documents published in fiscal year 1998 contained preamble sections addressing the NTTAA. In these sections, the rule writers summarized the requirements of the NTTAA, explained how they searched for potentially applicable voluntary consensus standards, and described their tentative or final decisions about the use of such standards in the regulation.

- EPA's Office of Policy, working with the Standards Executive and the Office of General Counsel, has developed the comprehensive EPA Rule-Writer's Guide to the NTTAA explaining the procedures needed to systematically assess the application of the NTTAA to proposed and final rules. When finalized, the Guide will be available on EPA's internal electronic network and will be periodically updated. In the meantime, the draft document is in regular use.

- EPA rule writers regularly use model language concerning the NTTAA and the use of voluntary consensus standards in both proposed and final regulations. This greatly facilitates the electronic tracking of the use, or consideration of the use, of voluntary consensus standards in EPA regulations. This, in turn, promotes the management of the EPA standards program and improves the quality and ease of preparing the agency annual report.

- The Assistant Administrator for the Office of Prevention, Pesticides and Toxic Substances (OPPTS) elevated the Standards Program within OPPTS to enhance the importance of voluntary consensus standards to EPA policies and programs and to facilitate agency-wide implementation of the requirements of the NTTAA and the Circular.

- $\quad$ EPA also revised the agency ethics guidance on participation in voluntary consensus standards organizations. The new EPA guidance, issued in September 1998, finally reconciled the competing interests of the criminal code provisions concerning financial conflicts of interest with the NTTAA directive that Federal employees participate in standard-setting activities of voluntary consensus standards organizations. Relying on recent memoranda from the Office of Legal Counsel of the Department of Justice and the Office of Government Ethics, the new guidance provides a clear pathway for EPA employee membership in standards development organizations, including serving on boards of directors and as committee chairs.

5.8 Federal Communications Commission (FCC) - The Commission continued to increase its use of voluntary consensus standards. In many instances the FCC has chosen not to implement 
regulations (or more detailed regulations) because adequate voluntary industry standards already exist or are under development. For example, the regulations for Personal Communications Service do not include transmission protocol standards because industry has voluntarily developed these standards. In other instances, where the adoption of a standard is or may be in the public interest, the FCC has attempted to use voluntary consensus standards whenever possible. For example, the FCC allows the industry to establish a spectrum etiquette policy for devices operating at millimeter wavelengths and are working with and looking to industry to develop standards for the transmission of digital radio. In addition, the Commission regularly works closely with industry though the negotiated rulemaking process to resolve technical compatibility issues.

5.9 National Aeronautics and Space Administration (NASA) - In 1998, NASA began an intensive effort to identify Voluntary Consensus Standards (VCS) currently used in NASA programs and to review them as candidates for formal adoption. Since October 1, 1997, NASA has adopted 414 voluntary consensus standards products based on current use by one or more NASA installations. Approximately 85 percent of the VCS adopted are in the area of materials and processes specifications. Also included are 10 standards for data communications that were converted in 1998 from international, inter-governmental standards to ISO standards. The adoptions were based on staff recommendations, concurrence of the NASA Engineering Standards Steering Council, and formal approval by the NASA EMC and the NASA Standards Executive. An additional 400 voluntary consensus standards are now in the final stages of the review process as candidates for formal adoption by NASA. The process will be completed in FY 1999.

5.10 Nuclear Regulatory Commission (NRC) - The NRC staff conducted two stakeholder meetings to identify issues and develop options for improving its participation in the development and use of consensus standards. The first meeting, held in July 1998, was with NRC staff (internal stakeholders) from various NRC offices to discuss issues and options related primarily to NRC participation on standards committees. Discussions focused on identifying options for improving the effectiveness and efficiency of NRC staff participation in developing consensus standards. The second meeting, held in Chicago in September 1998, was with external stakeholders to discuss their concerns regarding NRC staff participation in the development and use of consensus standards. This meeting included representatives from individual utilities (reactor licensees), the Nuclear Energy Institute (NEI), standards developing organizations (SDOs) such as the American Society of Mechanical Engineers (ASME), nuclear steam supply system (NSSS) vendors, the Department of Energy, NIST, state governments, and the public. A transcript of this meeting was made available at the NRC web site shortly after the meeting. Information gained from this meeting, and other sources, will be used to formulate a program to improve NRC participation in the development and use of consensus standards. 


\section{AGENCY USE OF GOVERNMENT-UNIQUE STANDARDS IN LIEU OF VOLUNTARY CONSENSUS STANDARDS}

P.L. 104-113 (NTTAA) requires agencies to identify all instances when they use governmentunique standards in lieu of voluntary consensus standards. During the FY 98 reporting period, six agencies reported 20 such actions. This compared with seven instances reported by only two agencies in FY 97, the first year in which agencies reported according to the law. The rationales and backgrounds are summarized below.

6.1 Department of Agriculture (USDA) - The Agricultural Marketing Service (AMS) uses government-unique specifications for the grading and certification of tobacco products. Authority for this program is contained in the Tobacco Statistics Act of 1929 and the Tobacco Inspection Act of 1935, as amended. Provisions of these acts require that all tobacco sold at auction must be inspected and graded by the USDA according to the U.S. standards.

The AMS also uses government-unique specifications for purchases of commodities for the School Lunch Program and other domestic feeding programs when voluntary consensus standards do not meet the nutritional or program requirements of these programs.

6.2 Environmental Protection Agency (EPA) - The EPA identified three final regulations where the use of an identified voluntary consensus standard was rejected in favor of a government-unique standard. It should be noted, however, that each of these regulations also cited or contained other technical standards where voluntary consensus standards were used. EPA rationales follow:

- 63 FR 48806 (9/11/98), National Volatile Organic Compound Emission Standards for Automobile Refinish Coatings: EPA considered the use of ASTM D-3960 as a possible substitute for EPA Method 24, which already relies on several ASTM methods. However, ASTM D-3960 contains some requirements above and beyond those needed for EPA regulatory purposes. As stated in the FR notice: "Because this other method [ASTM 3960] does not specify which units to use, it may result in inconsistent applications of the procedure and could make the standard more difficult to enforce. Consequently, the EPA determined that this other voluntary consensus method would be impractical to adopt. In addition, the EPA believes that it is appropriate to use Method 24 both because it has proven reliable and practical to achieve the goals of reducing VOC and because the EPA wishes to foster uniformity in testing nationwide." For this Rule, then, EPA specified EPA Method 24 which refers to ASTM Methods 2369, 1460, and 3970 (as does Method D-3960) while avoiding possible confusion caused by the presence of additional, unnecessary requirements.

- 63 FR 48848 (9/11/98), National Volatile Organic Compound Emission Standards for Architectural Coatings: EPA deemed ASTM-3960, modeled on EPA Method 24, itself 
referring to other ASTM methods, to be impractical for use in lieu of EPA Method 24 (see \#1 above).

- 63 FR 18504 (4/15/98), National Emission Standards for Hazardous Air Pollutants for Source Category: Pulp and Paper Productions: EPA decided to use EPA Method 1650. This Method was developed by drawing on various procedures contained in the methods of voluntary consensus standards bodies and other standards developers, such as ISO, DIN, SCAN, and Standard Methods (SM 5320). However, none of these more narrowly focused voluntary consensus standards contained the standardized quality control and quality control compliance criteria that EPA requires for data verification and validation in its water programs. Therefore, EPA found none of these VCS standing alone to meet EPA's needs.

There was also one proposed regulation where EPA proposed to reject the use of a particular voluntary consensus standard in favor of a government-unique standard:

- $\quad R 41134$ (7/31/98), National Primary Drinking Water Regulations: Analytical Methods for Certain Pesticides and Microbial Contaminations: Standard Methods 6640B for acid herbicides was tentatively deemed impractical for EPA's needs because its sample preparation and quality control procedures were not similar enough to EPA Method 515.1 to ensure that there would not be under reporting of acid herbicide contamination. EPA plans to offer to work with the Standard Methods committee to resolve this issue prior to the next publication.

6.3 National Aeronautics and Space Administration (NASA) - Because NASA uses the "categorical" method of reporting, "use" of government-unique standards is reported in terms of additions to the NASA Technical Standards Management System, rather than tracking individual procurement transactions. During FY 98 NASA developed 10 NASA-unique technical standards in three categories, namely: information technology, engineering, and safety and mission assurance. The 10 new standards are listed in the table on the next page.

The two NASA Information Technology (IT) standards developed in FY 98 (Items 1 and 2 of the table) are for internal use only and specify internal procedures or preferred use of COTS (Commercial off the Shelf) products. They do not duplicate voluntary consensus standards.

NASA Engineering standards are developed either to consolidate internal practices, or to provide guidance where no suitable national or international standards are available. Item 3 documented a unique set of requirements developed from failure experience on planetary spacecraft; Item 4 updates an existing standard which is now in the process of being converted into an ISO standard. NASA is participating with industry plus domestic and international voluntary consensus standard bodies to target those standards with external application for eventual transition to voluntary consensus standards. 
In the Safety and Mission Assurance area, Items 5 and 6, are manuals establishing safety requirements for NASA internal facilities and launch vehicle operations. Items 7-9 are interim re-issues of existing NASA standards based on failure experience in NASA unique space systems and in one case, Item 10, an area for which a fully adequate VCS has not been available. The Safety and Mission Assurance function has initiated an effort to identify possible VCS sponsors for these last four workmanship standards in FY 1999.

STANDARDS PUBLISHED IN FY 98 (October 1997 - October 1998)

1. NASA-STD-2807A The NASA Directory Service - Architecture, Standards, and Products (Previously Released as NASA X.500 Directory)

2. NASA-STD-2808A Interoperability Profile for NASA E-Mail Clients

3. NASA-HDBK-4001 Electrical Grounding Architecture for Unmanned Spacecraft

4. NASA-STD-6001 Flammability, Odor, Off gassing, and Compatibility Requirements and Test Procedures for Materials in Environments that Support Combustion (Formerly Published as NHB 8060.1C)

5. NASA-STD-8719.7 Facility System Safety Guidebook

6. NASA-STD-8719.8 Expendable Launch Vehicle Payload Safety Review Process Standard

7. NASA-STD-8739.3 Soldered Electrical Connections. (Previous Version Published as NHB 5300.4(3A-2)

8. NASA-STD-8739.4 Crimping, Interconnecting Cables, Harnesses, and Wiring (Previous Version Published as NAS $5300.4(3 \mathrm{G}-1))$

9. NASA-STD-8739.7 Electrostatic Discharge Control (Excluding Electrically Initiated Explosive Devices)

10. NASA-STD-8739.5 Fiber Optic Terminations, Cable Assemblies, and Installation

6.4 National Archives and Records Administration (NARA) - During this past reporting period, the NARA signed an agreement with the Department of Defense (DOD) to develop design criteria for electronic records management software applications. On December 19 of this year, NARA endorsed DOD's standard 5015.2. While this is a mandatory DOD standard, it is possible that it may one day become a government-wide mandate. There are currently no voluntary consensus standards that address this issue.

6.5 Department of Transportation (DOT) - During fiscal year 1998, there was one such instance of a government-unique standard. NHTSA issued a notice of proposed rulemaking (NPRM) that did not propose in all instances to use the requirements of a voluntary standard instead of government-unique requirements (63 FR 17976; April 13, 1998). 
NHTSA explained in the NPRM that the American National Standards Institute (ANSI) has a standard ${ }^{2}$ for product safety signs and labels (ANSI Z535.4) that identifies a hierarchy of hazard levels ranges from extremely serious to moderately serious and specifies corresponding hierarchies of signal words, i.e., "danger," "warning," and "caution," and of colors. For the header, the ANSI standard specifies a red background with white text for "danger," an orange background with black text for "warning," and a yellow background with black text for "caution."

\begin{tabular}{|c|c|c|}
\hline \multicolumn{3}{|c|}{$\begin{array}{l}\text { ANSI Requirements for Color-Coded Header Messages for the Different Levels of Hazard } \\
\text { (Listed in declining level of hazard) }\end{array}$} \\
\hline $\begin{array}{l}\text { Imminently hazardous situation which will result in } \\
\text { death or serious injury if not avoided }\end{array}$ & "Danger" & $\begin{array}{l}\text { Red background with } \\
\text { white text }\end{array}$ \\
\hline $\begin{array}{l}\text { Potentially hazardous situation which could result in } \\
\text { death or serious injury. }\end{array}$ & "Warning" & $\begin{array}{l}\text { Orange background } \\
\text { with black text }\end{array}$ \\
\hline $\begin{array}{l}\text { Potentially hazardous situation which could result in } \\
\text { minor or moderate injury. }\end{array}$ & "Caution" & $\begin{array}{l}\text { Yellow background } \\
\text { with black text }\end{array}$ \\
\hline
\end{tabular}

The ANSI standard specifies that pictograms should be black on white, with occasional uses of color for emphasis, and that message text should be black on white.

The agency noted in the NPRM that when it earlier updated the requirements for air bag warning labels to require the addition of color and pictograms, it had chosen not to adopt the colors specified in the ANSI standard. NHTSA chose to use yellow instead of orange in the background of the heading for the air bag warning label, even though the word "warning" was used, because of overwhelming focus group preference for yellow. Only two of the 53 participants preferred orange. Participants generally stated that yellow was more eye-catching than orange. Participants also noted that red (stop) and yellow (caution) had meaning to them, but not orange.

NHTSA asked for comment on three color options for the revised utility vehicle rollover warning label. Proposed label 1 used the ANSI color format with the heading background in orange with the words in black. The remainder of the label had a white background with black text and drawings. Proposed label 2 used a color scheme like the air bag warning labels, which is the same as the ANSI color format except that the background color for the heading in the label is yellow. Proposed label 3 employed the color scheme used in the focus groups - the heading area had a red background with white text. The graphic areas had a yellow background with black and white drawings. The text area had a black background with yellow text.

${ }^{2}$ This standard was not considered by the focus groups in their deliberations. 
Despite focus group preference for the signal word "danger," the agency proposed the use of the word "warning" as more appropriate to the level of risk. The agency also noted that the word "warning" is used in the air bag warning label.

Recognizing that it might encounter additional conflicts between focus group preferences and the ANSI standard in future rulemakings, NHTSA requested comments in the NPRM on the extent to which any final choice regarding colors and signal words should be guided by the focus group preferences instead of the ANSI standard. NHTSA also requested comments on the broader issue of the circumstances in which it would be appropriate for agency rulemaking decisions to be guided by focus group results or other information when such information is contrary to a voluntary consensus standard such as the ANSI standard.

At this time (February 22, 1999), a final decision is still pending regarding its proposal to upgrade the rollover-warning label. As to the general questions it posed in the NPRM, NHTSA recognizes that ANSI's mission differs somewhat from that of the agency's focus groups with respect to the labeling of hazardous situations. ANSI's mission is to develop and maintain a standard for communicating information about a comprehensive hierarchy of hazards, while the focus groups' mission is to design an effective label for a specific hazard. The agency recognizes further that, given the difference in their missions, their conclusions about the appropriate manner of communication might differ on occasion.

Since agency labeling decisions are highly dependent on the facts regarding the specific hazard being addressed, NHTSA anticipates making case-by-case determinations of the extent to which it should follow voluntary consensus standards versus information from focus groups and other sources. NHTSA will rely on its own expertise and judgement in making determinations under the NTTAA and the statutory provisions regarding vehicle safety standards.

6.6 Department of the Treasury (Treasury) - The Customs Service continues to support two government-unique standards. Customs and Trade Automated Interface Requirements (CATAIR) (Amendment 1, April 1996, Amendment 2, December 1996, Amendment 3 , September 1997, and Amendment 4, 1998) and Customs Automated Manifest Interface Requirements (CAMIR) (Amendment 1, April 1997 and Amendment 2, July 1998). CATAIR is used by the Customs brokerage industry, and some parties in the transportation sector used CAMIR. The maintenance of the government-unique standards within Customs applications (the CATAIR and CAMIR formats) is at the request of the participating industry groups that use those standards. 
Table 1. FEDERAL AGENCY INFORMATION ON PARTICIPATION/ADOPTION OF VOLUNTARY STANDARDS ACTIVITIES REQUIRED BY OMB CIRCULAR A-119 (DATA AS OF 9/30/98)

\begin{tabular}{|c|c|c|c|c|c|c|c|}
\hline AGENCY & $\begin{array}{l}\text { NO. OF } \\
\text { VOLUNTARY } \\
\text { CONSENSUS } \\
\text { STANDARDS } \\
\text { BODIES IN WHICH } \\
\text { AGENCY } \\
\text { PARTICIPATES }\end{array}$ & $\begin{array}{l}\text { CHANGE } \\
\text { FROM FY } 97\end{array}$ & $\begin{array}{l}\text { NO. OF AGENCY } \\
\text { EMPLOYEES } \\
\text { PARTICIPATING }\end{array}$ & $\begin{array}{l}\text { CHANGE } \\
\text { FROM FY } 97\end{array}$ & $\begin{array}{l}\text { NO. OF } \\
\text { VOLUNTARY } \\
\text { CONSENSUS } \\
\text { STANDARDS } \\
\text { USED SINCE } \\
10 / 97\end{array}$ & $\begin{array}{l}\text { NO. OF } \\
\text { VOLUNTARY } \\
\text { CONSENSUS } \\
\text { STANDARDS } \\
\text { SUBSTITUTED } \\
\text { FOR GOVT.- } \\
\text { UNIQUE } \\
\text { STANDARDS }\end{array}$ & $\begin{array}{l}\text { NO. OF GOVT.- } \\
\text { UNIQUE } \\
\text { STANDARDS } \\
\text { USED IN LIEU } \\
\text { OF } \\
\text { VOLUNTARY } \\
\text { CONSENSUS } \\
\text { STANDARDS }\end{array}$ \\
\hline USDA & 46 & 0 & 68 & +8 & 6 & & 0 \\
\hline DOC & 143 & +2 & 411 & +25 & & & 0 \\
\hline DOD & 89 & +3 & 683 & +83 & $464^{(1)}$ & 125 & 0 \\
\hline NCS (DOD) & 17 & 0 & 14 & -2 & 2 & & 0 \\
\hline DOED & 1 & - & 6 & - & 17 & 0 & 0 \\
\hline DOE & 65 & -10 & 681 & -190 & $31^{(2)}$ & 0 & 0 \\
\hline $\mathrm{HHS}$ & 46 & 0 & $274^{(4)}$ & +32 & $370^{(5)}$ & 0 & 0 \\
\hline HUD & 10 & +1 & 7 & -1 & 0 & & 0 \\
\hline DOI & 54 & +16 & 84 & -25 & 144 & 0 & 0 \\
\hline DOJ & 3 & +2 & 8 & +2 & 0 & & 0 \\
\hline DOL & 22 & +12 & 63 & +35 & 2 & 0 & 0 \\
\hline STATE & $1^{(8)}$ & 0 & 6 & 0 & & & 0 \\
\hline DOT & 106 & -27 & 292 & 0 & 197 & 7 & 1 \\
\hline TREASURY & 8 & -2 & 21 & -4 & 3 & 0 & 0 \\
\hline VA & 3 & -25 & 4 & -22 & 50 & 0 & 0 \\
\hline CPSC & 50 & +4 & 21 & -1 & 10 & 0 & 0 \\
\hline EPA & 14 & +3 & 200 & 0 & 157 & 0 & 3 \\
\hline $\mathrm{FCC}$ & 24 & +14 & 49 & +5 & 0 & 0 & 0 \\
\hline FEMA & $-(3)$ & & $-{ }^{-(3)}$ & & 4 & & 0 \\
\hline GSA & 91 & -9 & 45 & -9 & 1 & 10 & 0 \\
\hline NASA & 43 & -4 & 148 & -6 & $414^{(4)}$ & 4 & 0 \\
\hline NARA & 14 & -6 & 8 & -10 & 4 & 0 & 0 \\
\hline NSF & 3 & +1 & 4 & +1 & 0 & 0 & 0 \\
\hline NRC & 16 & 0 & $145^{(7)}$ & -20 & 0 & 0 & 0 \\
\hline TOTALS & 869 & -25 & 3242 & -99 & 1876 & 146 & 4 \\
\hline
\end{tabular}


(1) Total number of DOD-adopted voluntary consensus standards is 7991.

(2) Total number of DOE-adopted voluntary consensus standards is 840 .

(3) Information not available on an agency basis.

(4) Includes participation on 553 voluntary consensus standards development committees within the 46 standards bodies indicated.

(5) Includes standards recognized under the Food and Drug Administration Modernization Act of 1997 (FDAMA).

(6) An additional 400 voluntary consensus standards are in the final stages of review as candidates for formal adoption at NASA.

(7) Includes participation on a total of 254 consensus standards development and board level committees.

(8) Department of State represents the United States in the International Telecommunications Union (ITU). ITU is an intergovernmental organization of the United Nations System. 


\section{CONCLUSIONS}

Federal agencies have continued to implement P.L. $104-113$ and the revised OMB Circular A-119 successfully. Many agencies, including EPA, DOD, and NASA, have developed procedures for alerting the public about proposed regulations and procurement actions that involve voluntary consensus standards. Thus, EPA has developed wording for inclusion in its notices of proposed rulemaking to draw attention to opportunities for using voluntary consensus standards. This allows standards developing organizations the opportunity to bring possible standards activities to the attention of the agency.

The report also describes four instances in which government-unique standards were used in lieu of voluntary consensus standards, three at the Environmental protection Agency and one at the Department of Transportation. Some agencies provided additional information on their use of government-unique standards where no voluntary consensus standard alternative existed.

Agencies are continuing to improve their procedures by which they track their uses of standards in both regulation and procurement activities, according to the requirements of OMB Circular A-119. The decline noted in the FY 97 report in agency participation standards committees appears to have leveled off, but will be monitored on an ongoing basis.

\section{RECOMMENDATIONS}

All Federal agencies should continue to strengthen their efforts to implement the NTTAA and OMB Circular A-119, particularly in planning for resource and staff allocation for participation in appropriate voluntary consensus standard activities.

Most Federal agencies have continued to make progress in their use of voluntary consensus standards for agency programs and missions. This trend should be continued for both procurement and regulatory activities. Where appropriate, strategic alliances and teaming arrangements by Federal agencies with standards development organizations may be beneficial.

Federal agencies should continue to develop specific policy and programmatic elements to support the implementation of the NTTA and OMB Circular A-119. Elements for consideration should be the establishment of agency standards policy and units for monitoring standards activities, resource allocation, infrastructure, reporting, and assessing program effectiveness. The study by ICF Kaiser for the Environmental Protection Agency $^{3}$ provides more details on appropriate elements.

${ }^{3}$ Federal Agencies Participation in the Development and Use of Voluntary Standards, ICF Kaiser Consulting Group, October 1997. 
- Agencies should consider their own strategic needs when planning for agency participation in standards activities. They should use available resources, including NIST, to determine applicable Standards Development Organizations (SDOs) (both national and international), relevant voluntary standards, and the need for new standards emerging technologies and processes. NIST should continue to facilitate interactions between agencies and voluntary standards process.

- The ICSP should develop guidelines for use by agencies in preparing their staff for participation in standards-related activities. These guidelines, which the NIST Policy on Voluntary Standards might be used as a model, should reflect the need to prepare agency views and coordinate positions with other relevant Federal agencies so that all Federal needs are reflected as standards are developed. Consideration should be given to the appropriate agency role in committee activities to avoid the appearance of dominance and consideration of likely future agency and national needs during the development and revision of voluntary standards.

- Federal agencies should continue to develop, improve and utilize systems for tracking the adoption or referencing of voluntary standards, as well as the level of staff participation in voluntary standards developing bodies. Agencies should consider the use of electronic means for setting up directory databases of participants and exchanging information about standards-related issues.

- $\quad$ NIST should consider developing a newsletter and accompanying WEB-site to periodically provide current information about Federal agency standardization activities and other matters of interest to the ICSP membership and others. 


\section{APPENDIX A:}

\section{Cabinet Department Reports}




\section{DEPARTMENT OF AGRICULTURE}

The following information was prepared for the National Institute of Standards and Technology (NIST) by the Department of Agriculture (USDA) as required annually under Office of Management and Budget Circular A-119, "Federal Participation in the Development and Use of Voluntary Standards."

\section{BACKGROUND}

In the Department of Agriculture, the Standards Executive serves also as the Chief Information Officer (CIO), a position established in August 1996. This has made the Office of the CIO (OCIO) the coordinating organization within USDA for reporting on Circular A-119 activities.

\section{METHOD}

To prepare this report, OCIO sought information from USDA Agency Heads. Based on the requirements sent out by NIST, the CIO requested information on the number of agency employees engaged in the voluntary consensus standards-developing bodies and the number of such bodies; the number of voluntary consensus standards used since October 1,1997 ; the number of voluntary consensus standards substituted for government-unique standards in FY 1998; an evaluation of the effectiveness of Circular A-119 and recommendations for changes; and identification of all instances when the agency used government-unique standards in lieu of voluntary consensus standards. For each instance the CIO requested the inclusion of the agency rationale for such use, as well as specific government-unique standard used.

\section{DEPARTMENTAL VIEWS}

While the standards program falls under the CIO, standards, in a broader sense, include all standards, not just IT (Information Technology). Circular A-119 introduces opportunities for agencies to be involved directly in the voluntary consensus standards development activities through external standards bodies comprised of participants from Government, industry, universities, and international standards organizations. The voluntary consensus standards can be adopted by Federal agencies in lieu of government-unique standards. NIST traditionally publishes mandatory and optional standards for the Federal Government through the FIPS PUBs. Those standards may or may not meet the needs of the individual agencies. This rigidity can be mitigated by applying provisions of Circular A-119. However, voluntary consensus standards activities are subject to OMB, NIST, and Congressional oversight.

The Department of Agriculture encourages its agencies to participate in consensus standards development activities under A-119 to take advantage of the expertise from private industry, academic communities, and international standards bodies. Familiarization with international 
standards development activities also benefits USDA agencies in the area of Internet, trade, and other matters of global nature.

\section{USDA PARTICIPATION BY FUNCTIONAL AREAS}

\section{FARM AND FOREIGN AGRICULTURAL SERVICES}

\section{Foreign Agricultural Service (FAS)}

\section{NATURAL RESOURCES AND ENVIRONMENT}

\section{Natural Resources Conservation Service (NRCS)}

NRCS has an engineering mission to provide quality engineering products to its customers. Many of its employees have participated in organizations for the development of voluntary standards.

This year the agency reports that at least three of its members participated in the Open Geographic Information Systems (GIS) Consortium, a nonprofit public/private partnership focusing on GIS. The report indicates that the Consortium has done some work in the area of standards, especially regarding standards to facilitate the interoperability of Geographic Information Systems. These standards may become de facto standards for GIS or be adopted by the GIS industry.

NRCS has at least five people involved with the Federal Geographic Data Committee composed of primarily Federal agency representatives. The committee has done some work in the area of geospatial data standards, seeking to attain commonality among the Federal agencies to facilitate geospatial data sharing.

For FY 1998, NRCS reports that several employees have worked with a number of committees within the American Society for Testing and Materials (ASTM). Those Committees develop standards on materials, products, systems, and services. NRCS uses several hundred of ASTM standards for design and construction activities throughout the entire range of its conservation programs. The FY 1998 ASTM standards have not yet replaced the existing conservation practice standards developed internally by NRCS.

Several NRCS employees also were involved in the development of industry specifications under the sponsorship of the American Society of Agricultural Engineers (ASAE) and American Society of Civil Engineers (ASCE). Although those standards and specifications have not been adopted by NRCS, many agricultural communities have already applied some of the specifications for construction and quality products. One NRCS employee was actively involved in the development of voluntary consensus standards with the American Concrete Institute (ACI), particularly on the "Code for Environmental Engineering Concrete Structures." 
Although none of the above standards developed with NRCS involvement have yet replaced the agency's existing standards or specifications, NRCS is moving toward adopting those standards.

\section{RESEARCH, EDUCATION AND ECONOMICS (REE)}

\section{Economic Research Service (ERS)}

In FY 1998, ERS participated in six standards bodies. These activities involved eleven employees. There has been no substitution of voluntary consensus standards for governmentunique standards in response to agency reviews and no government-unique standards were used in lieu of voluntary consensus standards.

ERS reports that three analysts participated on technical advisory teams associated with the creation of the North American Industry Classification System (NAICS). The purpose of NAICS is to create a common industry classification system to replace the current individual systems of Canada, Mexico, and the United States. Common industry definitions for collecting and publishing data and information on inputs and outputs will improve inter-country measuring of productivity, unit labor costs, and level of capital intensity in production; estimating of employment-output relationships; constructing of input-output tables; and analyzing production relationships in the economy. ERS analysts participated on the Agriculture, Forestry, Manufacturing, and Fishing and Hunting sectors of the NAICS system.

ERS has one analyst who maintains contact with the Conservation Technology Information Center (CTIC) and attends the annual meeting regularly. CTIC periodically coordinates the definitions and standards for various crop residue management systems (CRMS). These systems are used to reduce wind and water erosion and are part of the farm conservation plans that must be implemented by the farmers to be eligible for most Federal Farm Program benefits. USDA agencies, including NRCS, ERS, and CSREES, along with representatives from other natural resource organizations and private industry establish criteria for different classes of crop residue management. These criteria are used in surveys conducted by CTIC to measure the adoption of conservation tillage and in USDA's Agricultural Resource Management Study to analyze economic and environmental effects of alternative crops.

ERS has one analyst who was a cooperator on the Environmental Stewardship Program (ESP) sponsored by the Environment Protection Agency (EPA). The ESP project was concluded last year and the group submitted a draft report on the voluntary standards for the Integrated Pest Management (IPM) on Potatoes. The activities involved in building the national definitions on potatoes included: developing a comprehensive list of State-level IPM practices; making a tentative rating of the practices in terms of their values; conducting an extensive review of the draft definitions. The State Extension specialists and commodity associations provided the basic information on potato pest management practices to IPM. The rating of the practices was based on the University of Massachusetts "Partners with Nature" IPM certification system model. The 
draft IPM definitions were reviewed by soliciting comments from EPA, land-grant university IPM specialists, food processors and commodity associations, chemical industries, suppliers, environmental groups, and others.

ERS has one analyst who regularly participates in the USDA Ecological Risk Assessment Working Group charged by the Secretary to develop standards and guidelines for USDA program managers to conduct risk assessments in their respective programmatic areas. Activities involve working with representatives from USDA agencies to define terms and develop standards and guidelines on how to conduct risk assessments.

ERS analysts monitor materials released by the Farm Financial Standards Council (FFSC) for use in developing measurements of financial indicators for farm businesses. FFSC standards are also used in developing questionnaires and preparing summary financial statements connected with farm financial performance.

ERS analysts interact with the American Agricultural Economics Association Commodity Costs and Returns Accounting Task Force. The Task Force published a report on July 20, 1998, establishing standards for use by the Federal and State governments, universities, nonprofit institutes, and other entities in the private sector when developing estimates on costs and return of agricultural commodities. ERS sought consensus with the American Agricultural Economics Association and experts in the agricultural economics profession in developing the estimates.

\section{National Agriculture Statistics Service (NASS)}

For FY 1998, NASS reports that one staff member was involved in the creation of the National Vegetation Classification and Information Standards for the Federal Geographic Data Committee. These standards will be used by Federal agencies and their cooperators in classifying vegetation. Otherwise, NASS relies mainly on off-the-shelf software and hardware for its statistical work. Circular A-119 has little effect on NASS.

NASS did not issue any regulations on the consensus standards during FY 1998, nor did it use any government-unique standards in procurement.

The Office of Procurement and Property Management (OPPM)

Last year's response: From the Office of Procurement and Property Management (OPPM), one staff member participates on one standards setting body. Since October 1, 1996, one set of standards is used. The organization stated that no prior standards were used by OPPM forprocurement which involved electronic commerce. Nor did OPPM comment on the effectiveness of guidelines in Section 7 of the proposed revision to Circular A-119. 


\title{
MARKETING AND REGULATORY PROGRAMS
}

\author{
Agricultural Marketing Service (AMS)
}

AMS reports that 20 employees participated in eight national voluntary standards bodies, and 17 employees participated in 17 international voluntary consensus standards bodies in FY 1998 and prior.

Since October 1, 1997, the agency has used the following voluntary consensus standards: Agreement on the International Carriage of Perishable Foodstuffs and Special Equipment; Certification Standards of the American Association of Seed Certifying Agencies; Codex Alimentarius International Grade Standards; Universal Cotton Standards Agreement; Analytical Standards of the American National Standards Institute (ANSI); Test Standards of the American Society for Testing and Materials (ASTM); and International Meat Purchase Specifications (IMPS). With the participation of the industry, AMS has developed 602 grade and classification standards that have been accepted by the industry for marketing of 230 agricultural commodities. These standards were created in response to the needs expressed by the industry for uniform standards that could be used and certified nationwide. The usage of these standards is voluntary.

The American Dairy Products Institute (ADPI) has published a series of milk and dry milk standards that can be used when USDA certification is not requested by the buyer or seller. These standards are based on the USDA standards and contain the same requirements as the U.S. Grade standards. Majority of the industry however prefers USDA certification because of its official value in certification.

The American National Standards Institute (ANSI) and American Society for Testing and Materials (ASTM) standards are used for most testings and analyses conducted by AMS in providing the certification services to the industry.

AMS has developed numerous grade standards and classifications in response to requests from industry. AMS does not view these standards and classifications as government unique since they were developed with full consultation and participation of the industry and their usage by the industry is voluntary.

The authority for AMS's development of the government-unique specifications for the grading and certification of tobacco products is contained in the Tobacco Statistics Act of 1929 and the Tobacco Inspection Act of 1935, as amended. Major provisions of these Acts dictate that all tobacco sold at auction must be inspected and graded by USDA personnel according to the U.S. standards. AMS's Tobacco Standards are published in the Code of Federal Regulations.

The Farmer Service Agency (FSA) in USDA handles most commodity purchases. The Food and Nutrition Service (FNS) is involved in the food and child nutrition programs authorized by the National School Lunch Act and the Child Nutrition Act of 1966 to provide nutritious foods and 
milk products to the school children. As partner agencies, FSA, FNS and AMS all have to agree with each other's standards in purchasing the commodities for the School Lunch and other feeding programs, particularly the nutritional guidelines set by FNS. In addition, AMS accepts commercial standards on the foods. When commercial standards fail to meet the nutritional requirements of the School Lunch and feeding programs, AMS sets specifications on the fat, salt and sugar contents, particularly on the canned and frozen foods. These requirements are included in the individual bids on a case-by-case basis, they are not coded permanently as the government-unique standards.

AMS also sets government-unique standards on beef, chicken, eggs, fish, juice, nuts and beans, pork, turkey, fruits, vegetables, milk, and dairy products through the grading process. Such standards can be found in USDA's Home Page (www.usda.gov). 


\section{DEPARTMENT OF COMMERCE (DOC)}

The Department of Commerce encourages and supports its staff to participate in standards committee activities relating to the mission of the Department, particularly in response to Office of Management and Budget (OMB) Circular A-119, "Federal Participation in the Development and Use of Voluntary Standards." Agency employees participate in the standards development activities of : U.S. private sector standardization bodies; local, state, and Federal governments; industry; and private and governmental (both treaty and non-treaty) international organizations. Standards of interest to the Department cover such areas as energy conservation, information and computer technology, telecommunications and environmental safety and health, and a variety of other product sectors and fields of technology.

The Standards Assistance and Management Information (SAMI) project in the Office of Standards Services, National Institute of Standards and Technology (NIST), collects and disseminates information on DOC staff participation in outside standards-writing activities. A directory, published annually, contains statistics on standards committee participation, alphabetical listings of staff participants and standards organizations and committees, and a list of acronyms and abbreviations. Department employees are encouraged to provide the SAMI office with additional information concerning participation in standards activities not already included in the directory.

The DOC information maintained by the SAMI office is divided into two parts: NIST and nonNIST agencies. During this reporting period, a total of 411 of the Commerce Department staff participated in the outside standards committees of 143 (100 national and 43 international) standards-developing organizations. Sixty-eight staff members of non-NIST Commerce agencies participated in 42 standards organizations (28 national and 14 international) encompassing 138 committees, holding 63 memberships on those committees. Eight of those standards organizations had five or more DOC participants. NIST had 343 participants in the activities of 101 standards organizations (72 national and 29 international). This participation encompassed 361 committees and 1,205 NIST memberships on these committees. Eleven of the standards organizations in which NIST staff members participated had 15 or more NIST memberships.

The following organizations/agencies accounted for 28 percent (39) of the 141 other DOC committee memberships.

Organizations Whose Standards Committees Have DOC Members:

No. of Committee Memberships

American National Standards Institute 19

International Organization for Standardization 
International Telecommunication Union - Telegraph

International Telecommunication Union - Radio

The following standards organizations accounted for 81 percent $(1,002)$ of the 1,205 NIST committee memberships:

Organizations Whose Standards Committees Have NIST Members:

No. of Committee Memberships

American Society for Testing and Materials 603

American National Standards Institute 107

Institute of Electrical and Electronic Engineers 43

International Organization for Standardization 76

American Society of Mechanical Engineers 33

International Organization of Legal Metrology 24 International Electrotechnical Commission 34 American Concrete Institute 16

Telecommunications Industry Association 24

National Conference on Weights and Measures 21 CIE

Total 1002

\section{OTHER DOC AGENCIES: SUMMARY OF STANDARDS-RELATED ACTIVITIES}

\section{National Oceanic and Atmospheric Administration (NOAA)}

Standardization of data acquisition and data management practices is vital to the mission at NOAA. NOAA seeks to establish voluntary standards with selected industrial associations, academia, and national organizations of state and local governments (e.g., the American Association of State Climatologists), as well as through participation in professional societies (e.g., American Meteorological Society). All NOAA line organizations engage in standards development for disciplines of interest to them. In general, standards that apply to many NOAA activities are established with other Federal agencies (e.g., DOD, FAA, USDA); through participation in international organizations such as the World Metrological Organization; and by means of bilateral and multilateral agreements with other nations. These standardization, activities apply to all phases of environmental data acquisition, processing and distribution. 
National Telecommunications and Information Administration (NTIA)

The NTIA contributes to the development and application of national and international telecommunication standards by way of participation and leadership roles in various voluntary standards committees at national and international levels (e.g., Telecommunications Industry Association, International Telecommunication Union). These standards enhance the quality and reliability of the domestic telecommunications infrastructure, promote healthy competition in telecommunications products and services, and expand international trade opportunities for U.S. telecommunications firms.

\section{Patent and Trademark Office (PTO)}

The Patent and Trademark Office participates and contributes to the resolution of identified requirements for international standards, primarily through the Permanent Committee on Industrial Property Information of the World Intellectual Property Organization (WIPO). PTO staff also participate in standardization activities of the International Patent Classification Union and the ANSI committee on Patent Standards.

\section{Bureau of the Census}

DOC's Bureau of the Census is active in the development of standards and specifications for definition of metropolitan statistical areas, digitizing of geographic information, and statistical, economic and geographic definitions.

National Institute of Standards and Technology (NIST): Summary of Standards-Related $\underline{\text { Activities }}$

- In addition to the activities described above in support of P.L. 104-113, the NIST's Office of Standards Services (OSS) operates a number of standards-related programs and services to assist business, industry, and government in using and understanding standards, technical regulations, and conformity assessment procedures affecting trade in the global marketplace.

- The National Center for Standards and Certification Information (NCSCI) is the U.S. focal point for standards information and related activities at home and abroad; it provides information on U.S., foreign, regional, and international voluntary standards bodies, mandatory government regulations, and conformity assessment procedures for nonagricultural products. NCSCI is the U.S. member of the International Organization for Standardization Information Network (ISONET), and serves as the U.S. inquiry point under the World Trade Organization (WTO) Agreement on Technical Barriers to Trade, the North American Free Trade Agreement (NAFTA), and the Asia Pacific Economic Cooperation (APEC) Subcommittee on Standards and Conformance. 
- NCSCI maintains an extensive collection of reference materials, including U.S. military and other Federal Government specifications, U.S. industry and national standards, international standards, and selected foreign national standards. Staff members respond to requests for specialized standards information; arrange for translations of foreign standards and regulations; and disseminate information to U.S. industry concerning proposed foreign regulations and general standards issues.

- Two telephone hotlines provide weekly updates on draft European standards and on proposed foreign technical regulations that might significantly affect trade.

\section{NIST Standards Advisory Committee}

The NIST Standards Advisory Committee implements the Office of Management and Budget's (OMB) Circular A-119 at NST, coordinating voluntary standards activities and addresses concerns across the Institute and providing a mechanism for information exchange among NIST professional staff on standards activities.

The Standards Advisory Committee, with broad representation, held five meetings during 1997 to develop recommendations for NIST standards policies and procedures. Committee members provided input into the Standards Assistance and Management Information project, which collects and disseminates information on a NIST-wide basis on staff participation in standards activities. The Committee has initiated a framework for Strategic Standards Management at NIST, drafted a standards policy for NIST participation in Voluntary Consensus Standards and is currently reviewing the Institute's standards policies, including the structure for handling standards participation fees and dues. The Chair of the Standards Advisory Committee provided two briefings on national and international standards to the NIST Visiting Committee on Advanced Technology (VCAT).

\section{National Cooperation for Laboratory Accreditation}

The NIST Office of Standards Services hosted a public workshop and facilitated the incorporation of the National Cooperation for Laboratory Accreditation (NACLA) as the recognized body to provide coordination and focus for laboratory accreditation programs in the United States and to become the U.S. point-of-contact for international accreditation efforts.

\section{Workshop on Circular A-119}

NIST conducted a Workshop with OMB on requirements contained in the revised OMB Circular A-119 in March 1998 to acquaint Federal agencies and the private sector with its requirements. 


\section{DEPARTMENT OF DEFENSE (DoD)}

1. DoD Employee Participation. The DoD has over 683 employees participating in the standards development activities of over 89 voluntary standards bodies.

2. DoD Adopted Voluntary Standards. Since our input for the FY 97 report, we have adopted an additional 464 voluntary standards, bringing the total number of DoD adopted voluntary standards to 7991 .

3. Government Standards Replaced by Voluntary Standards. The following 125 Government specifications and standards were replaced by voluntary standards since our input for the FY 97 report:

\begin{tabular}{|l|l|}
\hline \multicolumn{1}{|c|}{ SPEVCIFICATION/STANDARD } & \multicolumn{1}{c|}{ REPLACEMENT VOLUNTARY STANDARD } \\
\hline MIL-851D & SAE J1993, SAE J827 SAE J441 \\
\hline MLL-A-3029 & ASTM D449 \\
\hline MIL-C-5778 & SAE AS5778 \\
\hline MIL-B-6039 & SAE AS6039 \\
\hline MIL-H-6088 & SAE AMS6088 \\
\hline MIL-S-6144 & SAE AS6144 \\
\hline MIL-T-6480 & SAE AS6480 \\
\hline MIL-S-6625 & SAE AS6625 \\
\hline MIL-S-6852 & SAE AS6852 \\
\hline MIL-S-7720 & SAE AMS-S-7720 \\
\hline MIL-S-7916 & SAE AS-S-7916 \\
\hline MIL-D-8181 & SAE AS8181 \\
\hline MIL-A-8576 & SAE AMS-A-8576 \\
\hline MIL-V-8712 & SAE-AS8712 \\
\hline MIL-R-8791 & SAE AS8791 \\
\hline MIL-D-8804 & SAE AS8804 \\
\hline MIL-B-9972 & AWS-C3.6 \\
\hline MIL-S-10520 & ASTM-A711, ASTM-A575 \\
\hline MIL-M-12218 & ASTM-D5632 \\
\hline MIL-B-12672 & ANSI/AWS-C3.4 \\
\hline MIL-S-13165 & SAE AMS-S-13165 \\
\hline MIL-S-13727 & AWWA-B504 \\
\hline MIL-L-13762 & ASTM-A308 \\
\hline MIL-C-14550 & SAE-AMS2418 \\
\hline MIL-G-16491 & NASM16491 \\
\hline & \\
\hline MIL-T-18607 & REPLACEMENT VOLUNTARY STANDARD \\
\hline MIL-V-18796 & SAE AS18607 \\
\hline MIL-I-18802 & ASME B16.34, ASTM-F1508 \\
\hline MIL-F-20236 & SAE AS18802 \\
\hline & ANSI/ASME B16.9 \\
\hline & \\
\hline
\end{tabular}




\begin{tabular}{|c|c|}
\hline MIL-I-25135 & SAE AMS2644 \\
\hline MIL-G-3036 & NASM 3036 \\
\hline MIL-G-45204 & SAE AMS2422 \\
\hline MIL-G-45209 & ASTM B679 \\
\hline MIL-L-46064 & ASTM B200 \\
\hline MIL-A-46165 & ASTM D579, ASTM D2343 \\
\hline MIL-P-46184 & ASTM D5205 \\
\hline MIL-C-46971 & ASTM B220 \\
\hline MIL-B-81935 & SAE AS81935 \\
\hline MS2548 & SAE AS25481 \\
\hline MS3109 & SAE AS31091 \\
\hline MS3117 & SAE AS31171 \\
\hline MS3197 & SAE AS31971 \\
\hline MS3368 & SAE AS33681 \\
\hline MS3373 & SAE AS33731 \\
\hline MS3393 & SAE AS33931 \\
\hline MS9068 & SAE AS3582 \\
\hline MS9134 & SAE AS3491 \\
\hline MS9135 & SAE AS3492 \\
\hline MS9136 & SAE AS3493 \\
\hline MS9137 & SAE AS3494 \\
\hline MS9138 & SAE AS3495 \\
\hline MS9139 & SAE AS3496 \\
\hline MS9140 & SAE AS3497 \\
\hline MS9350 & NAS1715 \\
\hline MS9153 & NAS1715 \\
\hline MS9352 & NAS1715 \\
\hline MS99353 & SAE AS9353 \\
\hline MS9377 & SAE AS3498 \\
\hline MS9391 & SAE AS9391 \\
\hline MS9600 & SAE AS9600 \\
\hline MS9603 & SAE AS9603 \\
\hline MS9970 & SAE AS3581 \\
\hline MS14102 & SAE AS14102 \\
\hline MS14103 & SAE AS14103 \\
\hline MS14104 & SAE AS14104 \\
\hline MS14105 & SAE AS14105 \\
\hline MS14153 & SAE AS14153 \\
\hline MS14154 & SAE AS14154 \\
\hline MS14227 & SAE AS14227 \\
\hline $\begin{array}{l}\text { GOVERNMENT } \\
\text { SPECITICATIONISTANDARD }\end{array}$ & REPLACEMENT VOLUNTARY STANDARD \\
\hline MS14238 & SAE AS14238 \\
\hline MS17143 & SAE AS17143 \\
\hline MS17184 & SAE AS17184 \\
\hline MS17731 & NASM 1773 \\
\hline MS17732 & NASM 1772 \\
\hline
\end{tabular}




\begin{tabular}{|c|c|}
\hline MS20995 & NASM 20995 \\
\hline MS21122 & NAS 1715 \\
\hline MS21209 & NASM 21209 \\
\hline MS21323 & NASM 21323 \\
\hline MS21327 & NASM 21327 \\
\hline MS21332 & NASM 21332 \\
\hline MS21397 & NASM 21332 \\
\hline MS25420 & NASM 25420 \\
\hline MS27969 & BHMA-A156.20 \\
\hline MS27980 & NASM 27980 \\
\hline MS27981 & NASM 27981 \\
\hline MS27983 & NASM 27983 \\
\hline MS33530 & SAE AMS2253 \\
\hline MS33531 & SAE AMS2243 \\
\hline MS33583 & SAE AS33583 \\
\hline MS33611 & SAE AS3361 \\
\hline MS63044 & NAS 1711 \\
\hline MIL-STD-17/1 & ASTM F100, ASTM F856, ASTM Y32.2.6 \\
\hline MIL-STD-29 & ASTM Y14.13 \\
\hline MIL-STD-285 & IEEE 299 \\
\hline MIL-STD-373 & ASTM D5449 \\
\hline MIL-STD-374 & ASTM D5448 \\
\hline MIL-STD-410 & NAS 410 \\
\hline MIL-STD-498 & IEEE/EIA 12207 \\
\hline MIL-STD-1312 & NASM 1312 \\
\hline MIL-STD-1942 & ASTM C1161 \\
\hline A-A-43 & ASTM D2955 \\
\hline A-A-47 & ASTM D2356 \\
\hline A-A-48 & ASTM D455 \\
\hline A-A-49 & ASTM D499 \\
\hline $\mathrm{A}-\mathrm{A}-50$ & ASTM D2958 \\
\hline A-A-269 & ASTM D2356 \\
\hline A-A-373 & ASTM C669 \\
\hline $\mathrm{A}-\mathrm{A}-374$ & ASTM D928 \\
\hline A-A-392 & UL 626 \\
\hline A-A-895 & ASTM D456 \\
\hline $\mathrm{A}-\mathrm{A}-1109$ & ASTM F887 \\
\hline A-A-1818 & ASTM D5370 \\
\hline A-A-51125 & ASME B94.51 \\
\hline A-A-51184 & ASME B94.51 \\
\hline $\begin{array}{l}\text { GOVERNMENT } \\
\text { SPECIFLATION/STANDARD }\end{array}$ & REPLACEMENT VOUUNTARY STANDARO \\
\hline $\mathrm{A}-\mathrm{A}-51185$ & ASME B94.51 \\
\hline L-F-36 & ASME B94.51 \\
\hline O-S-598 & ANSI Z87 \\
\hline O-S-604 & ASTM D456 \\
\hline
\end{tabular}




\begin{tabular}{|l|l|}
\hline QQ-A-225 & ASTM D537 \\
\hline QQ-A-250 & ASTM B211, SAE AMS-QQ-A-225 \\
\hline QQ-W-321 & ASTM B209, SAE AMS-QQ-A-250 \\
\hline RR-D-2841 & ASTM B134, B159, B206 \\
\hline SS-T-312 & ASTM F918 \\
\hline VV-B-680 & ASTM F1066, ASTM F1700 \\
\hline VV-B-680 & SAE J1703 \\
\hline
\end{tabular}

4. The current OMB Circular A-119 provides clear guidance on using voluntary consensus standards and participating in voluntary consensus standards bodies. As written, this circular reinforces DoD policies regarding use of voluntary standards, reliance on performance documents, and encouragement of participation in voluntary standards bodies. DoD believes the Circular's plain language format greatly enhances its effectiveness. DoD does not believe additional changes are required at this time.

5. The DoD implements the provisions of P.L. 104-113 and OMB Circular A-119 through DoD 4120.3-M, "Defense Standardization Program Policies and Procedures." As set forth in existing DoD policies, items or materials that are normally procured using a voluntary standard by commercial firms, DoD activities also should be using a voluntary standard. Furthermore, DoD 4120.3-M requires DoD standards developers to actively look for opportunities to replace government documents with voluntary standards.

One aspect of the Department's MilSpec Reform initiative continues to be the replacement of military specifications and standards with voluntary standards wherever there is a dual-use application. As a result of this initiative, DoD completed a review of its $30,000+$ military specifications and standards to determine whether a replacement voluntary standard already existed or whether one could be developed. We identified over 3000 candidate military specifications and standards with potential to become voluntary standards. The Department has put procedures in place to ensure proliferation of military documents does not reoccur.

DoD is continuing to proactively enlist the support of industry associations and voluntary standards developing organization to help us review, identify, and plan for replacement of military specifications and standards with voluntary standards. In situations where a military standardization document is also used by commercial firms, DoD is working with the appropriate standards developing organization to create a suitable replacement. The Department relies on military specifications and standards in lieu of voluntary standards when the requirement can be justified as truly military-unique; when a voluntary standard does not exist and development is not imminent; when there is no industry interest to develop a voluntary standard to address DoD requirements. Since DoD has a large number of procurements, DoD has chosen to use the categorical basis as our means of conveying information on its voluntary consensus standards use. 


\section{NATIONAL COMMUNICATION SYSTEM (NCS)}

1. The Office of the Manager, National Communications System (OMNCS) provides the chair of the Federal Telecommunications Standards Committee (FTSC). This interagency committee prepares standards and recommendations on matters affecting national security and emergency preparedness (NS/EP) and in other areas of communications approved by the committee on the basis of requests from members.

2. During FY 1998, two Federal Telecommunications Recommendations (FTR), based on consensus standards committee approved documents, were approved by the FTSC for publication.

a. FTR 1024B-1998. Project 25 Radio Equipment [land mobile radio systems]. (Combination of Telecommunications Industry Association (TIA) documents in the 102 series.)

b. FTR-1050-1998. Group 3 Facsimile Apparatus for Document Transmission in the General Switched Telephone Network. (Based on ANSI/TIA/EIA-465-A-1995.)

3. Dr. Peter M. Fonash, Chief, Technology and Standards Division, and Chair, FTSC, is the OMNCS focal point for telecommunications and related information system standards. His telephone number is (703) 607-6200, and his email address is fonashp@ncs.gov.

4. The FTSC and members of the Office of the Manager, NCS (OMNCS) work extensively with voluntary standards organizations to ensure that Government requirements are considered as the standards are developed. The OMNCS has 14 employees who participate in industry voluntary standards activities. Paragraph 6 lists the committees in which they participate.

5. Voluntary standards related committees in which the staff of the OMNCS participate:

a. Organizations Accredited by the American National Standards Institute (ANSI)

- Committee T1, Telecommunications

- National Committee for Information Technology Standards (NCITS)

- TR-8, TR-29, TR-45, TR-46

- JTC1 TAG Information Technology

b. Commercial and International Organizations Not Accredited by ANSI

- ATM Forum

- Multimedia Forum

- Telecommunications Industry Forum (TCIF)

- Electronic Communications Implementation Committee (ECIC)

c. Federal Interagency Committees

- Federal Telecommunication Standards Committee (OMNCS furnishes Chair and 
Executive Secretary)

- Federal Wireless Policy Committee (OMNCS furnishes Vice-Chair)

- Federal Wireless User's Forum (OMNCS furnishes Co-Chair)

- Information Infrastructure Task Force (IITF)

- Federal Law Enforcement Wireless User's Group (FLEWUG)

d. Federal, State, and Local Committees

- Association of Public Safety Communications Officials (APCO)

- Project 25

- Project 31

e. International Organizations

- International Telecommunications Union-Telecommunications Sector (ITU-T)

(OMNCS heads U.S. delegations to 2 study groups)

- International Telecommunications Union-Radio Sector (ITU-R)

- International Organization for Standardization (ISO) and the International Electrotechnical Committee (IEC) 


\section{DEPARTMENT OF EDUCATION}

For the past several years the U.S. Department of Education (ED) has been actively working with the American National Standards Institute (ANSI) on developing EDI transaction sets through their Accredited Standards Committee (ASC) X12 committee. This committee is charged with developing uniform standards for electronic interchange of business transactions. The X12 Committee develops standards to facilitate electronic interchange relating to such business transactions as order placement and processing, shipping and receiving, invoicing, payment, and cash application data associated with the provision of products and services.

The Department of Education's National Center for Education Statistics (NCES) has one voting member and has sponsored the work of task groups to attend ANSI ASC X12 meetings.

Information about the activities that NCES has been involved in can be obtained at: http://nces.ed.gov/edi. In addition, ED has had another voting member that is part of the Department's Office of Postsecondary Education. The Department has been involved in developing EDI transaction sets for Student Financial Aid. These activities fall under the umbrella of Project EASI. For more information on Project EASI please visit:

http://easi.ed.gov/inside_projecteasi/HTML/inside_main.html. Participation in this voluntary consensus building body has allowed ED to forge ahead in developing standards while including the necessary members of the affected communities to help transition to adoption.

Transaction sets that ED has promulgated for information about students (both at the elementary/secondary level and at the postsecondary level) and other aspects of education are the following:

Transaction Sets Relating to Individual Student Records

TS 130 - Student Educational Record (Transcript)

TS 131 - Student Educational Record (Transcript) Acknowledgment

TS 138 - Testing Results Request and Report

TS 146 - Request for Student Educational Record (Transcript)

TS 147 - Response to Request for Student Educational Record (Transcript)

TS 189 - Application for Admission to Educational Institutions

\section{Implementation Guides}

Transaction Sets Relating to Personnel Records

TS 132 - Personnel Information

Transaction Sets Relating to Student Financial Aid Records

TS 135 - Student Loan Application 
TS 139 - Student Loan Guarantee Result

TS 144 - Student Loan Transfer and Status Verification

TS 190 - Student Enrollment Verification

TS 191 - Student Loan Pre-Claims and Claims

TS 810 - Invoice

TS 820 - Payment Order/Remittance Advice

\section{Transaction Sets Relating to Institutional Records}

TS 133 - Educational Institutional Profile

TS 152 - Statistical Government Information used to transmit CCD, IPEDS and Library surveys to NCES

TS 188 - Educational Course Inventory 


\section{DEPARTMENT OF ENERGY (DOE)}

The DOE implements the Federal guidance and requirements in OMB Circular A-119 and the statutory requirements in Public Law (P.L.) 104-113 (15 USC 272) on the use of voluntary standards through specific Departmental directives (policy, requirements, guides, and technical standards) and supporting management systems.

DOE P 251.1, “Directives System," establishes a Directives System for managing DOE requirements and guidance documents and incorporates technical standards (i.e., those standards that are specifically addressed in P.L. 104-113) as the foundation of the Department's directives system hierarchy. This policy clearly states DOE's preference to “adopt National Consensus Standards and other commercial and industry standards " in the conduct of Departmental activities. The policy also contains provisions restricting the use of mandated technical standards in DOE rulemaking and Orders stipulating DOE-specific requirements. DOE requirements in Orders and rules reference appropriate voluntary consensus standards when they are acceptable to meet the requirements.

DOE P 410.1A, "Promulgating Nuclear Safety Requirements," also requires notice and comment rulemaking to promulgate new nuclear safety requirements. The new nuclear safety requirements promulgated by the Department are "performance-based" rules which permit the adoption of commercial and industry standards as acceptable methods to implement the rules when appropriate for the work to be conducted and the hazards to be encountered.

These Departmental policies on the use of voluntary standards are subsequently implemented through a management system established through DOE Order 1300.2A, "Department of Energy Technical Standards Program." This Order requires DOE elements to use international and national voluntary standards in preference to Federal and DOE standards, consistent with P.L. 104-113 and OMB A-119. It also establishes an integrated Department-wide Technical Standards Program and supporting infrastructure designed to implement Federal and DOE technical standards requirements and manage related activities within DOE. As advocated in OMB Circular A-119 and P.L. 104-113, the Order encourages and supports staff participation in the planning, development, and coordination activities of voluntary standards committees.

As of October 1998, DOE Order 1300.2A is being updated to incorporate references to P.L. 104-113 and the February 1998 revision to OMB Circular A-119. In the interim, the Assistant Secretary for Environment, Safety and Health issued an information memorandum to the Department's cognizant secretarial officers (i.e., senior DOE line managers in Washington, D.C.) describing the new Public Law, its impact upon DOE, and the planned implementation of the law through the Technical Standards Program. The Department had already incorporated the technical standards provisions of P.L. 104-113 and OMB Circular A-119 into its current Technical Standards Program Procedures, and currently manages its technical standards activities in conformance with their requirements. Furthermore, DOE hosted a Federal Technical 
Standards Workshop with broad participation from Federal agencies in August of 1998 to discuss standards management issues and share experience related to implementing P.L. 104-113 and OMB Circular A-119.

Another element serving to manage implementation of P.L. 104-113 and OMB Circular A-119 is DOE's Department Standards Program. This Program was established to institute "standards" (in this application, "standards" include policy, laws, rules, guides, and technical standards) as the basis for work throughout the Department. A Department Standards Committee (DSC) was established in 1994 and served to establish DOE standards policy and remove barriers to implementing a Department-wide standards-based culture. The DSC assists DOE line organizations in the implementation of this Department Standards Program. The "Criteria for the Department's Standards Program," DOE/EH/-0416, August 1994, describes elements of the standards-based operating culture envisioned by DOE leadership. Information on the Department Standards Program and the DSC can be accessed at the following Internet address (URL):

http://www.dsc.doe.gov.

The DSC has sponsored development and implementation of a DOE-wide process that enables DOE contractors to select voluntary consensus standards as the basis for their work in-lieu-of DOE-developed standards if it is appropriate for the work. This "Work Smart" standards approach (also referred to as the "necessary and sufficient" process) enables DOE laboratory and management and operating or integrating contractors, with DOE approval, to identify and apply the set of standards (including technical standards) that best fits their activities. This approach focuses on outcomes and performance, rather than "how" things are to be done within DOE, and is supported by a major contract reform effort designed to more closely link performance expectations with contractual obligations based on standards.

Key Departmental policy and requirements documents defining this approach include DOE P 450.3, "Authorizing Use of the Necessary and Sufficient Process for Standards-Based Environment, Safety and Health Management," and DOE M 450.3-1, "The Department of Energy Closure Process for Necessary and Sufficient Sets of Standards." Field pilot projects of the approach have been completed, and significant efficiencies and cost-savings have been demonstrated. Based on the success of the pilot projects, the "Work Smart" standards approach was expanded to cover a broad range of Department programs and facilities. In fiscal year (FY) 1998, key Technical Standards Program personnel participated in several DSC working groups that focused on tailoring/integration of "Work-Smart" standards activities and DSC support for the Department's "Integrated Safety Management" initiative. The Department is reviewing our experience with "Work Smart" to assess the need for revised or additional guidance.

The DOE Standards Executive, Richard L. Black, Director, Office of Nuclear Safety Policy and Standards, continues to be responsible for developing and implementing the DOE Technical Standards Program throughout the Department. He also advises and provides staff support to the Department Standards Committee. Through Mr. Black's participation on the Interagency 
Committee on Standards Policy, DOE continues to provide information to other Federal agencies on the Department's approach to establishing a standards-based culture.

DOE Order 1300.2A emphasizes the use of technical standards within the Department. The Department's Technical Standards Program Office (TSPO) operates under this directive to implement program policy, support the conversion of Department standards to voluntary standards, identify voluntary standards that can suit Department needs, develop and maintain data bases to support the program and meet reporting requirements, and coordinate day-to-day Department technical standards activities. The TSPO has developed procedures, methods, and training approaches to implement the DOE Technical Standards Program and communicate the policy to use voluntary standards throughout DOE and, when appropriate, participate in voluntary standards committee activities. The program procedures establish a five-year standards review cycle to check for continued applicability; the procedures also provide guidance on the conversion of Department standards to voluntary standards.

Information on the Technical Standards Program and the TSPO can be accessed at the following Internet address (URL):

http://apollo.osti.gov/html/techstds/techstds.html.

Technical Standards Managers (approximately 70 individuals representing the various Department headquarters, field, laboratory and contractor organizations) have been designated to coordinate the consistent implementation of the program. Established in 1992, the Technical Standards Managers' Committee (comprised of these Technical Standards Managers) operates under the DOE Technical Standards Program, supports the DOE sites in technical standards activities, facilitates communications on program implementation issues, and participates in establishing program goals and procedures. Publications documenting the voluntary standards adopted by DOE and the personnel participating in the activities of voluntary standards groups are developed by the TSPO; the information in those publications is electronically posted for Internet access.

In FY 1998, the Technical Standards Program continued the recognition of "topical" standards committees within the Department. These committees are composed of subject matter experts in the DOE community and can be used as a focal point for standards activities in specific technical areas. The topical committees provide a forum for all interested DOE parties to join and participate in reviewing technical standards produced by counterpart voluntary standards organizations, address standards application issues within their area of technical expertise, and work to develop Department and Federal positions on standards issues. As of October 1998, 19 DOE topical committees have been recognized by the Technical Standards Program. (These committees are identified on the program Internet address listed above).

The Department has also established a DOE Information Technology Standards Program (Internet address is http://cio.doe.gov) that is conducted in accordance with the DOE Technical Standards Program. The DOE Information Technology Standards Program is managed by staff 
from DOE's Office of the Chief Information Officer with assistance from over 70 designated DOE and contractor Information Technology Points-of-Contact representing key programs and sites. It coordinates information technology standards activities Department wide, including the identification, adoption, implementation, and retirement of non-government and government information technology standards in support of the DOE Information Architecture. This program has stressed the use of international and voluntary consensus information technology standards over development of internal standards in its adoption processes.

The Department also implements a legislatively mandated, multi-year effort to improve the energy efficiency in the Nation's buildings through energy efficiency standards, codes and guidelines for buildings, building equipment, and appliances through its Office of Energy Efficiency and Renewable Energy (Internet address is http://www.eren.doe.gov/). The Department's codes and standards development efforts in these areas are closely coordinated with standards development organizations and include early involvement of industry and state stakeholders and relevant Federal agencies.

DOE continues to take a "pro-active" approach to standards and standards management even as its mission continues to evolve in response to the conclusion of the Cold War and shrinking Congressional appropriations. A number of programs and facilities have shifted their focus from production, research, and/or development to environmental remediation and restoration, where DOE will literally be breaking new ground and setting standards for others to follow. In addition, Department staffing levels are declining to meet Congressional budget constraints. Still, in the face of a changing mission and a reduced work force, DOE continues to actively use and support the development of voluntary standards to meet its needs. In FY 1998, the number of voluntary standards adopted for use increased to 840 ( 809 in 1997). However, the number of individuals participating in voluntary standards activities decreased to 681 (871 in 1997), and the number of documented participation in standards developing groups declined to 1321 (1540 in 1997). We believe this reflects the very significant "downsizing" and budget cuts experienced by DOE in recent years, rather than any reduced interest on the part of Departmental organizations.

Also, DOE (through the TSPO) is continuing its initiative (in response to contacts from voluntary standards organizations on how the Department is meeting P.L. 104-113) to better define "candidate" DOE technical standards for conversion to voluntary standards. We are continuing to work with representatives of the American National Standards Institute's Nuclear Standards Board (ANSI-NSB) on the conversion of selected DOE technical standards to voluntary standards. (Four candidate standards have been identified to date).

In addition, DOE sponsored a meeting in August 1998 with representatives of several voluntary standards organizations (ASTM, ASME, ANS, NFPA, IEEE, et al.) as part of a more structured program interface with the voluntary standards community to promote developing new standards that may be needed through those organizations rather than within DOE. Other highlights of DOE's interaction with voluntary standards bodies include the following: 
- From FY 1993 through FY 1997, DOE conducted annual national workshops promoting the Technical Standards Program and the use of voluntary standards within the Department. Each workshop was attended by approximately 150 standards developers and users.

- In FY 1998, DOE hosted the first-ever Federal Technical Standards Workshop with the goal of furthering the implementation of P.L. 104-113 throughout the Federal Government. The Workshop was co-sponsored with the National Institute of Standards and Technology (NIST), the Environmental Protection Agency (EPA), the National Aeronautics and Space Administration (NASA), the Food and Drug Administration (FDA), and the Partnership in Reliability, Maintainability, and Supportability (RMS) Standards. More than 200 standards developers and users attended the workshop. Another Federal Technical Standards Workshop is being planned for FY 2000.

- In addition to the ANSI-NSB, DOE representatives participate on ANSI's Board of Directors and Executive Standards Council. DOE also participates in a number of international standards groups such as ISO/TC 85, Nuclear Energy, ISO/TC 176, Quality Assurance, and ISO/TC 207, Environmental Management

\section{Reporting Requirements for OMB Circular A-119:}

1) The number of voluntary consensus standards bodies in which there is agency participation, as well as the number of agency employees participating.

--Number of standards bodies: 65

--Number of agency personnel participating: 681

--Total number of agency participation: 1321

2) The number of voluntary consensus standards the agency has used since October 1, 1997, based on the procedures set forth in sections 11 and 12 of the Circular: 840

3) Identification of voluntary consensus standards that have been substituted for government-unique standards as a result of an agency review under section $15 \mathrm{~b}(7)$ of the Circular: 0

4) An evaluation of the effectiveness of this policy and recommendations for any changes.

Response -- The guidance in OMB Circular A-119 appears to be sufficient in terms of outlining the basic functions and responsibilities of Federal agency standards management and standards participation activities. It allows sufficient latitude for each Federal agency to develop its own approach tailored to specific agency needs, and places the emphasis on outcomes rather than processes.

5) As required by P.L. 104-113, when the agency used government-unique standards in-lieu-of voluntary consensus standards. 
Response -- There were no recorded cases in FY 1998 where the Department selected to use an internal standard in-lieu-of an equivalent, existing voluntary standard. 


\section{FEDERAL ENERGY REGULATORY COMMISSION}

The Federal Energy Regulatory Commission (FERC or Commission) regulates in the public interest electric power, natural gas, oil pipelines and nonfederal hydroelectric power. The Commission ensures that the rates, terms and conditions of service for the electric power, natural gas, and oil industries are just and reasonable and not unduly discriminatory or preferential, and that licensing, administration, and safety actions for the hydropower industry and other approvals for all four industries are consistent with the public interest.

As a consequence of changes in the energy marketplace, the Commission is reconsidering the proper role of traditional command and control economic regulation. The evolving electric power and natural gas industries, encouraged to be competitive by the Congress and driven by economic and technological developments, are challenging long-held regulatory assumptions and practices. The Commission is committed to promoting competition where feasible, thus providing the benefits of competitive commodity markets to consumers of electricity and natural gas.

With respect to natural gas, the Commission issued a series of measures (Order Nos. 436, 500, and 636) that opened pipeline transportation to all on equal terms and that eventually resulted in the interstate pipelines relinquishing their traditional merchant function. The Commission is seeking to develop alternative regulatory methods that encourage further competition by continually examining its regulations and revising them to foster the mixed competitive regulatory market.

Natural gas commodity markets can be made better by continuing to improve standardization among pipeline systems for both information and business so that gas can be moved more efficiently. With the encouragement of the Commission, the Gas Industry Standards Board (GISB) has adopted more than 150 business practice standards, including standards relating to electronic communication over the Internet, aimed at simplifying the process of transacting business across the interstate natural gas pipeline grid. To implement the standards, each natural gas pipeline was required to make a tariff filing with the Commission. The Commission reviewed the filings and any comments, requiring revisions as appropriate. The majority of filings required at least one compliance filing in order to effect implementation. In total, over 500 GISB implementation filings were processed.

$\underline{\text { GISB }}$

Before Order 636, transportation contracts between pipelines (transportation service providers) and shippers prohibited any assignment or sale of the contract to any other shipper. Without prior approval of the Commission, availability of natural gas (capacity) could only be used by the 
contracting shipper. Order 636 gave shippers the right to sell all or any portion of a contract's rights for all or any portion of capacity release. This process of selling capacity is known as capacity release.

The process of standardizing business practices in the natural gas industry began with a Commission initiative to convene a technical conference to standardize electronic communication of natural gas capacity release transactions. To develop the required standards, the participants at the conference agreed to form working groups composed of representatives from all segments of the industry. In addition to the capacity release standards, the conference participants decided that standardization of other business transactions, such as nominations and flowing gas, was important and formed an additional working group to begin developing standards for these transactions. By consensus of that working group, recommendations were made that industry be permitted to develop and implement such standards voluntarily. While the Commission endorsed the importance of this effort in helping to facilitate gas movement across the pipeline grid, it was not actively involved in the process. The Commission pledged to reevaluate its role in the development and implementation of standards based on the progress made by the industry.

At the same time, industry sought to formalize the working group by forming a private standards organization to continue and expand the working group's efforts to develop electronic standards. In 1995, the industry formed GISB as a consensus standards organization open to all members of the gas industry. GISB's procedures require balanced voting representation from all five segments of the industry--pipelines, local distribution companies, natural gas producers, endusers, and services (including marketers, brokers, financial services companies, consultants, law firms, computer firms and other businesses). At the Executive Committee level, a consensus of the five segments must approve each standard. In addition, the industry, under the auspices of the Interstate Natural Gas Association of America (INGAA) and the Associated Gas Distributors (AGD) began a Grid Integration Project to consider standards for coordinating pipeline business practices to simplify the process of shipping gas across multiple pipelines. After GISB expanded its scope from electronic standards to encompass business practice standards, the Grid Integration Project was folded into GISB.

GISB is governed by two 25-member governing boards with members from each segment; the Board of Directors, which has responsibility for administrative and financial matters; and the Executive Committee, which, with the assistance of a number of working groups and task forces, is responsible for developing the standards themselves. There is also an Advisory Committee made up of regulatory and legislative representatives. GISB's voting rules ensure that all decisions are the result of a genuine industry consensus. Prospective standards must get at least 17 affirmative votes in the Executive Committee, and there must be at least two affirmative votes for each segment. Standards must then be ratified by the GISB membership; a 67 percent affirmative vote of those submitting ballots is required for a standard to get approval. On the Board of Directors, changes in bylaws or articles of incorporation need at least 19 affirmative 
votes, with at least two affirmative votes from each segment. GISB has filed with American National Standards Institute (ANSI) to be approved as an accredited standards organization.

1) The number of voluntary consensus standards bodies in which there is agency participation, as well as the number of agency employees participating.

At present, FERC does not actively participate in any consensus standards body as specified in section 7 of the Circular. FERC instead incorporates standards by reference in its regulations. These standards are adopted by recommendation and issuance of industry groups and set for review and possible incorporation by the Commission.

With regard to the gas industry, the Commission in 1995 issued an advanced notice of proposed rulemaking requesting the submission of detailed proposals from the industry by March of 1996 that would enable the Commission to adopt regulations for business practices and procedures involving transactions between pipelines and their customers. The Commission established January 1997 as the target deadline for compliance with the standards and urged the segments of the industry to work together to achieve consensus on standards. FERC anticipated then that GISB would become the forum for coordinating these industry efforts and has given great weight to consensus proposals emanating from the GISB process.

2) The number of voluntary consensus standards the agency has used since October 1,1997 based on the procedures set forth in section 11 and 12 of the Circular.

The Commission has adopted the standards developed by GISB for application throughout the natural gas industry. Since March, 1996, GISB has submitted over 150 proposed standards to FERC, which were accepted by FERC in Order No. 587 and in successive orders. In Order Nos. $587,587-\mathrm{B}$, and $587-\mathrm{C}$ the Commission adopted regulations to standardize the business practices and communication methodologies of interstate pipelines in order to create a more integrated and efficient pipeline grid. On July 15, 1998, the Commission issued Order No. 587-H, a Final Rule which incorporates by reference the standards relating to intra day nominations and nomination and scheduling procedures issued by GISB on March 12, 1998.

The nominations process is the way in which those who want to transport natural gas (local distribution companies and other shippers) request space on interstate pipelines. Nominations are notices to transportation service providers of how much gas the shipper wishes to transport, where the gas will be entering the pipeline system (receipt point), and where it will be delivered (delivery point). An intra-day nomination is a nomination submitted after the initial nomination deadline at 11:30 a.m. to change a shipper's scheduled quantities for the next gas day.

3) Identification of voluntary consensus standards that have been substituted for governmentunique standards as a result of agency review under section 15 (b) 7 of the Circular.

FERC has relied on the standards developed by the voluntary consensus organizations, in particular GISB, rather than develop its own or government-unique standards. GISB sets standards for the entire industry. 
4) An evaluation of the effectiveness of Circular A-119 policy and recommendations for any changes.

This report is FERC's initial submission to comply with the reporting provisions of OMB Circular A-119 as codified in P.L.104-113 "National Technology Transfer and Advancement Act of 1995". Currently, FERC is implementing the standards of the voluntary consensus organization, GISB.

Because of FERC's limited application of voluntary consensus standards it lacks the familiarity to apply all of the Circular's provisions. These provisions are directed to agencies that are in the process of continually developing or adopting standards issued by voluntary consensus organizations. However, as a regulatory agency FERC has taken specific interest in Section 11 of the circular. As FERC does not have a significant interest in standards and its FERC's exposure to the implementation of standards has been limited to a specific industry, FERC requests further elaboration on the particular forums that should be used by regulatory agencies to increase their awareness of available voluntary consensus standards and when can they be substituted for government-unique standards. FERC is following the provisions of Section 11(1)(b) of the Circular to notify the public of the standards it has adopted. However, FERC is not subject to the requirements of Executive Order 12866.

5) As required by P.L. 104-113, identification of all instances when the agency used government-unique standards in lieu of voluntary consensus standards (for each instance include agency rationale for such use, as well as the specific government-unique standard).

As noted above, FERC has relied on the standards issued by a single voluntary consensus organization (GISB). Where GISB has not reached consensus, FERC has stepped in to implement the use of such standards.

In the Commission's earlier orders, the Commission adopted standards only when all segments of the industry concurred that the standard was needed to improve efficiency. However, the Commission has recognized that policy disputes between the segments may prevent the development of an integrated pipeline grid. The Commission has identified several disputed standards where four industry segments supported the standards, but the pipeline segment prevented a consensus from being reached. These standards included the following:

- intra-day nominations (intra-day nomination is a nomination submitted after the initial nomination deadline at 11:30 a.m. to change a shipper's scheduled quantities for the next gas day. See above for Nominations);

- operational balancing agreements (OBAs) (contract between two parties that specifies the procedures to be used to manage operating variances at an interconnection. The OBA specifies how imbalances or differences in hourly flow of gas will be handled by the two parties); 
- netting and trading of imbalances (imbalance is a discrepancy between the quantity of gas a shipper tenders to the pipeline at a receipt point and the amount of gas the shipper takes at the delivery point. This is the ability of shippers to offset a positive imbalance on one contract with a negative imbalance on another contract.);

- notices of operational flow orders (OFOs) (OFOs are orders by a pipeline requiring shippers to take certain actions to alleviate emergency operational conditions on the pipeline's system). 


\title{
HEALTH AND HUMAN SERVICES, DEPARTMENT OF (HHS)
}

\author{
Food and Drug Administration (FDA)
}

Summary of the nature and extent of FDA participation in the development and utilization of voluntary consensus standards.

1) The number of voluntary consensus standards bodies in which there is agency participation = $\underline{46}$;

the number of agency employees participating $=\underline{274} ; *$ (on $\underline{553}$ voluntary consensus standards development committees)

* NOTE: Individual employees with specific expertise often participate simultaneously on two or more standards development committees within the same or different standards bodies. Therefore, 274 agency employees participate on 553 standards development committees, within 46 voluntary consensus standards development bodies.

2) The number of voluntary consensus standards the agency has used since October 1, 1997, based on the procedures set forth in sections 11 and 12 of the Circular $=\underline{370}$; *

* NOTE: Includes standards recognized under the Food and Drug Administration Modernization Act of 1997 (FDAMA).

3) Identification of voluntary consensus standards that have been substituted for governmentunique standards as a result of an agency review under section $15 b(7)$ of the Circular) $=\underline{0}$; *

* NOTE: Although certification to these standards does not replace any government-unique standards, it does replace some data submission requirements manufacturers must meet when seeking premarket approval for medical devices.

4) An evaluation of the effectiveness of Circular A-119 policy and recommendations for any changes;

The policy and recommendations contained in Circular A-119 are consistent with FDA's framework for standards management as announced in the Federal Register of October 11, 1995, and enhanced by FDAMA. Resource constraints oblige the agency to focus attention on the highest priority activities and to strive to make its participation in those activities very effective.

Voluntary consensus standards are most relevant for medical devices, where they are used extensively in the agency's regulatory work and where the majority of the agency's standards activities are centered. Voluntary consensus standards are less relevant in the areas of human and veterinary pharmaceuticals, biologicals, and food, where such standards are generally neither 
available nor being developed, and where standards of other international organizations (WHO, $\mathrm{FAO}, \mathrm{ICH})$ as well as regulatory standards predominate.

5) Number of instances when the agency used government-unique standards in lieu of voluntary consensus standards $=\underline{0}$.

Narrative Summary:

The central purpose for Food and Drug Administration (FDA) involvement in the development and use of standards is to assist the agency in fulfilling its domestic public health and regulatory missions. The agency participates widely in the development of standards, both domestic and international, and adopts or uses standards when this action will enhance its ability to protect consumers and the effectiveness or efficiency of its regulatory efforts. Further, using standards, especially international ones, is a means to facilitate the harmonization of FDA regulatory requirements with those of foreign governments, and thus to further domestic and global public health protection. Therefore, FDA encourages participation in the development of standards as a useful adjunct to regulatory controls.

FDA has been involved in standards activities for more than twenty years. In January 1977 the agency promulgated a final regulation now found at 21 CFR 10.95 covering participation by FDA employees in standards development activities outside the agency. This regulation encourages FDA participation in standards activities that are in the public interest, and specifies the circumstances under which FDA employees can participate in various types of standards bodies.

The agency built upon that rule with a draft policy statement published in the Federal Register on November 28, 1994, and a subsequent final policy published on October 11, 1995. Entitled International Harmonization; Policy on Standards, it provides the agency's overall policy on development and use of standards for all product areas regulated by the agency. In an initiative aimed at furthering harmonization, on January 28, 1995, FDA published in the Federal Register a proposed rule to facilitate the sharing of draft regulations and other predecisional documents with State and foreign officials. The final rule, Public Information; Communications with State and Foreign Government Officials, was published on December 8, 1995.

FDA's development and use of voluntary consensus standards varies within each of the agency's centers, because of differing availability and applicability of such standards in each product area. Voluntary consensus standards are most relevant to medical devices, and consequently the majority of the agency's standards activities addressed by Circular A-119 are centered there.

\section{Center for Devices and Radiological Health (CDRH)}

On October 10,1997, a draft guidance document was made available for public comment on the agency's Internet home page, which provided guidance to FDA medical device reviewers on the use of the International Electrotechnical Commission (IEC) 60601 series of standards, including declaration of conformity to the standards, during the evaluation of premarket submissions for 
electrical medical devices. A notice announcing the availability of the draft guidance, entitled Use of IEC 60601 Standards - Medical Electrical Equipment, was published in the Federal Register on January 13, 1998. Written comments were due to the agency by April 13, 1998.

Section 204 of the Food and Drug Administration Modernization Act of 1997 (FDAMA) (Pub. L. 105-115, 111 Stat. 2296), November 21, 1997, amended section 514 of the Federal Food, Drug, and Cosmetic Act (21 U.S.C. 360d), allowing the agency to recognize consensus standards established by international and national standards development organizations that may be used to satisfy identified portions of device premarket review submissions or other requirements. In a Federal Register notice published on February 25, 1998, the agency announced the availability of a guidance document entitled Recognition and Use of Consensus Standards describing how FDA planned to implement that part of FDAMA, and providing an initial list of recognized standards.

The agency decided not to finalize the draft guidance document entitled Use of IEC 60601 Standards - Medical Electrical Equipment, and withdrew it in a Federal Register notice on October 16,1998. In its place the agency published modifications to the initial list of standards (originally published in the February 25, 1998 notice) that will be recognized for use in the premarket review process. Recognition of the standards became effective on November 16, 1998 , and will assist manufacturers who elect to declare conformity with consensus standards to meet all or part of medical device review requirements. Periodic updates are contemplated.

Due to its extensive participation in voluntary consensus standards activities, CDRH has maintained a database to track the standards activities of its employees for many years. The Center recently invested in, and routinely uses searchable ROM databases of voluntary consensus standards to facilitate reference to current voluntary consensus standards by agency reviewers.

Center for Drug Evaluation and Research (CDER) / Center for Biologics Evaluation and $\underline{\text { Research (CBER) }}$

Voluntary consensus standards are less applicable to pharmaceutical and biological products. CDER and CBER therefore have extremely limited involvement in such activities, but do participate on relevant committees of at least two voluntary consensus standards bodies.

While the agency's involvement with voluntary consensus standards development is limited in these particular areas (mostly because such standards are not available nor under development in these areas), it should be noted that the agency does participate in many other types of standards development activities which are excluded from Circular A-119 reporting requirements.

Seventy-three employees in CDER and other FDA Centers are involved in the standards development activities of the U.S. Pharmacopeia (USP), a private, voluntary, not-for-profit national standard setting body of more than 1500 health care professionals, recognized authorities in medicine, pharmacy, and allied sciences. USP publishes and revises the United States Pharmacopeia and the National Formulary (NF), the legally recognized compendia of drug 
standards in the United States. However, it does not meet the criteria for a voluntary consensus standards organization as defined in OMB Circular A-119. Both CDER and the CBER participate in the International Conference on Harmonization of Technical Requirements for Registration of Pharmaceuticals for Human Use (ICH). This ongoing project, begun in 1989, has been undertaken by government agencies responsible for regulation of pharmaceuticals and by industry trade organizations for the European Union (EU), Japan, and the United States ICH brings together regulatory authorities and experts from the pharmaceutical industry in the three regions to discuss scientific and technical aspects of new product registration. The work products, created in working groups of experts from the regulatory agencies and industry, consist of a series of consensus guideline documents to harmonize pharmaceutical testing guidelines. FDA officials also participate in a consensus standards development activity sponsored by the Council for International Organizations of Medical Sciences and implemented in $\mathrm{ICH}$, that is aimed at standardizing the safety-related terminology used in adverse experience reporting.

FDA actively participates with the World Health Organization (WHO) in developing international standards for ensuring the quality of pharmaceutical and biological products, and the Organization for Economic Cooperation and Development (OECD) on good laboratory practices for animal studies. In 1997, a new hemispheric initiative was launched on pharmaceutical harmonization in the Americas, with emphasis on relevant $\mathrm{ICH}$ and WHO standards. The Pan American Health Organization (PAHO) is the convener. A conference to be held in January 1999 will help advance this initiative, and FDA plans to send four participants.

Although FDA's work with USP is specifically excluded from reporting under Circular A-119, and $\mathrm{ICH}, \mathrm{OECD}$ and $\mathrm{WHO}$ do not meet the definition of voluntary consensus standard bodies under the Circular, substantial agency resources are devoted to the development of these various standards, and this work is the core part of FDA's overall standards activities for pharmaceuticals.

\section{Center for Food Safety and Applied Nutrition (CFSAN) / Center for Veterinary Medicine (CVM)}

While voluntary consensus standards have minimal relevance to food and veterinary medicine products, standards activities of multilateral organizations such as the WHO and the OECD are often important in these areas, and CFSAN and CVM are actively engaged in standards and policy development with these organizations. The principal international standards activities in the areas of food and veterinary medicine fall under the activities of the Codex Alimentarius Commission under the Food and Agricultural Organization (FAO) and the WHO, and the Office of International Epizooties (for veterinary medicine). FDA experts from CFSAN, CVM, Office of Policy and Office of Regulatory Affairs are heavily involved in Codex activities.

CVM is very active in a harmonization initiative similar to the ICH for human pharmaceuticals, that is developing harmonized requirements for the registration of veterinary drugs. It is known as VICH, for Veterinary ICH. Agency employees participate on numerous committees that are drafting VICH guidelines. 


\section{International/Treaty Standards-Related Activities}

FDA takes part in a variety of international standards activities which fall under treaty organizations, and thus are not reportable under the provisions of Circular A-119. These standards activities are nonetheless important to the agency in fulfilling its public health regulatory mission. Some of these are referred to above, i.e., WHO, FAO, and OECD.

The agency participates in international trade discussions of the World Trade Organization (WTO), specifically committees on the Agreement on Technical Barriers to Trade (TBT), the Agreement on Sanitary and Phytosanitary Measures (SPS), and the same counterpart committees of the North American Free Trade Agreement (NAFTA), to ensure that FDA's requirements are preserved and its regulatory practices can remain focused on fulfilling the agency's mission to protect the public health while being supportive of emerging, broader U.S. Government obligations and policies. FDA has participated in several initiatives that are part of the Asia Pacific Economic Cooperation (APEC) forum. FDA topics have included food safety, food labeling, bulk drugs, standards for latex gloves and condoms, and medical device regulation.

\section{FDA Standards Policy and Program Management}

The FDA Standards Policy Committee (SPC) is chaired by the agency standards executive, and composed of top management representatives from all centers and offices within the agency. The SPC meets periodically to review and discuss both domestic and international standards issues, and recommend agency-wide standards policy to the Commissioner. The committee oversees the coordination of FDA standards activities and policies regarding official participation of employees in standards development endeavors both within and outside FDA; tracks, compiles and reports required information; and ensures appropriate standards review when applicable.

The agency experts on quality systems and environmental management serve as liaison members to the FDA SPC, to strengthen agency expertise and participation in issues and activities related to these areas. The agency also has a contact group of experts on private laboratory issues that holds meetings as needed to assure coordination of testing and conformity assessment issues.

It is the intent of FDA's standards policy to (1) enable the agency to participate in international standards activities that will assist it in implementing statutory provisions for safeguarding the public health; (2) increase its efforts to harmonize its regulatory requirements with those of foreign governments, including setting new standards that better serve the public health; and, (3) respond to laws and policies that encourage agencies to use voluntary standards that provide the desired degree of protection.

FDA conducts a comprehensive review of its existing regulations on an ongoing basis. As part of this review, the agency considers the appropriateness of existing regulations and policies, as specified in Circular A-119. During 1998 the agency plans to conduct training on the requirements set forth in Circular A-119, for both regulation writers and employees involved in 
standards development and management activities. The FDA standards executive also serves as the HHS standards executive. During 1998 training will be conducted for other HHS agencies that are increasingly involved in the development and use of voluntary consensus standards. 


\section{DEPARTMENT OF HOUSING AND URBAN DEVELOPMENT (HUD)}

In response to the reporting requirements of OMB Circular A-119, Paragraph 9 dated October 20, 1993, HUD reports the following information:

A. (1) There are a total of seven HUD employees participating in standards development groups. Two employees from the Manufactured Housing \& Standards Division and two employees from the Office of Lead Hazard Control are participating on ten voluntary consensus standards bodies and a NIST standards activity. Organizations with which they participate are:

a. American Architectural Materials Association

b. American Hardboard Association

c. American National Standards Institute

d. American Society for Civil Engineers

e. American Society for Testing \& Materials

f. Council of American Building Officials

g. International Approval Services

h. NSF International

i. Underwriters Laboratories

j. National Fire Protection Association

(2) No new voluntary consensus standards have been adopted which resulted from agency participation in a standards development group since October 1, 1997.

(3) The Department published a proposed rule in the FR to update the reference standards incorporated into the Federal Manufactured Home Construction and Safety Standards, 24CFR 3280 , to the latest edition on October 30,1998. The Department expects to issue the final rule during the first half of 1999 . This will cover 163 standards incorporated by reference except: 3 standards will require separate rulemaking because of significant changes in requirements, 12 new standards are being added, and 11 are being deleted.

(4) The Department selected The National Fire Protection Association to function as the secretariat for the Federal Manufactured Home Construction and Safety Standards (Standards) in 1998. This is the first step in the Department's process to have these Standards a consensus based standards consistent with OMB Circular A-119. The appropriate committees have been established with 3 HUD staff participating as voting members. The first deliberations were held in December 1998.

B. No voluntary consensus standards have been adopted during this period for the purpose of promoting environmentally sound and energy efficient materials, products, systems, services or practices. HUD is updating its reference to the CABO Model Energy Code for housing insured under the FHA mortgage insurance programs to incorporate the 1995 revisions. 
C. HUD supports the policy of OMB Circular A-119 and references more ASTM voluntary consensus standards than any other Federal agency. 


\section{DEPARTMENT OF THE INTERIOR}

Based on a survey of offices and bureaus, the Department of the Interior's response is as follows:

1) The number of voluntary consensus standards bodies in which there is agency participation is 54 , with 84 agency employees participating.

2) The number of voluntary consensus standards the agency has used since October 1, 1997, based on the procedures set forth in sections 11 and 12 of the Circular: 144

3) Identification of voluntary consensus standards that have been substituted for governmentunique standards as a result of an agency review under section $15 \mathrm{~b}(7)$ of the Circular: None (0)

4) An evaluation of the effectiveness of the guidelines Circular A-119 and recommendations for any changes: The Department of the Interior has no recommendations for any changes to the Circular at this time.

5) As required by P.L. 104-1113, identification of all instances when the agency used government-unique standards in lieu of voluntary consensus standards: None. 


\section{DEPARTMENT OF JUSTICE (DOJ)}

Based on our previous conversations, the following information is being submitted in accordance with circular A-119:

1. We have 8 individuals that participate in 3 consensus standard bodies; this is an increase of 2 additional consensus bodies, and two new participants.

2. The Department is currently in the final stages of approving its technical reference model (part of the Information Technology Architecture), which will be used in the analysis of projects selected in the future for information technology investments. The Department has not officially added any consensus standards since last year. There will be a suite of standards identified during this calendar year which reflect OMB requirement for development of an Information Technology Architecture.

3. A process is included in the draft technical reference model for identification of consensus standards that have been substituted for government-unique standards. We anticipated the attached list of standards to be used during calendar year 1999. Additionally, standards recommended by APCO 25 are under serious consideration by the Department.

4. The department uses all standards involved in complying with Public Law 102.486, Executive Orders 12759 and 12845, and Federal Regulation Interim Rule 1 and Bulletin C-35 concerning Energy-Star-qualifying computer equipment. The Government also is required to use the security standards for protection of information unless a wavier is granted. A list of security related standards are attached. Additional standards attached are standards that are currently under analyses for selection to the Technical Reference Model, which is part of the Information Technology Architecture.

Computer Security:

$\begin{array}{ll}\text { FIPS 46-2 } & \text { Data Encryption Standard } \\ \text { FIPS 102 } & \text { Certification and Accreditation } \\ \text { FIPS 112 } & \text { Password Usage } \\ \text { FIPS 140-1 } & \text { Cryptographic Modules } \\ \text { FIPS 171 } & \text { Key Management using ANSI X9.17 } \\ \text { FIPS 180-1 } & \text { Secure Hash Standard } \\ \text { FIPS 185 } & \text { Escrowed Encryption Standard } \\ \text { FIPS 186-1 } & \text { Digital Signature Standard } \\ \text { FIPS 196 } & \text { Enity Authenication Using Public Key Cryptography } \\ & \text { Secure Socket Layer (SSL) } \\ \text { ISAKMP X.509 } & \text { Certificates } \\ \text { NIST PUB 800-18 } & \text { System Security Plans (New) }\end{array}$


Computer Security Act of 1987

OMB A-130 particularly Appendix III

IPSec IETF RFC 1825

Internet Security Association \& Key Management Protocol (ISAKMP)

E-Mail:

Simple Mail Transfer Protocol (SMTP)

Multi-purpose Internet Message Extensions (MIME)

Secure MIME (S/MIME)

Hyper Text Transfer Protocol (HTTP)

Internet Message Access Protocol (IMAP4)

Store information for exchange:

Rich Text Format (RTF)

ASCII Text

Tag Image File Format (TIFF)

Joint Photographic Experts Group (JPEG)

Moving Pictures Experts Group (MPEG)

File Transfer Protocol (FTP)

Portable Document Format (PDF)

Directory Services:

X.500

ITU X.400

Directory Access Protocol (DAP)

Lightweight DAP (LDAP)

Distributed Computing Environment (DCE)

Resource naming and resolution

Domain Name Service (DNS)

Video Teleconferencing:

ITU H.320, H.323, H.324, H.310, T.120, \& IETF RFC 1112

Electronic Commerce

FIPS 161-2 ANSI X.12 Electronic Data Interchange (EDI)

Database Store \& Retrieve:

FIPS 127-2 ANSI X3.135, System Query Language (SQL)

Calendaring - iCalendar, vCalendar, Calendaring Interoperability (CIP), Calendaring

Interoperability under HTTP (CIH)

Wire Standards

Category 5, FDDI

\section{LAN}


IEEE 802.1.3 Ethernet, 802.3u 100BaseT Ethernet, 802.11 wireless

LAN \& WAN

Transmission Control Protocol (TCP)

Internet Protocol (IP) IPv4, RFCs for IP, IPv6

Dynamic Host Configuration Protocol (DCHP) IETF 1997

Internet Control Message Protocol (ICMP)

Asynchronous LAN

Point to Point Protocol (PPP)

Serial Line Internet Protocol (SLIP)

Multilink Point-to-Point Protocol (MPP)

WAN

Integrated Service Digital Network (ISDN)

Frame Relay ANSI T1.606:1990

Asynchronous Transfer Mode (ATM)

Support Network Management

Simple Network Management Protocol (SNMP) version 2

Management Information Base (MIB)

Facsimile

ITU T.4 Group 3, \& T.6 Group 4

Remote Access

Telnet InterNIC IS 0008-1983

TN3270

Wireless

Project 25

Cellular Digital Packet Data (CDPD)

Desktop

Microsoft Windows

JAVA OS

Common Object Request Broker Architecture (CORBA)

Distributed Component Object Model (DCOM)

Object Linking and Embedding (OLE)

FIPS 127-2 SQL 


\section{DEPARTMENT OF LABOR (DOL)}

Below are the responses from the only two agencies within the Department of Labor that have activities to report:

Mine Safety and Health Administration (MSHA) and Occupational Safety and Health Administration (OSHA)

1. MSHA's involvement with organizations and use of national consensus standards is the same as last year. We now have 35 individuals on 51 separate committees or subcommittees of 17 organizations. Some committees are joint ventures of two organizations. OSHA currently has representation (about 100 people) on about 50 national consensus standards committees of organizations such as ANSI (the American National Standards Institute); NFPA (the National Fire Protection Association); ASTM (the American Society for Testing and Materials); and ASME (the American Society of Mechanical Engineers).

2. MSHA participated in the development of ASTM F432-95, "Standard Specification for Roof and Rock Bolts and Accessories." We subsequently revised our standards to include this revision on April 22, 1998 (63 FR 20026). OSHA has reviewed about 25 voluntary standards as a resource in its standards development work.

3. We have not identified any voluntary standards that are suitable to be substituted for an MSHA mine-specific standard. OSHA has not substituted any voluntary consensus standards for government unique standards.

4. MSHA has no recommendations. OSHA has no comment on this question.

5. Zero. For the most part, MSHA has already used the voluntary consensus standards that are applicable to mining. Any further action would be to update the revision referenced. There were no instances where OSHA used government-unique standards in lieu of voluntary consensus standards.

It should be noted that Section 6 of the OSHA Act requires "Whenever a rule promulgated by the Secretary differs substantially from an existing national consensus standard, the Secretary shall, at the same time, publish in the Federal Register a statement of the reasons why the rule as adopted will better effectuate the purposes of this Act than the national consensus standards." It is for this reason that OSHA is so involved in consensus standards making committees. 


\section{DEPARTMENT OF STATE}

The Department of State has a major interest in standards from a policy perspective, but less direct involvement in the actual development of technical standards, with the important exception as outlined in the following paragraphs discussion the Department's policy role as obligated by international treaty. The Bureau of Economic and Business Affairs (EB) represents the Department of State on the Interagency Committee on Standards Policy (ICSP) and the Government Member Council and the Information Infrastructure Standardization Panel (IISP) and its steering committee of the American National Standards Institute.

Acting as the United States Administration under the treaty obligations found in the Convention of the International Telecommunication Union (ITU), Minneapolis, 1998, the Department of State, through its Communications and Information Policy Deputate of the Bureau of Economic and Business Affairs, provides the forum where the United States telecommunications industry, both public and private sectors, develops positions and contributions for presentation at meetings of the three permanent organs of the ITU, responsible for international telecommunications recommendations (voluntary standards). The Department authorizes and/or hosts open public meetings under the Federal Advisory Act, wherein U.S. telecommunications standard-setting positions are established. The Department coordinates, leads, and/or accredits United States delegations to meetings of the International Telecommunication Union's Telecommunications Standardization Sector (ITU-T), the Radio Communications Sector (ITU-R), the Development Sector (ITU-D), and the Inter-American Telecommunication Commission (CITEL), an organ of the OAS.

More than eighty-five (85) U.S. corporations are paying and participating members of the ITU-T and the ITU-R, more than 30 are associate members of the CITEL's permanent consultative committee, under the sponsorship of the State Department. Those entities, along with all interested governmental agencies, including but not limited to the Department of Defense, National Institute of Standards and Technology (NIST), National Telecommunications and Information Administration (NTIA), National Aeronautics and Space Administration (NASA), Federal Communications Commission (FCC), participate and play major roles in the voluntary standard-setting process. Within that process, a great deal of interaction takes place with other organizations involved in telecommunications standard-setting, such as, but not limited to the International Organization for Standardization (ISO), the American National Standards Institute (ANSI), Committee T1 (the ANSI accredited committee for U.S. domestic telecommunications standards). CITEL's committees extend this interaction to a number of Latin American and Caribbean regional organizations as well.

Study Groups and Working parties of these sectors convene international standardization meetings on a frequent basis to develop international voluntary telecommunications standards. In addition to accrediting and supporting delegations to the ITU and its Standardization Sectors, as well as CITEL, the State Department's Bureau of International Organization Affairs, although 
it has no direct interaction with voluntary standards bodies, serves as policy overseer and contributors to overall standardization policy within the Economic Commission for Europe (ECE) by ensuring participation by relevant specialized agencies and private sector groups in the deliberations of the ECE's Working Party on Standardization, especially where they have a direct bearing on U.S. commercial interests.

For example, each year the Bureau of International Organization Affairs accredits and funds representatives from the Department of Agriculture, the Department of Commerce, the Department of Transportation, and the National Institute of Standards and Technology and also accredits their industrial representatives to key ECE meetings on standardization policies. These gatherings seek to harmonize standards and/or make recommendations on standardization policies in such areas as trade, transport, agricultural products, motor vehicles, timber and coal to improve industrial efficiency and quality as well as to facilitate international trade in these areas. While the standards developed in the ECE are not officially adopted for use in the United States, they serve as guides for adjusting product design and are widely taken into account in manufacturing plans. 


\section{DEPARTMENT OF TRANSPORTATION}

In response to the request by the Office of Management and Budget (OMB) for information regarding the Department of Transportation's (DOT) implementation of OMB Circular A-119, "Federal Participation in the Development and Use of Voluntary Standards," we respectfully submit this report. The included data represent the 1998 fiscal year activities for the department and its agencies.

1)

The number of voluntary consensus standards bodies in which there is agency participation, as well as the number of agency employees participating:

Six DOT agencies have reported varying degrees of participation in standards-setting organizations and related activities.

- The total reported number of DOT employees participating in at least one-standardsdeveloping group is approximately two hundred and ninety-two (292) although there are three operating administrations who have yet to report their activities (BTS, FHWA, and FRA).

- The total number of voluntary standards groups in which DOT employees participate is one hundred and six (106).

\section{Bureau of Transportation Statistics (BTS)}

This year, BTS did not provide a response, although based on last year's response, BTS does participate in voluntary standards organizations

\section{Federal Aviation Administration (FAA)}

Approximately one hundred and eleven (111) employees of FAA participate in at least one standards-developing group. These employees participate in approximately eight (8) standards-developing groups.

\section{Federal Highway Administration (FHWA)}

This year, FHWA did not provide a response, although, based on last year's response, FHWA does participate in voluntary standards organizations.

\section{Federal Railroad Administration (FRA)}

This year, FRA did not provide a response, although, based on last year's response, FRA does participate in voluntary standards organizations. 


\section{Federal Transit Administration (FTA)}

Five (5) employees of FTA participate in at least one standards-developing group.

Maritime Administration (MARAD)

Six (6) employees of MARAD participate in at least one standards-developing group.

National Highway Traffic Safety Administration (NHTSA)

Twenty-nine (29) employees of NHTSA participate in at least one standards-developing group.

\section{Office of the Secretary (OST)}

No employees participate in standards-developing groups.

Research and Special Programs Administration (RSPA)

Forty (40) employees of RSPA participate in at least one standards-developing group.

\section{St. Lawrence Seaway Development Corporation (SLSDC)}

No employees participate in standards-developing groups.

\section{United States Coast Guard (USCG)}

One hundred and one (101) employees of USCG participate in at least one standardsdeveloping group. These employees participate in forty-two (42) standards-developing groups.

2) The number of voluntary consensus standards the agency has used since October 1, 1997 based on the procedures set forth in sections 11 and 12 of the Circular.

- The total reported number of voluntary consensus standards used by DOT since October 1 , 1997 based on the procedures set forth in sections 11 and 12 of the Circular is one hundred and ninety-seven (197).

\section{Federal Aviation Administration (FAA)}

Since October 1, 1997, FAA has used approximately 30 voluntary standards based on the procedures set forth in sections 11 and 12 of the Circular. 


\section{National Highway Traffic Safety Administration (NHTSA)}

Since October 1, 1997, NHTSA has proposed to adopt one voluntary consensus standard based on the procedures set forth in sections 11 and 12 of the Circular.

$\underline{\text { Research and Special Programs Administration (RSPA) }}$

Since October 1, 1997, RSPA has used approximately 160 voluntary standards based on the procedures set forth in sections 11 and 12 of the Circular.

\section{$\underline{\text { United States Coast Guard (USCG) }}$}

Since October 1, 1997, USCG has used approximately 6 voluntary standards based on the procedures set forth in section 11 of the Circular. Regarding section 12 of the Circular, the Coast Guard's Office of Procurement Management (G-CPM) reports that there is currently no database which can provide information on how Coast Guard procurement offices identify, manage, review and use voluntary consensus standards in procurement. Plans are being developed to gather this information for FY 99 and beyond.

3) The identification of voluntary consensus standards that have been substituted for government-unique standards as a result of an agency review under section $15 b(7)$ of the Circular:

\section{Federal Aviation Administration}

Aerospace Material Specification AMS 2647B, Fluorescent Penetrant Inspection, Aircraft and Engine Component Maintenance.

AIA-NAS-410, Aerospace Industries Association, National Aerospace Standard, NAS Certification and Qualification of Nondestructive Test Personnel.

ATA Specification 105, Air Transport Association, Guidelines for Training and Qualifying Personnel in Nondestructive Testing Methods.

HBAW98-01, Air Carrier Strobe Light Maintenance Program, resulted from collaboration with NIST Physics Laboratory and SAE ARP 5029 Task Group.

MIL-STD-410E, Military Standard, Nondestructive Testing Personnel Qualification and Certification.

In addition, the FAA is considering adopting a portion of the voluntary standards put out by NFPA, ASTM and Illuminating Engineering Society (CIE).

\section{National Highway Traffic Safety Administration}

Heavy Truck Conspicuity Treatments (63 FR 8143, February 18, 1998) -- NHTSA substituted compliance with an SAE Recommended Practice for a government-unique standard. 


\section{$\underline{\text { Research and Special Programs Administration }}$}

During fiscal years 1997 and 1998, RSPA's Office of Hazardous Materials Safety (OHMS) did not adopt any rules that substituted voluntary consensus standards for government-unique standards. However, RSPA has issued a Notice of Proposed Rulemaking under Docket HM-220 to adopt approximately 10 new standards that will substitute for the existing government-unique regulations for the manufacture, testing and retesting of cylinders used in compressed gas service. In addition, in Docket HM-215C, OHMS has proposed to update the references to approximately 10 voluntary consensus standards that are incorporated in the Hazardous Materials Regulations. During fiscal year 1998, RSPA's Office of Pipeline Safety (OPS) did not adopt any rules that substituted voluntary consensus standards for government-unique standards. However, OPS is currently reviewing rulemakings to adopt more than 12 new standards that will substitute for the existing government-unique regulations for aboveground oil storage tanks, corrosion protection procedures and facilities, and computational pipeline monitoring systems. These rulemakings will be completed in early 1999 .

4) An evaluation of the effectiveness of Circular A-119 policy and recommendations for any changes:

While all of the individual operating administrations within the Department of Transportation have not performed an evaluation of the effectiveness of Circular A-119, the general consensus is that Circular A-119 is working effectively. DOT recognizes the importance and the advantages of using voluntary consensus technical standards since the use of voluntary standards can save both time and money for regulatory agencies. The Department also recognizes the value in participating in standards-developing organizations. For example, NHTSA's participation in standards-developing organizations has helped the agency to be on the cutting edge of motor vehicle-related technological innovations and the development of regulatory solutions to vehicle safety problems.

5) As required by P.L. 104-113, identification of all instances when the agency used government-unique standards in lieu of voluntary consensus standards (for each instance include agency rationale for such use, as well as the specific government standard used:

During fiscal year 1998, there was one such instance. NHTSA issued a notice of proposed rulemaking (NPRM) that did not propose in all instances to use the requirements of a voluntary standard instead of government-unique requirements. (63 FR 17976; April 13, 1998) NHTSA explained in the NPRM that the American National Standard Institute (ANSI) has a standard ${ }^{4}$ for product safety signs and labels (ANSI Z535.4) that identifies a hierarchy of hazard levels ranging from extremely serious to moderately serious and specifies corresponding hierarchies of signal words, i.e., "danger," "warning," and "caution," and of colors. For the

\footnotetext{
${ }^{4}$ This standard was not considered by the focus groups in their deliberations.
} 
header, the ANSI standard specifies a red background with white text for "danger," an orange background with black text for "warning," and a yellow background with black text for "caution."

\begin{tabular}{|c|c|c|}
\hline \multicolumn{3}{|c|}{$\begin{array}{l}\text { ANSI Requirements for Color Coded Header Messages for the Different Levels of } \\
\text { Hazard } \\
\text { (Listed in declining level of hazard) }\end{array}$} \\
\hline $\begin{array}{l}\text { Imminently hazardous situation which will } \\
\text { result in death or serious injury if not avoided }\end{array}$ & "Danger" & $\begin{array}{l}\text { Red background with } \\
\text { white text }\end{array}$ \\
\hline $\begin{array}{l}\text { Potentially hazardous situation which could } \\
\text { result in death or serious injury. }\end{array}$ & "Warning" & $\begin{array}{l}\text { Orange background } \\
\text { with black text }\end{array}$ \\
\hline $\begin{array}{l}\text { Potentially hazardous situation which could } \\
\text { result in minor or moderate injury. }\end{array}$ & "Caution" & $\begin{array}{l}\text { Yellow background } \\
\text { with black text }\end{array}$ \\
\hline
\end{tabular}

The ANSI standard specifies that pictograms should be black on white, with occasional uses of color for emphasis, and that message text should be black on white.

The agency noted in the NPRM that when it earlier updated the requirements for air bag warning labels to require the addition of color and pictograms, it had chosen not to adopt the colors specified in the ANSI standard. NHTSA chose to use yellow instead of orange in the background of the heading for the air bag warning label, even though the word "warning" was used, because of overwhelming focus group preference for yellow. Only two of the 53 participants preferred orange. Participants generally stated that yellow was more eye-catching than orange. Participants also noted that red (stop) and yellow (caution) had meaning to them, but not orange.

NHTSA asked for comment on three color options for the revised utility vehicle rollover warning label. Proposed label 1 used the ANSI color format with the heading background in orange with the words in black. The remainder of the label had a white background with black text and drawings. Proposed label 2 used a color scheme like the air bag warning labels, which is the same as the ANSI color format except that the background color for the heading in the label is yellow. Proposed label 3 employed the color scheme used in the focus groups - the heading area had a red background with white text. The graphic areas had a yellow background with black and white drawings. The text area had a black background with yellow text.

Despite focus group preference for the signal word "danger," the agency proposed the use of the word "warning" as more appropriate to the level of risk. The agency also noted that the word "warning" is used in the air bag warning label. 
Recognizing that it might encounter additional conflicts between focus group preferences and the ANSI standard in future rulemakings, NHTSA requested comments in the NPRM on the extent to which any final choice regarding colors and signal words should be guided by the focus group preferences instead of the ANSI standard. NHTSA also requested comments on the broader issue of the circumstances in which it would be appropriate for agency rulemaking decisions to be guided by focus group results or other information when such information is contrary to a voluntary consensus standard such as the ANSI standard.

At this time (February 22, 1999), a final decision is still pending regarding its proposal to upgrade the rollover warning label. As to the general questions it posed in the NPRM, NHTSA recognizes that ANSI's mission differs somewhat from that of the agency's focus groups with respect to the labeling of hazardous situations. ANSI's mission is to develop and maintain a standard for communicating information about a comprehensive hierarchy of hazards, while the focus groups' mission is to design an effective label for a specific hazard. The agency recognizes further that, given the difference in their missions, their conclusions about the appropriate manner of communication might differ on occasion.

Since agency labeling decisions are highly dependent on the facts regarding the specific hazard being addressed, NHTSA anticipates making case-by-case determinations of the extent to which it should follow voluntary standards versus information from focus groups and other sources. NHTSA will rely on its own expertise and judgement in making determinations under the NTTAA and the statutory provisions regarding vehicle safety standards. 


\section{DEPARTMENT OF TREASURY (TREASURY)}

The Department of the Treasury reports the following:

1) The number of voluntary consensus standards bodies in which there is agency participation, as well as the number of agency employees participating;

The Department participated in eight voluntary consensus standards bodies that accounted for approximately twenty-one employees participating.

2) The number of voluntary consensus standards the agency has used since October 1, 1997 based on the procedures set forth in Sections 11 and 12 of the Circular;

The Department has used three voluntary consensus standards. In addition, an unknown number of voluntary consensus standards are used as a result of implementing commercialoff-the-shelf hardware and software.

3) Identification of voluntary consensus standards that have been substituted for governmentunique standards as a result of an agency review under section $15 \mathrm{~b}(7)$ of the Circular;

No voluntary consensus standards have been substituted for government-unique standard as a result of our Department-wide review of existing standards.

4) An evaluation of the effectiveness of A-119 policy and recommendations for any changes; and

We believe that the guidelines prescribed in Circular A-119 are effective. Circular A-119 has placed the focus on using voluntary consensus standards as opposed to the development of government-unique standards. Wide use of voluntary consensus standards promotes the development of an increased number of standards compliant products facilitating the use of new technology and increasing flexibility to meet new requirements.

5) As required by P.L. 104-113, identification of all instances when the agency used government-unique standards in lieu of voluntary consensus standards (for each instance include agency rational for such use, as well as the specific government-unique standards used.)

Customs continues to support two government-unique standards which are Customs And Trade Automated Interface Requirements (CATAIR) (Amendment 1, April 1996, Amendment 2, December 1996, Amendment 3, September 1997, and Amendment 4, 1998) and Customs Automated Manifest Interface Requirements (CAMIR) (Amendment 1, April 
1997 and Amendment 2, July 1998). CATAIR is used by the Customs brokerage industry and CAMIR is used by some parties in the transportation sector. The maintenance of the government-unique standards within Customs applications (the CATAIR and CAMIR formats), are at the request of the participating industry groups that use those standards. 


\section{DEPARTMENT OF VETERANS AFFAIRS (VA)}

The following information was requested from the Department of Commerce for inclusion in the 1998 Annual Report to the Office of Management and Budget (OMB):

1. The number of voluntary consensus standards bodies in which there is agency participation, as well as the number of agency employees participating.

We have 4 employees participating in three voluntary consensus standards bodies.

2. The number of voluntary consensus standards the agency has used since October 1,1997 based on the procedures set forth in sections 11 and 12 of the Circular.

40 from ANSI/RESNA and 10 from SAE (Security of Automotive Engineers)

3. Identification of voluntary consensus standards that have been substituted for governmentunique standards as a result of an agency review under section $15 \mathrm{~b}(7)$ of the Circular.

None.

4. An evaluation of the effectiveness of Circular A-119 policy and recommendations for any changes.

The Circular has had no unexpected side effects to our present Department goal. We accept and conform to the standards developed by the Joint Commission on Accreditation of Hospitals Organization (JCAHO) for the VA health care system in order to obtain JCAHO certification of VA health care facilities. Standards as outlined in the accreditation program for hospitals, psychiatric facilities mental health centers, long-term and hospice programs, ambulatory health care facilities, community and nursing homes under VA contract, state home facilities, hospital based care programs, and various JCAHO accreditation standards (National Fire Protection Association, Life Safety Code requirements, and other building, plumbing, electrical, mechanical, and equipment standards/requirements) continue to be utilized in the regulatory, contractual, and grant determinations executed by the Veterans Health Administration. Standards are benchmarked with both private and public sectors to assure industry compliance, costeffectiveness, and quality control. These national standards have been adopted by industry and are familiar to those in the building profession.

5. As required by P. L. 104-113, identification of all instances when the agency used government-unique standards in lieu of voluntary consensus standards (for each instance include agency rationale for such use, as well as the specific government-unique standard used.)

None. 


\section{Appendix B:}

\section{Independent Agency Reports}

B-1 


\section{CONSUMER PRODUCT SAFETY COMMISSION (CPSC)}

The Consumer Product Safety Act (CPSA), as amended, requires the Commission to defer to issued voluntary standards, rather than promulgate mandatory standards, when the voluntary standards would eliminate or adequately reduce the risk of injury addressed and it is likely that there will be substantial compliance with the voluntary standards. In addition, the Commission is required, after any notice or advance notice of proposed rulemaking, to provide technical and administrative assistance to persons or groups who propose to develop or modify an appropriate voluntary standard. Additionally, the Commission is encouraged to provide technical and administrative assistance to groups developing product safety standards and test methods, taking into account Commission resources and priorities.

Since its inception in 1973, the Commission has promoted the development of voluntary product safety standards. Policy statements in support of voluntary standards were published by the CPSC in 1975 and 1978. These policy statements were updated in 1988 (16 U.S.C. 1031), and a staff directive on implementation of portions of these policy statements was promulgated in October 1989.

Since the principles set forth in the OMB Circular A-119 were published, they have been consistently supported by the Commission. The CPSC Voluntary Standards Coordinator also serves as CPSC's Standards Executive for the purpose of implementing OMB Circular A-119 and provides general oversight for staff involvement in existing standards projects including the development of strategies for increasing the level of involvement by the CPSC staff in voluntary standards activities. The Voluntary Standards Coordinator provides reports on voluntary standards activities as well as provides similar information for the Commission's Annual Report.

The Commission had 21 employees directly participating in 50 voluntary standards development projects during FY 1998. Since October 1, 1997, the Commission incorporated by reference portions of 10 voluntary standards in CPSC regulations. During FY 1998, there were no voluntary consensus standards that were substituted for government-unique standards as a result of an agency review of existing standards.

During FY 1998, the Commission's efforts to enhance voluntary standards development was complemented by the overall Federal policy set forth in the Circular. CPSC involvement in voluntary standards activities was consistent with Circular A-119 Revised. There are no recommendations for changes in the Circular at this time.

As part of the implementation of the provisions of the Circular, Mr. Colin B. Church was appointed the agency Standards Executive. The executive establishes agency views on standards issues and decisions through Commission response to staff briefing packages and 
recommendations. These views are reflected in the Commission's Operating Plan and Budget. Coordinating participation within the Commission and with others in voluntary standards activities is a responsibility of the Voluntary Standards Coordinator. Likewise the Voluntary Standards Coordinator is responsible for meeting reporting requirements applicable to voluntary standards involvement of Commission staff. 


\section{ENVIRONMENTAL PROTECTION AGENCY (EPA)}

The U.S. Environmental Protection Agency is pleased to submit to the National Institute for Standards and Technology (NIST), for submission to the Office of Management and Budget (OMB) and Congress, the following report on EPA's fiscal year 1998 implementation of the National Technology Transfer and Advancement Act (NTTAA), Sec 12 (d) and the OMB Circular A-119 on Federal Participation in the Development and Use of Voluntary Consensus Standards and in Conformity Assessment Activities.

\section{HIGHLIGHTS}

The following highlight EPA's 1997-98 accomplishments associated with the implementation of the NTTAA and Circular A-119.

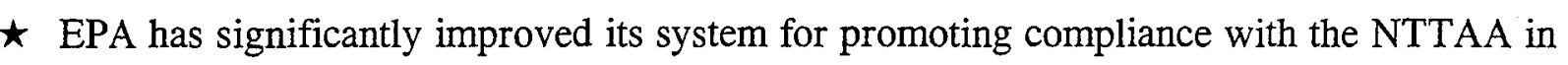
rulemaking:

1) EPA regulators now routinely consider the use of voluntary consensus standards in proposed and final Agency regulations. Nearly one hundred Federal Register documents published in fiscal year 1998 contained preamble sections addressing the NTTAA. In these sections, the rule writers summarized the requirements of the NTTAA, explained how they searched for potentially applicable voluntary consensus standards, and described their tentative or final decisions about the use of such standards in the regulation. EPA's Office of Policy, working with the Standards Executive and the Office of General Counsel has developed a comprehensive "EPA Rule Writer's Guide to the NTTAA" explaining the procedures needed to systematically assess the application of NTTAA to a proposed and final rules. When finalized, the Guide will be available on EPA's internal electronic network and will be periodically updated. In the meantime, the draft document is in regular use.

2) EPA rule writers are regularly using model language concerning the NTTAA and the use of voluntary consensus standards in both proposed and final regulations. This greatly facilitates the electronic tracking of the use, or consideration of the use, of voluntary standards in EPA regulations. This, in turn, promotes the management of EPA standards program and improves the quality and ease of preparing this annual report. More detail on the extent to which standards have been considered and used is provided below.

$\star$ The EPA Standards Program has increased visibility and stature within the Agency.

In August, EPA Administrator Carol Browner appointed Dr. Mary C. McKiel, of the Office of Prevention, Pesticides and Toxic Substances (OPPTS), to be the new EPA Standards Executive. More recently, the Assistant Administrator for OPPTS elevated the Standards Program within OPPTS to enhance the importance of voluntary standards to EPA policies and 
programs and to facilitate Agency-wide implement of the requirements of The NTTAA and the Circular. The Standards Executive represents the Agency on the Interagency Committee on Standards Policy Standards Policy and works cooperatively with the Office of the General Counsel, all applicable EPA program and policy offices, and intra-agency groups with standards-related interests.

EPA revised the Agency ethics guidance on participation in voluntary standards organizations.

The new EPA guidance, issued in September 1998, finally reconciled the competing interests of the criminal code provisions concerning financial conflicts of interest with the NTTAA directive that Federal employees participate in standard-setting activities of voluntary standards organizations. Relying on recent memoranda from the Office of Legal Counsel of the Department of Justice and the Office of Government Ethics, the new guidance provides a clear pathway for EPA employee membership in standards development organizations, including serving on boards of directors and as committee chairs. A copy of the guidance is attached.

\section{REQUIRED REPORTING ELEMENTS UNDER OMB CIRCULAR A-119}

1. The number of voluntary consensus standards bodies in which there is Agency participation and the number of employees participating.

A. Approximately 200 EPA employees participate in the following 14 standards organizations:

- The American National Standards Institute (ANSI)

- The American Gas Association (AGA)

- The American Petroleum Institute (API)

- The American Society of Quality Control (ASQ)

- The American Society for Mechanical Engineers (ASME)

- ASTM, (formerly known as the American Society of Testing and Materials)

- The National Fire Protection Association (NFPA)

- NSF International

- The Society of Automotive Engineers (SAE)

- The Technical Association of the Pulp and Paper Industry (TAPPI)

- Underwriters Laboratories, Inc. (UL)

- The International Organization for Standardization (ISO)

- The International Electrotechnical Commission (IEC)

- NACE International (formerly National Association of Corrosion Engineers)

B. In addition to participation, several of the above number of employees serve as officers on Boards and Committees. These include but are not limited to: 
- Board of Directors, American National Standards Institute

- Technical Advisory Board, Society of Automotive Engineers

- Chairman's Advisory Council, Underwriters Laboratories, Inc.

- ANSI Accredited Standards Committee Z-1 on Quality and Environmental Management

- U.S. Technical Advisory Group to ISO Technical Committee 176 on Quality Management

- U.S. Technical Advisory Group to ISO Technical Committee 207 on Environmental Management

2. The number of voluntary consensus standards the Agency has used since October 1, 1997.

This response addresses EPA's use of voluntary standards in regulations, not procurement activities. In 1998, EPA published 6 final regulations incorporating (by reference) more than 90 voluntary consensus standards. Some of these standards were newly included in EPA regulations. In other cases, EPA decided to continue the use of the same voluntary consensus standards. EPA cites the same test methods (for example, the fuels test methods of ASTM) in multiple rules -- some of which are new and others increase stringency of existing rules. EPA may also cite updated versions of a standard currently in use.

In addition, EPA published 10 proposed regulations, or documents requesting comments on prior proposals, that would incorporate voluntary consensus standards. These included reference to 67 voluntary consensus standards.

3. Identification of voluntary consensus standards that have been substituted for government-unique standards as a result of an Agency review of existing standards.

A. EPA identified no instances for this year where the preamble (following the model language) stated that a voluntary standard was being substituted for a pre-existing governmentunique standard.

However, an excellent example of an Agency review process this past year was done by the Emission Measurement Center (EMC) within EPA's Office of Air Quality Planning and Standards (OAQPS). EMC undertook and completed a study to search the National Standards System Network (NSSN) and to identify and compare potentially applicable voluntary consensus standards in that data base to (A) all existing EMC emission methods, (B) technical standards in EPA's official list of Hazardous Air Pollutants, and (C) technical standards in new, forthcoming MACT -- Maximum Achievable Control Technology -- Standards. The work currently is being reviewed to determine next appropriate steps. Results of the analysis and any subsequent actions will be reported in the Agency's 1999 report.

B. In the area of quality management, the voluntary American National Standard ANSI/ASQC E4-1994 ("Specifications and Guidelines for Quality Systems for Environmental Data Collection and Environmental Technology Programs") has been adopted, by means of EPA Order 5360.1 CHG1, as the technical basis for the Agency-wide mandatory quality 
system. Furthermore, by means of revision to FAR Part 46, (48 CFR Part 46) the Federal Acquisition Regulation now acknowledge E-4 as a "high level standard". Previously, the regulations in 40 CFR Part 30 governing financial assistance to non-profit organizations were revised to include conformance to E4 as the quality requirements. Currently, EPA is completing action on a new Term and Condition for financial assistance to State and local governments (under 40 CFR Part 31) to establish the same requirement. When these actions are completed, the quality requirements for all extramural agreements will be the same as for internal Agency programs.

\section{Evaluation of the effectiveness of Circular A-119 policy and recommendations for any changes}

EPA enthusiastically endorsed the publication of the final, revised Circular in February. While EPA notes a few minor issues in A-119, the Agency finds that the policies and procedures set out work well. EPA does not recommend any changes at this time.

5. Agency use of government-unique standards in lieu of voluntary consensus standards.

In FY 1998, EPA identified 3 final regulations where the use of an identified voluntary consensus standard was rejected in favor of a government-unique standard. It should be noted, however, that each of these regulations also contained other technical standards where voluntary consensus standards were used. EPA rationale for each instance follows:

- 63 FR 48806 (9/11/98), National Volatile Organic Compound Emission Standards for Automobile Refinish Coatings: EPA considered the use of ASTM D-3960 as a possible substitute for EPA Method 24 which already relies on several ASTM methods. However, ASTM D-3960 contains some requirements above and beyond those needed for EPA regulatory purposes. As stated in the FR notice: "Because this other method [ASTM 3960] does not specify which units to use, it may result in inconsistent applications of the procedure and could make the standard more difficult to enforce. Consequently, the EPA determined that this other voluntary consensus method would be impractical to adopt. In addition, the EPA believes that it is appropriate to use Method 24 both because it has proven reliable and practical to achieve the goals of reducing VOC and because the EPA wishes to foster uniformity in testing nationwide." For this Rule, then, EPA specified EPA Method 24 which refers to ASTM Methods 2369, 1460, and 3970 (as does Method D-3960) while avoiding possible confusion caused by the presence of additional, unnecessary requirements.

- 63 FR 48848 (9/11/98), National Volatile Organic Compound Emission Standards for Architectural Coatings: EPA deemed ASTM-3960, modeled on EPA Method 24, iteself referring to other ASTM methods, to be impractical for use in lieu of EPA Method 24 (see \#1 above); 
- 63 FR 18504 (4/15/98), National Emission Standards for Hazardous Air Pollutants for Source Category: Pulp and Paper Productions: EPA decided to use EPA Method 1650. This Method was developed by drawing on various procedures contained in the methods of voluntary consensus standards bodies and other standards developers, such as ISO, DIN, SCAN, and Standard Methods (SM 5320). However, none of these more narrowly focused voluntary consensus standards contained the standardized quality control and quality control compliance criteria that EPA requires for data verification and validation in its water programs. Therefore, EPA found none of these VCS standing alone to meet EPA's needs.

- There was also one proposed regulation where EPA proposed to reject the use of a particular voluntary consensus standard in favor of a government-unique standard:

- 63 FR 41134 (7/31/98), National Primary Drinking Water Regulations: Analytical Methods for Certain Pesticides and Microbial Contaminations: Standard Methods 6640B for acid herbicides was tentatively deemed impractical for EPA's needs because its sample preparation and quality control procedures were not similar enough to EPA Method 515.1 to ensure that there would not be underreporting of acid herbicide contamination. EPA plans to offer to work with the Standard Methods committee to resolve this issue prior to the next publication.

\section{EPA STANDARDS-RELATED ACTIVITIES}

EPA standards-related activities go well beyond what is required by the NTTAA and the Circular. Innovative programs, driven by Administration objectives for better public communication, more efficient and effective protection and a focus on pollution prevention, are using a variety of tools. Among those tools is an increased reliance on voluntary consensus standards and conformity assessment mechanisms.

By no means an exhaustive list, these examples do represent accomplishments since the last EPA report, and illustrate the variety of voluntary standards applications at the Agency.

\section{Work on New Standards}

Productive communication between EPA and standards developers has spurred the development of voluntary standards, some of which may be incorporated into EPA guidance standards. For example, EPA representatives in the Underground Storage Tank program successfully worked with ASTM to develop multiple standards. One (ASTM G 158 "Standard Guide for Three Methods of Assessing Buried Steel Tanks") generally satisfies one of two options in an EPA guidance and is expected to supplant the other option: actual third-party evaluation according to a particular EPA protocol or its equivalent. Another (ASTM E 1990

"Standard Guide for Performing Evaluations of Underground Storage Tank Systems for 
Operational Conformance with 40 CFR Part 280 Regulations") allows general compliance status to be easily determined.

In another instance, cooperation among ASTM, manufacturers of opacity monitors and the Emission Measurement Center (EMC) within the EPA's Office of Air Quality Planning and Standards resulted in a new voluntary standard for quality assurance / quality control applicable to the monitors. EMC is reviewing the standard for inclusion in a revised EPA Performance standard (PS-1). This is expected to provide major benefits to all concerned. Until now, the EPA method, extensively used, has lacked a standard, agreed-upon quality assurance for manufacturers of the monitors. Inclusion of the ASTM method may go a long way toward addressing the problem which has vexed regulator and regulated alike.

\section{International Standards}

In the area of international voluntary standards, EPA continues to have very active roles in the development and revision of standards within the International Organization for Standardization's (ISO) Technical Committees \# 176 for Quality Management Systems, and \# 207 for Environmental Management Systems. These international standards play an increasingly important role in U.S. business, manufacturing and trade as well as environmental performance and measurement. In 1997, the international community stepped up efforts to make the quality and environmental standards compatible. A major focus of these efforts is to make it easier for organizations to obtain certification to both without going through entirely separate processes. EPA employees are working to help advance this goal while maintaining the integrity, and benefits, of the environmental management system.

\section{The Use of Standards in EPA Procurement}

EPA will evaluate the proposed amendments to the FAR designed to address NTTAA implementation issues. The proposed rule was published December 10 (63 FR 68344). In 1998 at least one RFP solicited information about voluntary consensus standards that might be usable in lieu of a government-unique standard proposed for use to evaluate software. No suggestions were made.

\section{Standards in EPA Voluntary Programs}

Several programs and initiatives within EPA, while not specifically required to report under the OMB Circular, use voluntary consensus standards in substantive ways to meet program or project goals. Two examples are given below.

1. Usage of the ISO 14001 EMS Specification by the EPA Region I StarTrack Program. The StarTrack Program is a voluntary compliance and environmental management systems third-party certification program in EPA Region I. Participants agree to implement an EMS modeled on the ISO 14001 EMS specification. An independent third-party certifies 
that the StarTrack participant has an acceptable compliance program and an effective overall EMS, or an implementation plan to fully implement an ISO 14001-based EMS. Current program policy is to accept ISO 14001 conformity assessments performed by ANSI-RAB* accredited registrars as meeting the StarTrack program requirements for EMS implementation and independent third-party certification of the EMS. The StarTrack Program is currently evaluating the extent to which ISO 14001 conformity assessments performed by ANSI-RAB accredited registrars meet the compliance certification requirements of the program. At this time, 5 of the 15 organizations participating in the StarTrack Program are registered as conforming to ISO 14001.

*(American National Standards Institute and the Registrar Accreditation Board cooperative run the U.S. National Accreditation Program for ISO 14001)

2. Environmentally Preferable Products Program. In 1998, EPA and the Office of the Federal Environmental Executive issued policy on how Federal agencies can use Non-Governmental Entities to help achieve the Administration's mandate of purchasing environmentally preferable goods and services. Non-Governmental Entities (NGE's)/ Third Parties are defined as including but not limited to, standard setting organizations, third party certification programs, environmental labeling or environmental report card programs, and other environmental consulting organizations.

The purpose of the pilot project approach is to demonstrate how Executive Agencies can use NGEs to support Federal environmentally preferable purchasing efforts. EPA believes there are several advantages to this approach.

First, it increases the variety of product categories which are studied. Second, through the pilot project approach EPA may determine where the use of outside expertise is appropriate and helpful. Third, the most effective and practical ways to achieve the goal of environmentally preferable purchasing will be identified. Finally, this approach may encourage increased competition among existing and new organizations/programs that can support the procurement of environmentally preferable products.

\section{ISSUES \& PLANS FOR ENHANCEMENTS}

1. Strategic Standardization Program. Under the Standards Program, EPA is improving internal coordination on voluntary standards use, and on establishing mechanisms for effective resource allocation to meet standards needs. The aim of Agency standards program is to increase efficiency and effectiveness. More work is needed to ensure that EPA has the right people on the right committees to meet the needs of the Agency. This may mean that some Agency personnel, serving on standards committees in their own capacity as technical experts, would be reassigned committee work based on the needs of the Agency and in some cases, committee work will be dropped entirely. 
2. Improved Tracking. In some cases, EPA employees are members of more than one committee or standards organization. Analysis of the number of involved employees gives only part of the picture. A format for more accurate tracking of the total involvement is currently underway. The Office of Standards Services at NIST and the standards office at the Department of Energy have provided some model formats which EPA will use in developing a more accurate tracking system.

3. Participation Guide and Training Programs. EPA employees represent an impressive variety and depth of expertise in technical matters important to environmental protection. A Guide document is under development to assist EPA technical experts in making the most of participation on voluntary standards committees. Again, existing documents from NIST and other Federal agencies is being used in the development of the EPA guide. In addition, formal training programs for EPA personnel are also under development in cooperation with standards development organizations.

cc: The Administrator

The Deputy Administrator

Lynn Goldman, M.D.

Susan Wayland, OPPTS

Scott Fulton, OGC

James Nelson, OGC 


\section{FEDERAL COMMUNICATIONS COMMISSION (FCC)}

This is in reply to your letter of December 8,1998, requesting a report on the Federal Communications Commission's interaction with voluntary consensus standards bodies, as required by proposed revision of OMB Circular A-119. In keeping with your suggested outline, the Commission's report is as follows:

1. The Federal Communications Commission participates in a variety of organizations that develop telecommunications standards. The actual level of participation with each organization varies depending on the need for Commission involvement and importance of the work relative to our objectives. The Commission presently has approximately 49 employees involved in more than 24 standards bodies and approximately 100 sub-groups within these bodies. The Commission uses voluntary standards in several different ways:

To satisfy industry and user requirements where it appears that mandatory standards are unnecessary. Examples include telephone industry standards for network protocols and interfaces, International Special Committee on Radio Interference (CISPR) standards to control radio emissions from automobiles, Telecommunications Industry Association (TIA) standards for digital cellular radio protocols, and TIA/TI standards for protocols in the personal communications service.

To correct problems that might otherwise require regulation. For example, the Commission has strongly encouraged compliance with Electronics Industry Association (EIA) standards on television susceptibility to interference rather than moving swiftly to mandatory regulations. It has worked with the industry and local governments to develop voluntary measurement standards for testing the signal quality of cable systems, and is working with TIA to encourage development and voluntary implementation of a standard for telephone immunity to interference.

As the basis for mandatory requirements, either by incorporating voluntary standards by reference, or including the normative portion of the standard in the FCC rules. Examples include ANSI measurement procedures for radio noise emitted by digital devices, ANSI/EIA standards on AM broadcast transmission specifications, EIA standards for telephone compatibility with hearing aids, International Telecommunications Union (ITU-R) recommendations on digital selective calling equipment for use in ship and coast marine stations, EIA task-force recommendations on standards for displaying closed-captioning information on television receivers, and an EIA/TIA standard for protection of microwave systems from interference from personal comminations systems. 
The Commission continues to increase its use of voluntary standards. In many instances we have chosen not to implement regulations (or more detailed regulations) because adequate voluntary industry standards already exist or are under development. For example, the regulations for Personal Communications Service do not include transmission protocol standards because industry has voluntarily developed these standards. In other instances, where the adoption of a standard is or may be in the public interest, we have attempted to use voluntary standards whenever possible. For example, we are allowing the industry to establish a "spectrum etiquette" policy for devices operating at millimeter wavelengths and are working with and looking to industry to develop standards for the transmission of digital radio. In addition, the Commission regularly works closely with industry though the negotiated rulemaking process to resolve technical compatibility issues.

2. The Commission has not used or adopted any voluntary consensus standards since October 1, 1997.

3. No voluntary consensus standards have replaced government-unique standards as result of agency review of existing standards since October 1, 1997.

4. The Commission recognizes the benefits of using voluntary consensus standards when applicable and endeavors to comply with the guidance provided in OMB Circular A-119 and the mandates of P.L. 104-113. The Commission's current Standards Executive is:

Dale N. Hatfield

Chief, Office of Engineering and Technology

Federal Communications Commission

1919 M Street, N.W., MS 1300

Washington, DC 20554

Telephone: (202) 418-2470

The Standards Executive will carry out his responsibilities by:

a. Providing guidance to each of the agency's Commissioners on standardsrelated issues;

b. monitoring the standards-setting activities of the agency's bureau and offices, and providing guidance to each one on how its activities relate to the requirements of OMB Circular A-119.;

c. producing the reports required by OMB Circular A-119;

d. developing a five-year standards review cycle to be followed by each of the Commission's bureaus and offices that will ensure compliance with OMB Circular A-119. 
The Commission's Office of Engineering and Technology, which is under the leadership of the Commission's Standards Executive, monitors, participates, and coordinates Commission efforts with respect to on ongoing national and international developments in the standards area. Specifically, the Office of Engineering and Technology's Standards Development Branch is tasked, in part, with coordinating standards activities within the FCC and with participating in and monitoring the work of standards committees. The Commission endeavors to increase its interaction with the private sector in the area of standards development to promote a greater use of voluntary standards where appropriate.

5. The Commission has not used or adopted any government-unique standards in lieu of voluntary consensus standards since October 1, 1997. 


\section{FEDERAL EMERGENCY MANAGEMENT ASSOCIATION (FEMA)}

The number of voluntary consensus standards bodies in which there is agency participation, as well as the number of agency employees participating;

During the reporting period, FEMA has not collected that information on an agency basis.

The number of voluntary consensus standards the agency has used since October 1, 1997 based on the procedures set forth in sections 11 and 12 of the Circular;

On November 2, 1998, FEMA issued initial Information Technology Architecture, which discusses in detail the agency=s approach to standards. FEMA is committed to an enterprise IT architecture based on open system standards for interoperability, portability, and scalability. Until now, FEMA has had an implied IT architecture as a de facto agency-wide standard. The common practice has been to declare a commercial tool as the agency standard. Therefore, the adoption of open systems standards over company or industry standards is among the highest priorities for FEMA. However, unless open system standards are also industry consensus standards, vendor support will fall short of architectural objectives.

In many instances, FEMA is using consensus standards when possible.

For example:

Digital Line Graph Level 3 (DLG3) as the standard data model for the distribution and storage of digital flood insurance rate map (DFIRM) products;

Hypertext Markup Language (HTML) as the standard for FEMA=s web site; discussion is underway to replace HTML with Extensible Markup Language (XML);

Multi-purpose Internet Mail Extension (MIME) is used to encode e-mail attachments. FEMA uses standard protocols to run the e-mail operations

Portable Document Format (PDF) is used to retrieve and post formatted documents between differing computing environments.

Identification of voluntary standards that have been substituted for government-unique standards as a result of an agency review under section $15 \mathrm{~b}(7)$ of the Circular;

Voluntary standards are preferred; but because FEMA is a small agency, no formal review has been imposed on the program directors. 
An evaluation of the effectiveness of Circular A-119 policy and recommendations for an changes; and cost-savings and operational efficiency are the driving factors in FEMA adopting consensus standards. Ease of interoperability, portability, scalability force a small agency like FEMA to seek out these products. As important for adoption are the availability of training, documentation, and regular upgrades at modest cost to the agency.

As required by P.L. 104-113, identification of all instances when the agency used governmentunique standards in lieu of voluntary consensus standards (for each instance include the agency rationale for such use, as well as the specific government-unique standard used.)

Interview conducted with program managers for the IT architecture found no use government standards in lieu of voluntary consensus standards. 


\section{GENERAL SERVICES ADMINISTRATION (GSA)}

GSA has 45 employees participating in 91 voluntary consensus standards bodies. The decrease from last year's report is due to a reorganization that involved the reassignment of technical personnel to other functional areas, and to our continuing emphasis on the procurement of commercial off-the-shelf products and services.

The GSA Public Buildings Service has adopted the Building Owners and Managers Association International (BOMA) standard method of measuring floor area in office buildings.

As a result of the review of existing standards, the following voluntary standards have been substituted for government-unique standards.

Voluntary Standard
ASTM D 456
NFPA STD. NO. 1961
NFPA STD. NO. 1964
2281

ANSI/ASME B94.9

ASME B107.14M

ASTM F1085**

ASME B56.11.12**

ASTM C547, C553,

C592 and C612**

ASTM E11 and E323**
Government Standard*

O-S-598

A-A-2160

A-A-2279, A-A-2280 and A-A-

A-A-624, A-A-1267, GGG-T-60

and GGG-T-70

GGG-W-686

$\mathrm{V}-\mathrm{M}-96$

FF-H-106/GEN

HH-I-558

RR-S-366

*Includes Federal specifications, standards and commercial item descriptions.

**These were substituted during FY 1997, but overlooked in last year's report.

We have no comments or recommendations for changes concerning OMB Circular A-119.

No government-unique standards are being used in lieu of existing voluntary standards. 


\section{NATIONAL AERONAUTICS AND SPACE ADMINISTRATION (NASA)}

NASA policy for technical standards is documented in NASA Policy Directive (NPD) 8070.6, which was revised in 1998 to reflect the new requirements of Public Law 104-113 and Office of Management and Budget (OMB) Circular A-119. NPD 8070.6 specifically cites the preference for use of Voluntary Consensus Standards (VCS), encourages participation in VCS development to meet NASA needs, establishes responsibilities for standards management in NASA, and references OMB Circular A-119 for detailed requirements.

The NASA Chief Engineer is the NASA Standards Executive. Policy level issues are coordinated through the Engineering Management Council (EMC), an Agencywide group of senior management officials from the NASA Engineering and the Safety and Mission Assurance Functions. The Chief Engineer has total responsibility for administration of the NASA Technical Standards Program, with some discipline oversight responsibilities delegated to other functional offices.

Implementation and management responsibility for the NASA Technical standards program has been assigned to the Marshall Space Flight Center which chairs an Agencywide Engineering Standards Steering Council responsible for procedures and the coordination of internal document development and adoption of VCS.

NASA's use of standards is entirely for procurement purposes, so the Agency has chosen a "categorical" or standards management system approach for reporting in response to OMB Circular A-119. The NASA Technical Standards Management System is still under development, but currently contains listings of preferred technical standards, lists of NASA participants in VCS activities, and extensive links to other sources of technical standards. The "home page" for the NASA Technical Standards Management System can be found on the Internet at http://standards.msfc.nasa.gov.

I. The number of voluntary consensus standards bodies in which there is Agency participation. as well as the number of Agency employees participating.

In fiscal year 1998, NASA had 148 employees participating in 43 voluntary consensus standards (VCS) developing bodies, both domestic and international. This is approximately 10 percent less than reported in 1997, largely due to corrections deleting the names of employees who were members of professional societies but not directly involved in the development of standards. The total turnover of participants in the past year was approximately 30 percent. 
II. The number of voluntary consensus standards the Agency has used since October 1, 1997, based on the procedures set forth in sections 11 and 12 of the Circular.

In 1998, NASA began an intensive effort to identify VCS currently being used on NASA programs and to review them as candidates for formal adoption. Since October 1, 1997, NASA has adopted 414 voluntary consensus standards products based on current use by one or more NASA installations. Approximately 85 percent of the VCS adopted are in the area of materials and processes specifications. Also included are 10 data communications standards that were converted in 1998 from international inter-governmental standards to ISO standards. The adoptions were based on staff recommendations, concurrence of the NASA Engineering Standards Steering Council, and formal approval by the NASA EMC and the NASA Standards Executive. An additional 400 voluntary consensus standards are now in the final stages of the review process as candidates for formal adoption by NASA. The process will be completed in FY 1999.

III. Identification of voluntary consensus standards that have been substituted for governmentunique standards as a result of an Agency review under section 15b(7) of the Circular.

NASA participates in the Department of Defense (DoD) Single Process Initiative (SPI) to eliminate the use of redundant and conflicting Government specifications at contractor facilities for meeting common requirements. In 1998, as a result of SPI proposals, the NASA Lewis Research Center has accepted replacement of four Government (MIL-) standards with VCS. In 1998, NASA began an extensive of review of Government standards currently in use, including both installation-unique technical standards, and standards of other Government agencies, such as the Department of Defense. The objective of this review is to identify all Government standards used across the Agency for inclusion in the NASA Technical Standards Management System. The next phase is to identify which government-unique technical standards in the system can be eliminated or replaced with VCS. Completion of this review is a major objective for the Technical NASA Standards Program during 1999.

\section{An evaluation of the effectiveness of Circular A-119 policy and recommendations for any changes.}

OMB Circular A-119 continues to provide stimulus for NASA's effort to improve the standards management system, enhance the use of voluntary consensus standards products, and challenge the need for NASA-unique technical standards requirements. It is an integral part of the NASA Technical Standards Program.

For example, as part of an internal system review in 1998, the Jet Propulsion Laboratory eliminated 1700 Center specific standards either because of obsolescence or replacement with VCS. 
Promoting the participation of NASA employees in voluntary consensus developing bodies received major emphasis in the NASA Technical Standards Awareness Initiative begun in 1998.

V. As required by P.L.104-113, identification of all instances when the Agency used government-unique standards in lieu of voluntary consensus standards (for each instance include Agency rationale for such use, as well as the specific government-unique standard used).

Because NASA uses the "categorical" method of reporting, "use" of government-unique standards is reported in terms of additions to the NASA Technical Standards Management System as opposed to tracking individual procurement transactions. During 1998 NASA has developed ten NASA-unique technical standards in three categories, namely: information technology, engineering, and safety and mission assurance. The new standards are listed in a table at the end of this report.

The two NASA Information Technology (IT) standards developed in 1998 (Items 1 and 2 below) are for internal use only, and specify internal procedures or preferred use of COTS (Commercial off the Shelf) products; they do not duplicate voluntary consensus standards. NASA Engineering standards are developed either to consolidate internal practices, or to provide guidance where no suitable national or international standards are available. Item 3 below documented a unique set of requirements developed from failure experience on planetary spacecraft; Item 4 updates an existing standard which is now in the process of being converted into an ISO standard. NASA is participating with industry, plus domestic and international voluntary consensus standard bodies, to target those standards with external application for eventual transition to voluntary consensus standards.

In the Safety and Mission Assurance area, Items 5 and 6 are manuals establishing safety requirements for NASA internal facilities and launch vehicle operations. Items 7-9 are interim re-issues of existing NASA standards based on failure experience in NASA unique space systems and in one case, (Item 10) an area for which a fully adequate VCS has not been available. The Safety and Mission Assurance function has initiated an effort to identify possible VCS sponsors for these last four workmanship standards in FY 1999.

\section{STANDARDS PUBLISHED IN 1998 (October 1997 - October 1998)}

1. NASA-STD-2807A

2. NASA-STD-2808A

3. NASA-HDBK-4001

4. NASA-STD-6001
The NASA Directory Service - Architecture, Standards, and Products (Previously Released as "NASA X.500 Directory" Interoperability Profile for NASA E-Mail Clients Electrical Grounding Architecture for Unmanned Spacecraft Flammability, Odor, Offgassing, and Compatibility Requirements and Test Procedures for Materials in Environments that Support Combustion (Formerly Published as NHB 8060.1C) 
5. NASA-STD-8719.7 Facility System Safety Guidebook

6. NASA-STD-8719.8 Expendable Launch Vehicle Payload Safety Review Process Standard

7. NASA-STD-8739.3 Soldered Electrical Connections. (Previous Version Published as NHB 5300.4(3A-2

8. NASA-STD-8739.4 Crimping, Interconnecting Cables, Harnesses, and Wiring (Previous Version Published as NAS 5300.4(3G-1)

9. NASA-STD-8739.7 Electrostatic Discharge Control (Excluding Electrically Initiated Explosive Devices

10. NASA-STD-8739.5 Fiber Optic Terminations, Cable Assemblies, and Installation 


\section{NATIONAL ARCHIVES AND RECORDS ADMINISTRATION (NARA)}

The National Archives and Records Administration (NARA) continues to be active in the area of voluntary standards. Unfortunately, due to limited resources, attrition, and other priorities, the number of NARA staff involved in standards activities during this period has declined.

1. The number of voluntary consensus standards bodies in which there is agency participation, as well as the number of agency employees participating.

A total of eight NARA employees are active on a variety of voluntary consensus standards organizations, committees, and subcommittees either as official NARA representatives or alternates. These eight individuals serve on approximately fourteen voluntary standards bodies at the organization, committee, or subcommittee level. In addition, NARA is also a voting member of the National Information Standards Organization (NISO). During this past year, NARA staff members participated in the review of drafts for various International Organization for Standardization (ISO) standards. NARA also was asked by NISO to represent them in the development of an ISO records management standard. By working on a common set of methods, processes, and materials, we can help foster standards that further NARA's central mission of ensuring ready access to essential evidence.

2. The number of voluntary consensus standards the agency has used since October 1, 1997, based on the procedures set forth in sections 11 and 12 of the Circular.

Although NARA has incorporated by reference in our regulations twenty-five voluntary standards outlined in 36 CFR Chapter 12, staff this past year worked on revisions to four standards that are reflected in our regulations.

3. Identification of voluntary consensus standards that have been substituted for governmentunique standards as a result of an agency review under section 15b(7) of the Circular.

No government-unique standards were replaced with voluntary consensus standards during the fiscal year. Any government-unique standards currently used by NARA reflect performance standards currently unavailable as voluntary standards.

4. An evaluation of the effectiveness of Circular A-119 policy and recommendations for any changes.

The question and answer format used in the development of this circular is very helpful in understanding the complexities of voluntary consensus standards. NARA has no recommendation for changes. 
5. As required by P.L. 104-113, identification of all instances when the agency used governmentunique standards in lieu of voluntary consensus standards (for each instance include agency rational for such use, as well as the specific government-unique standards used.)

During this past reporting period, NARA signed an agreement with the Department of Defense (DOD) to develop design criteria for electronic records management software applications. On December 19 of this year, NARA endorsed DOD's standard 5015.2. While this is a mandatory DOD standard, it is possible that it may one day become a government-wide mandate. There are currently no voluntary standards that address this issue.

Adoption of standards will continue to be important to the work of the National Archives and Records Administration. As much as possible, the agency will continue to provide time and travel support for staff members who contribute to the work of standards organizations. 


\section{NUCLEAR REGULATORY COMMISSION (NRC)}

The NRC Strategic Plan for fiscal year 1997 - fiscal year 2002 establishes a framework that will guide future decision-making and will help the NRC continue to meet its responsibility for protecting public health and safety, promoting the common defense and security, and protecting the environment. The plan includes general goals consistent with the NRC's mission in specific strategic arenas that include nuclear reactor safety and nuclear materials safety. In these arenas, one strategy is to increase the involvement of licensees and others in the NRC regulatory process. Consistent with the provisions of Public Law 104-113, "National Technology Transfer and Advancement Act of 1995," enacted March 7, 1996, NRC will encourage industry to develop codes, standards, and guides that can be endorsed by the NRC and carried out by the industry. Agency-wide procedures are being developed to further promote the efficiency and effectiveness of the NRC process for implementing Public Law 104-113 and the supporting procedures in OMB Circular A-119, "Federal Participation in the Development and Use of Voluntary Standards and in Conformity Activities," issued February 19, 1998.

During the period for this annual report, the NRC staff conducted two stakeholder meetings to identify issues and develop options for improving its participation in the development and use of consensus standards. The first meeting, held in July 1998, was with NRC staff (internal stakeholders) from various NRC offices to discuss issues and options related primarily to NRC participation on standards committees. Discussions focused on identifying options for improving the effectiveness and efficiency of NRC staff participation in developing consensus standards. The second meeting, held in Chicago in September 1998, was with external stakeholders to discuss their concerns regarding NRC staff participation in the development and use of consensus standards. This meeting included representatives from individual utilities (reactor licensees), the Nuclear Energy Institute (NEI), standards developing organizations (SDOs) such as the American Society of Mechanical Engineers (ASME), nuclear steam supply system (NSSS) vendors, the Department of Energy, State governments, and the public. A transcript of this meeting was made available at the NRC web site shortly after the meeting. Information gained from this meeting, and other sources, will be used to formulate a program to improve $\mathrm{NRC}$ participation in the development and use of consensus standards.

The following is the NRC response to the reporting provisions of OMB Circular A-119.

1. The number of voluntary standards bodies in which there is agency participation, as well as the number of agency employees participating

There are $145 \mathrm{NRC}$ staff members who participate on 16 standards developing organizations (SDOs). NRC staff participate on a total of 254 standards writing, consensus, and board level committees. 
2. The number of voluntary consensus standards the agency has used since October 1, 1997. based on the procedures set forth in Sections 11 and 12 of the Circular

None. Procedures are in place to ensure that proposed and final rulemakings request information on the use of government-unique standards in accordance with the Circular. The NRC endorsed 27 standards in regulatory guides, which provide one method acceptable to the NRC staff for meeting NRC regulations, and 28 standards in NUREG reports, which contain consolidated guidance for material licensees. These standards and the means of endorsement are identified in the table below.

3. Identification of voluntary consensus standards that have been substituted for government-unique standards as a result of an agency review under section $15 \mathrm{~b}(7)$ of the $\underline{\text { Circular }}$

No voluntary consensus standards were substituted for government-unique standards.

4. An evaluation of the effectiveness of Circular A-119 policy and recommendations for any changes

The NRC believes that OMB Circular A-119 has been effective in providing a basis for uniform implementation of P.L. 104-113 by Federal agencies, and that coordination by the Interagency Committee on Standards Policy has been equally effective. We do recommend, however, that additional guidance be provided regarding whether a report need be provided to OMB if an agency places limitations or modifications on a voluntary consensus standard that it uses in a regulation. Depending on the guidelines, this could appreciably increase the number of instances in which a report would be required to be submitted to OMB.

5. As required by P.L. 104-113, identification of all instances when the agency used government-unique standards in lieu of voluntary consensus standards (for each instance include agency rationale for such use, as well as the specific government-unique standard used)

No government-unique standards were used by NRC in lieu of voluntary consensus standards. 


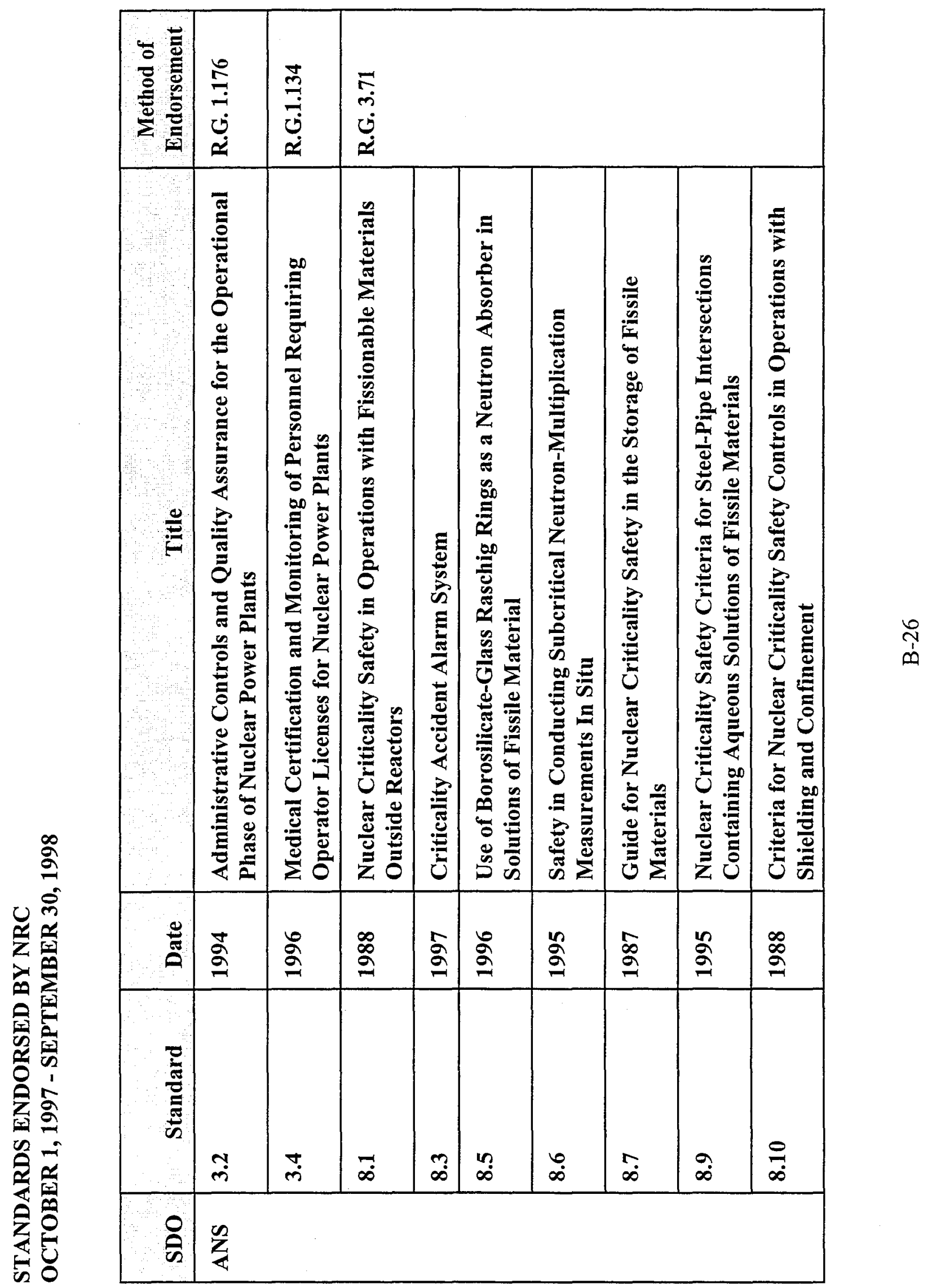




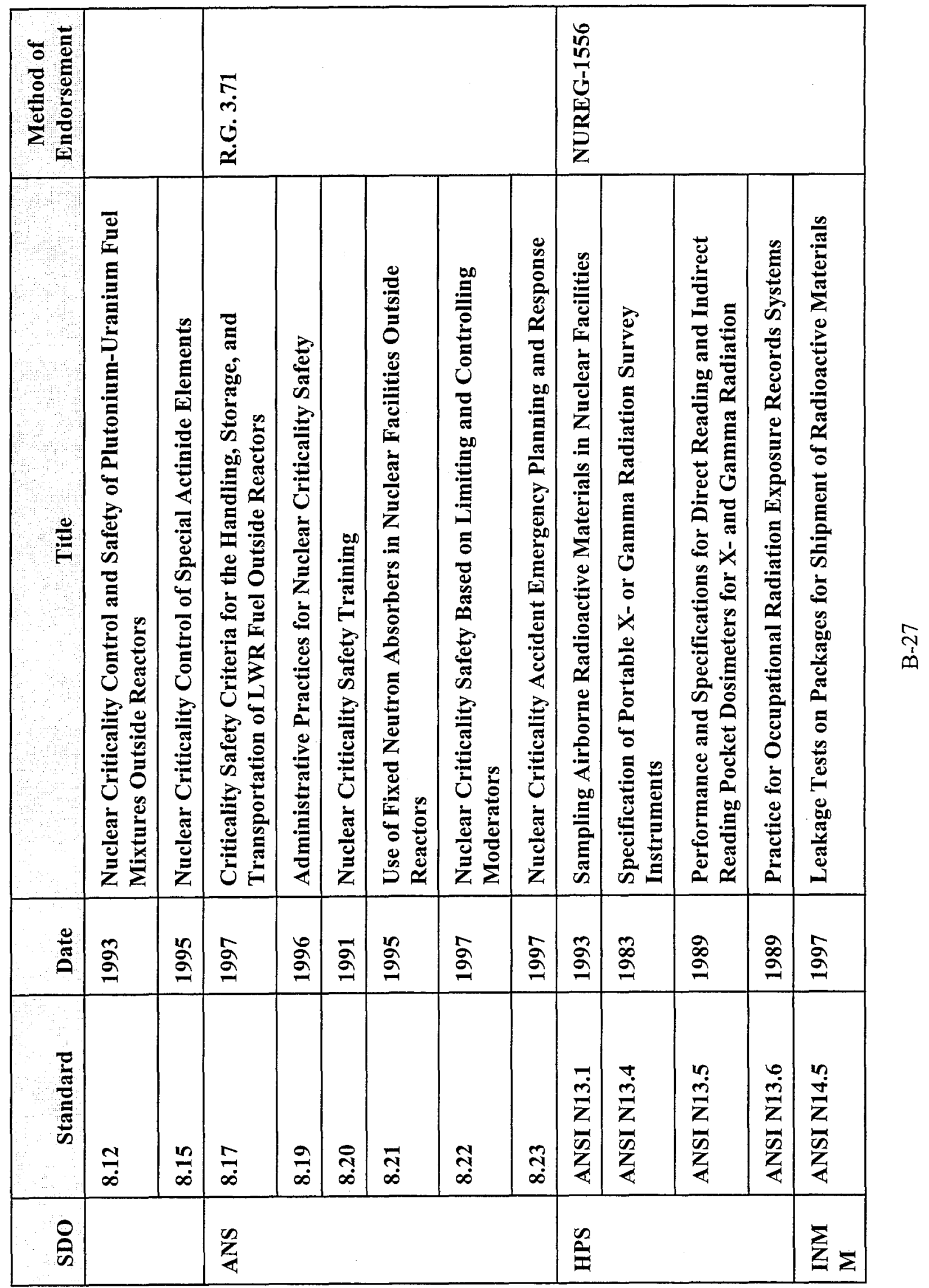




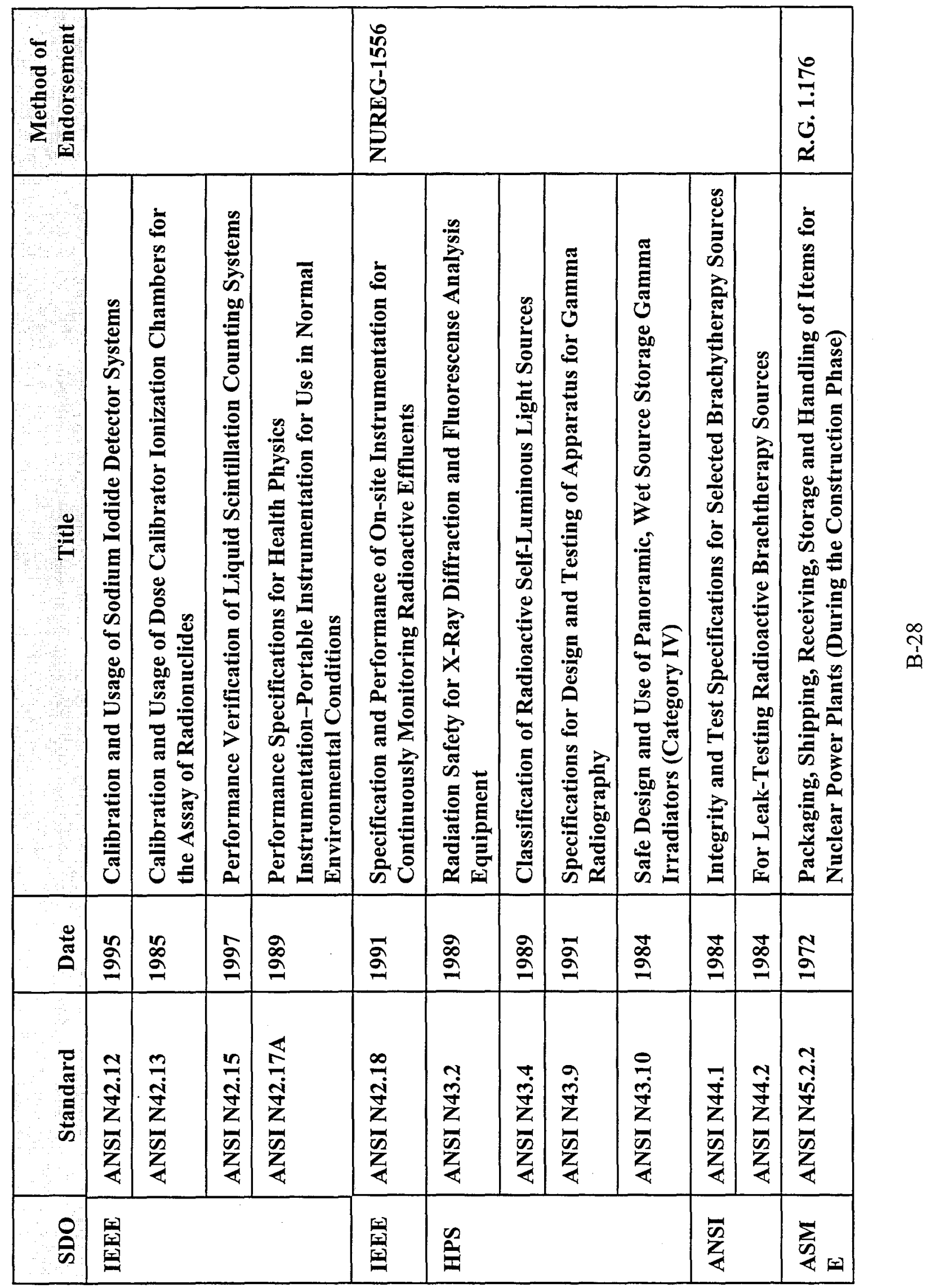




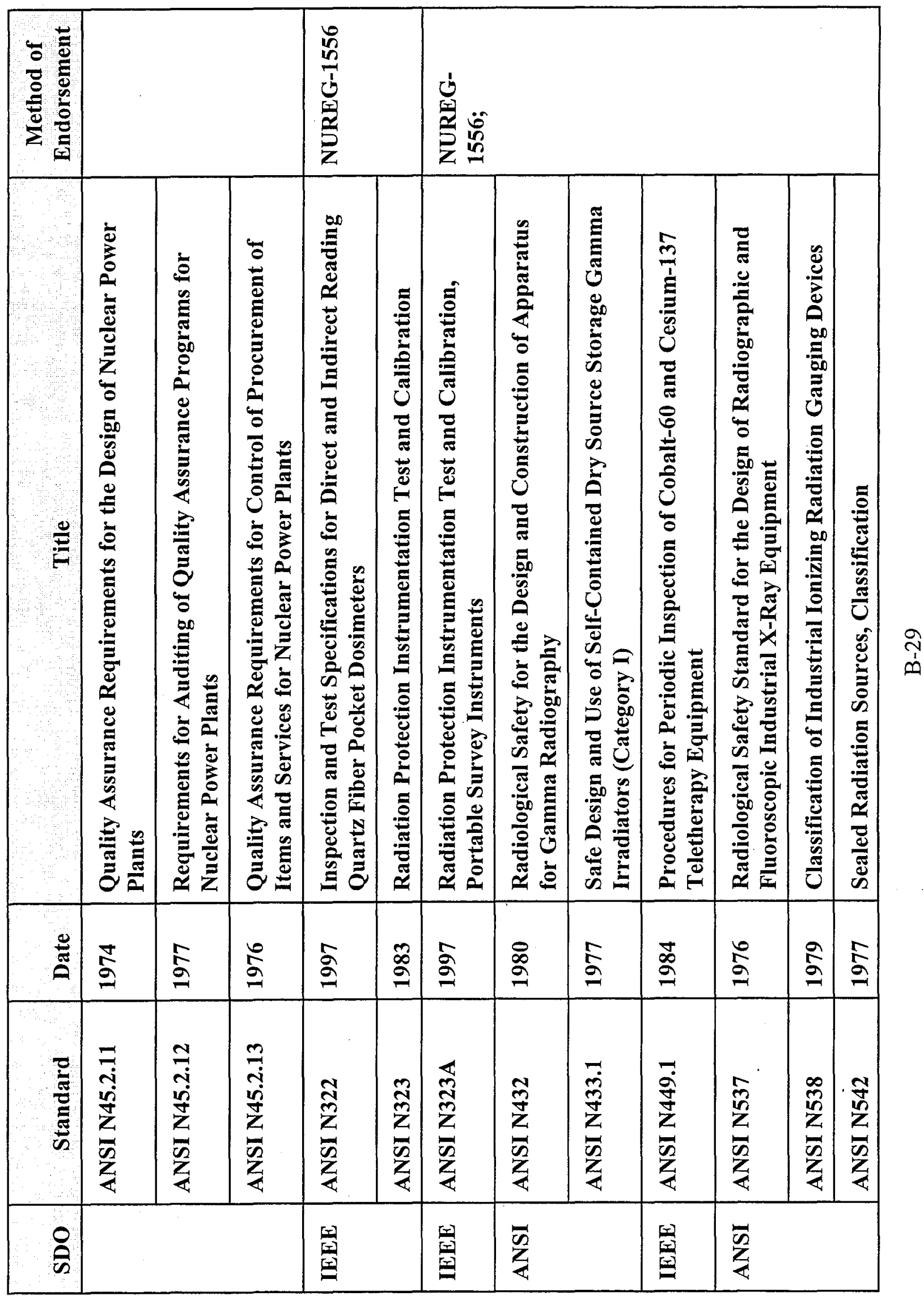




\begin{tabular}{|c|c|c|c|c|c|c|c|c|c|}
\hline 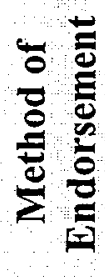 & 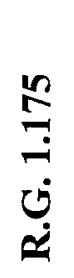 & & 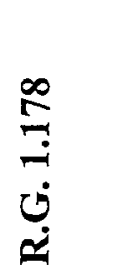 & & & $\begin{array}{l}\vec{\nabla} \\
\dot{0} \\
\dot{0} \\
\dot{x} \\
\end{array}$ & 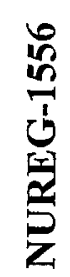 & & \\
\hline$\stackrel{\mathscr{E}}{\equiv}$ & 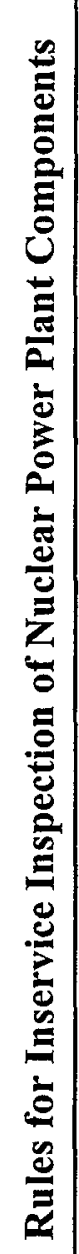 & 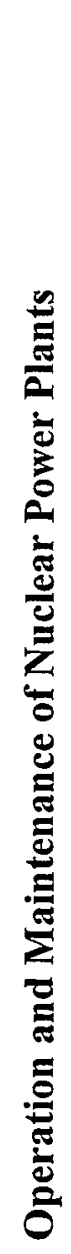 & 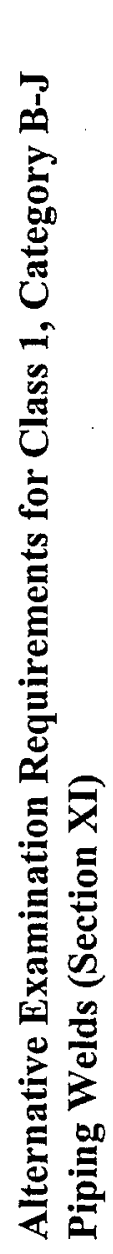 & 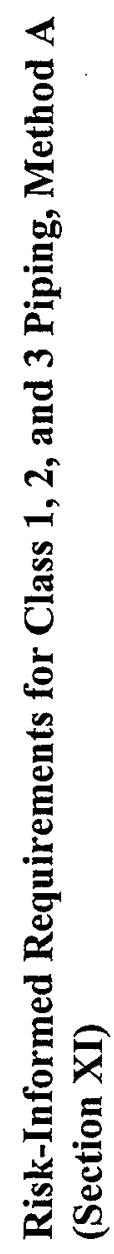 & 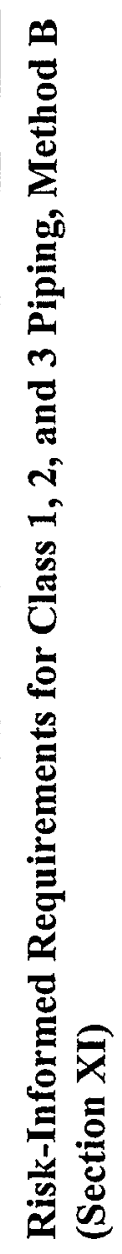 & 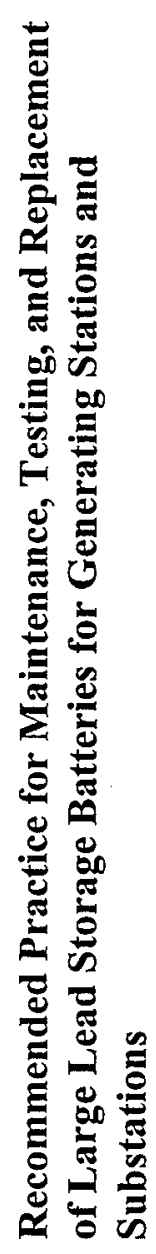 & 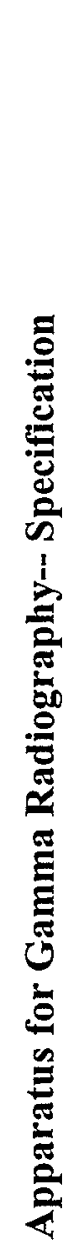 & 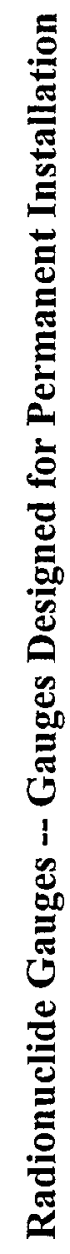 & 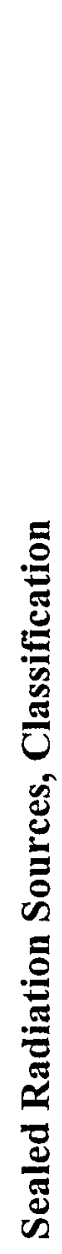 \\
\hline 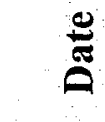 & $\begin{array}{l}\stackrel{\otimes}{\partial} \\
\stackrel{2}{2}\end{array}$ & $\stackrel{2}{\sigma}$ & ڤ & $\hat{\sigma}$ & $\hat{\sigma}$ & $\begin{array}{l}\hat{\infty} \\
\stackrel{0}{O}\end{array}$ & 点 & $\stackrel{\circ}{\stackrel{\circ}{\varrho}}$ & $\stackrel{\circ}{\stackrel{\circ}{\varrho}}$ \\
\hline एँ & 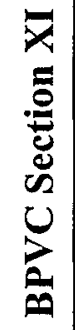 & $\begin{array}{l}\frac{0}{0} \\
\dot{0} \\
\vdots\end{array}$ & 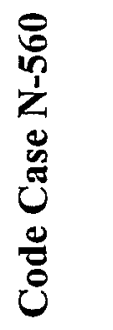 & 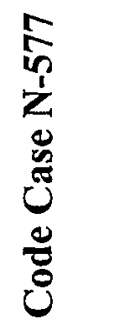 & 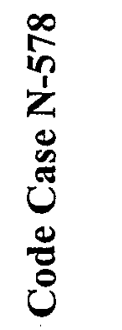 & फิ & बे & $\stackrel{n}{\stackrel{2}{*}}$ & $\sqrt{\mathrm{A}}$ \\
\hline के & \multicolumn{5}{|l|}{$\sum_{\sum}^{K}$} & 鳬 & \multicolumn{3}{|l|}{$\underline{\mathscr{2}}$} \\
\hline
\end{tabular}

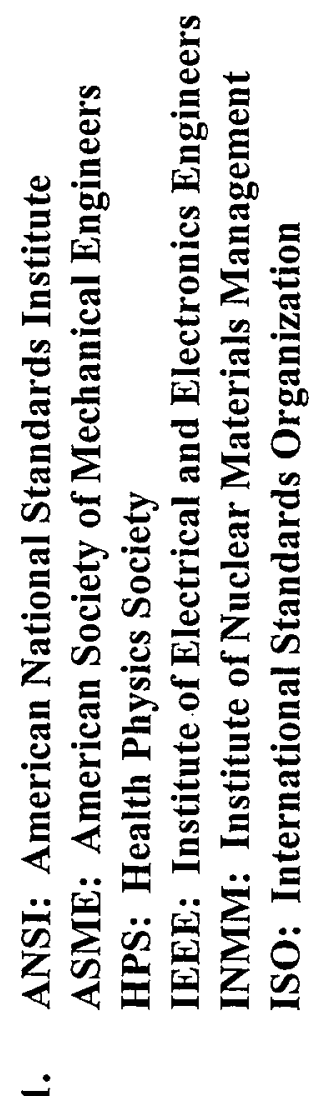

ஜ̊ 
2. $\quad$ R.G. 1.134: Regulatory Guide 1.134 (Revision 3) -- Medical Evaluation of Licensed Personnel at Nuclear Power Plants (March 1998)

R.G. 1.175: Regulatory Guide 1.175 -- An Approach for Plant-Specific, RiskInformed Decision-Making: Inservice Testing (August 1998)

R.G. 1.176: Regulatory Guide 1.176 -- An Approach for Plant-Specific, RiskInformed Decision-Making: Graded Quality Assurance (August 1998)

R.G. 1.178: Regulatory Guide 1.178 -- An Approach for Plant-Specific, RiskInformed Decision-Making: Inservice Inspection of Piping (September 1998)

R.G. 3.71: Regulatory Guide 3.71 -- Nuclear Criticality Safety Standards for Fuels and Materials Facilities (August 1998)

R.G. 5.44: Regulatory Guide 5.44 (Revision 3) -- Perimeter Intrusion Alarm Systems (October 1997)

NUREG-1556: Consolidated Guidance About Materials Licenses (Program specific guidance in nine volumes) 


\section{NATIONAL SCIENCE FOUNDATION (NSF)}

1) there are three voluntary consensus standards bodies in which there is agency participation, with four employees participating;

2) the number of voluntary consensus standards the agency has used since October 1, 1997 is zero;

3) the number of voluntary consensus standards that have been substituted for governmentunique standards is zero;

4) an evaluation of the effectiveness of the guidelines in Section 7 of the proposed revision of the Circular and recommendations for any changes;

The proposed guidelines allow appropriate agency participation in standards activities. No changes are recommended.

5) the National Science Foundation has not used any government-unique standards in lieu of voluntary consensus standards during this reporting period. 


\section{Appendix C:}

\section{Charter of the Interagency Committee on Standards Policy}




\section{DEPARTMENT OF COMMERCE}

\section{CHARTER \\ OF THE \\ INTERAGENCY COMMITTEE ON STANDARDS POLICY}

\section{Establishment}

1. The Interagency Committee on Standards Policy (herein after referred to as the Committee) is established to advise the Secretary of Commerce and the heads of other Federal agencies in matters relating to standards policy.

2. The Committee fulfills the mandates set out in paragraph 8.a.2 of the Office of Management and Budget (OMB) Circular No. A-119, "Federal Participation in the Development and Use of Voluntary Standards," in its revision of October 20, 1993.

3. The Committee reports to the Secretary of Commerce through the Director of the National Institute of Standards and Technology.

\section{Purpose}

The purpose of the Committee is to ensure effective participation by the Federal Government in domestic and international standards activities and to promote the adherence to uniform policies by Federal agencies in the development and use of standards. Well-considered Federal policies reflecting the public interest can expedite the development and adoption of standards that stimulate competition, promote innovation, and protect the public safety and welfare. The establishment and application of appropriate standards for the characteristics or performance of goods, processes, and services can contribute significantly to national and international prosperity, economic growth, and public health and safety. The establishment of such standards can also further national goals for environmentally sound and energy efficient materials, products, systems, services, or practices. Heightened national and international awareness of the importance of standards activities, as reflected by enactment of the National Technology Transfer and Advancement Act of 1995 (P.L. 104-113, signed into law March 7, 1996), and recommendations presented in the National Research Council's report "Standards, Conformity Assessment, and Trade into the 21st Century" (National Academy Press, 1995) call for the Committee to intensify its efforts to identify the broad roles and appropriate interactions of agencies in exercising the Government's authority. 


\section{Objective}

The objective of the Committee shall be to promote effective and consistent standards policies in furtherance of U.S. domestic and foreign goals and, to this end, to foster cooperative participation by the Federal Government and U.S. industry and other private organizations in standards activities, including the related activities of product testing, quality system registration, certification, and accreditation programs.

\section{Functions}

1. As appropriate, the Committee shall gather, analyze, and maintain current information about standards, product testing, quality system registration, accreditation and certification, and related regulations, rules, policies, and activities:

(a) conducted within or established by Federal agencies;

(b) conducted by private domestic and foreign national standards bodies and by regional and international private and intergovernmental organizations engaged in such programs; and

(c) pertaining to the relationships among agencies of the Federal Government with industry and the various national, regional, and international organizations engaged in such programs.

2. On the basis of such information and when appropriate with respect to the activities named in paragraph one above, the Committee shall make recommendations to the Secretary of Commerce to:

(a) strengthen coordination of the standards-related policies and activities among the Federal agencies;

(b) improve the efficiency within the Federal Government of standardization efforts with the U.S. private sector, as well as with regional and international organizations, both private and governmental;

(c) promote standards-related policies, including directory of personnel participating in standards activities, within the Federal Government consistent with statutory obligations in regard to interactions with non-federal government organizations;

(d) ensure effective representation of the Federal Government at significant regional and international standards-related meetings and conferences;

(e) promote the use of internationally acceptable standards and related activities with a view to increasing trade and economic integration and development;

(f) monitor U.S. technical obligations as a signatory to the World Trade Organization, the U.S.-Canada Free Trade

Agreement, the North American Free Trade Agreement, and other treaties encompassing standards-related trade issues; 
(g) encourage the development of agency strategic plans for managing and monitoring use of voluntary standards and participation in standards-related activities;

(h) promote the use of standards that serve national goals related to increased use of the metric system of measurement and environmentally sound and energy efficient materials, products, systems, services, and practices; and

(I) assess and improve the adequacy of such agency plans and activities.

\section{Membership}

1. Together with the Department of Commerce the following agencies constitute the membership of the Committee:

Department of Agriculture

Department of Defense

Department of Education

Department of Energy

Department of Health and Human Services

Department of Housing and Urban Development

Department of the Interior

Department of Justice

Department of Labor

Department of State

Department of Transportation

Department of the Treasury

Department of Veterans Affairs

Office of Consumer Affairs

Consumer Product Safety Commission

Environmental Protection Agency

Federal Communications Commission

Federal Emergency Management Agency

Federal Trade Commission

General Services Administration

International Trade Commission

Office of Management and Budget

National Aeronautics and Space Administration

National Archives and Records Administration

National Communications Systems (Dept. of Defense)

(non-voting member)

National Science Foundation

Nuclear Regulatory Commission

U.S. Agency for International Development 
U.S. Government Printing Office (legislative liaison non-voting member)

U.S. Postal Service

Office of the U.S. Trade Representative

The head of each member agency shall ensure representation by a responsible high level policy official (Senior Executive Service or higher) who serves as the agency representative on the Committee. Such agency representative shall also serve as the "Standards Executive" as defined in section 8.b.2 of OMB Circular No. A-119. Appointments to the Committee shall be for an indefinite term.

2. Agency representatives may designate alternates of equivalent senior status to serve in their absence.

3. Experts from organizations within the member agency may be designated by agency representatives to serve on task groups established by the Committee.

4. Other Federal agencies may become members of the Committee upon application to or invitation by the Secretary of Commerce.

\section{Administrative Provisions}

1. The Director of the National Institute of Standards and Technology (NIST) or the Director's designee shall chair the Committee.

2. NIST shall provide administrative arrangements for the Committee including secretarial services, calling of meetings, arranging for a meeting place, and preparation of an agenda, discussion material, and reports.

3. The Committee shall meet at least three times each year. Other meetings may be called at the discretion of the Chair or at the written request of five (5) members of the Committee.

4. The Committee may establish task groups as appropriate.

5. Attendance at Committee meetings by at least one half of the designated members of the Committee shall constitute a quorum. Decisions internal to the Committee's operations, such as formation of a task group, shall be made by a majority of those present and voting. Voting on Committee business and proposals shall be limited to designated agency members. Decisions concerning Committee recommendations to the Secretary of Commerce on governmental policy or other matters set out in paragraph two of the section entitled "Functions" shall require ratification by two-thirds of the members present and voting. Dissenting positions of the decision may be made a matter of record. The Chair shall not vote except in the case of a tie vote. 
6. The annual cost of operating the Committee is estimated at $\$ 31,000$ (with overhead) which includes 0.20 staff year for staff support.

7. The Committee shall submit an annual report to the Secretary of Commerce so that the Secretary may satisfy the reporting requirements set forth in OMB Circular No. A-119, as applicable to the Secretary, and in P.L. 104-113, as applicable to the head of each agency. Each such report shall also summarize the Committee's activity during the period covered and shall include a listing of all recommendations formulated by the Committee during that period.

\section{Duration}

The need and mission of the Committee shall be reexamined three years after the date of this Charter to determine the need for the Committee's continuation.

/signed/

Secretary of Commerce

Dated: October 29, 1997 


\section{Appendix D:}

Membership of the Interagency

Committee

on Standards Policy

FY 1998 
AGENCY MEMBER

Agency for International Development, U.S. (USAID)

\section{Agriculture, Department of (USDA)}

\section{Commerce, Department of}

\section{Consumer Product Safetv Commission (CPSC)}

Alternate:

\section{REPRESENTATIVE}

Mr. James Murphy

Deputy Director, Office of Procurement

13000 Pennsylvania Ave

Washington, DC 20523-7900

Phone: 202-712-0610

Fax: 202-216-3395

Email: imurphy@usaid.gov

Ms. Anne F. Thomson Reed

Acting Chief Information Officer

Room 416-W

Jamie L. Whitten Federal Building

1400 Independence Avenue, SW

Washington, DC 20250-7603

Phone: 202-720-8833

Fax: 202-720-1031

Mr. Ronald Garbin Program, Planning \& Management Division Office of the Chief Information Officer

Stop 7603 Room 447-W

Jamie L. Whitten Federal Building

1400 Independence Avenue, SW

Washington, DC 20250-7603

Phone: $202-720-8026$

Fax: 202-690-2688

Dr. Belinda L. Collins

Director, Office of Standards Services

National Institute of Standards and Technology

100 Bureau Drive STOP 2100

Gaithersburg, MD 20899-2100

Phone: 301-975-4000

Fax: 301-963-2871

Email: belinda.collins@nist.gov

Mr. Colin B. Church

Voluntary Stnds \& International Activities Coordinator

4340 East-West Highway

Room 604-C

Bethesda, MD 20207

Phone: $301-504-0554 \times 2229$

Fax: 301-504-0407

Email: cchurch@cpsc.gov

Ms. Jacquie Elder

Deputy Assistant Executive Director

Room 702

Bethesda MD 20207

Phone: 301-504-0554 x 2254

Fax: 301-504-0407

Email: jelder@cpsc.gov 
Defense, Department of (DOD)

\section{Alternate:}

Education, Department of (DOEd)

Energy, Department of (DOE)

Alternate:

Environmental Protection Agency (EPA)
Mr. Gregory E. Saunders

Director, Defense Standardization Program Office

Defense Standardization Program Office

ATTN: DLSC-LM

8725 John J. Kingman Road, Suite 2533

Fort Belvoir VA 22060-6221

Phone: 703-767-6888

Fax: 703-767-6876

Email: gregory saunders@hq.dla.mil

Ms. Trudie Williams

Defense Standardization Program Office ATTN: DLSC-LM

8725 John J. Kingman Road, Suite 2533

Fort Belvoir VA 22060-6221

Phone: 703-767-6875

Fax: 703-767-6876

Mr. Gerald Malitz National Center for Education Statistics 555 New Jersey Avenue, NW

Washington, DC 20208

Phone: 202-219-1364

Fax: 202-219-1728

Email: gerald malitz@Ed.gov

Mr. Richard L. Black

Director, Office of Nuclear Safety Policy and Standards (EH-31)

Room A-430, GTN

Washington, DC 20854

Phone: 301-903-3465

Fax: 301-903-6172

Email: r.black@eh.doe.gov

Mr. Richard J. Serbu

Manager, DOE Technical Standards Program (EH-31)

19901 Germantown Road

Germantown MD

Phone: 301-903-2856; Fax: 301-903-6172

Email: richard.servu@eh.doe.gov

Ms. Mary McKiel

Director, EPA Voluntary Standards Network Office of Pollution Prevention \& Toxics

401 M Street, S.W., MC 7409

Washington, DC 20460

Phone: 202-260-3584

Fax: 202-260-0178

Email: mckiel.mary@epamail.epa.gov 
Alternate:

Federal Communications Commission (FCC)

Federal Emergency Management Agency (FEMA)

\section{Federal Trade Commission (FTC)}

General Services Administrations (GSA)

\section{Alternate:}

Mr. Craig Annear

Office of General Council (2322)

401 M Street, SW

Washington DC 20460

Phone: 202-260-5328

Fax: 202-260-8392

Email: annear-craig@epamail.epa.gov

Mr. Julius P. Knapp

Chief, Office of Engineering and Technology

1919 M Street, NW

Mail Stop Code 1300

Washington, DC 20554

Phone: 202-418-2468

Fax: 202-418-1944

Email: iknapp@fcc.gov

Ms. Rosetta Bowsky

Information Technology Svcs Directorate

FEMA Room 252 FCP

Washington, DC 20472

Phone: 202-646-3827

Fax: 202-646-3074

Email: rosetta.bowsky@fema.gov

Mr. Dean Graybill

Associate Director for the Division of Service Industry Practices

Bureau of Consumer Protection

6th and Pennsylvania Avenue, NW

Room 200

Washington, DC 20580

Phone: 202-326-3284

Fax: 202-326-3392

Mr. William N. Gormley

Assistant Commissioner

Office of Acquisition, Federal Supply Service (FC)

Jefferson Davis Highway

Room 710

Arlington, VA 22202

Phone: 703-305-7901

Fax: 703-305-6851

Email: william.gormley@gsa.gov

Charles P. Gallagher

Director, Environmental \& Engineering Policy (FCOE)

Jefferson Davis Highway

Room 703

Arlington, VA 22202

Phone: 703-305-6930

Fax: 703-305-6731

Email: charles.gallagher@gsa.gov 


\section{Government Printing Office, U.S. (GPO)}

Health and Human Services, Department of (HHS)

Alternate:

Housing and Urban Development, Department of (HUD)

Alternates:
Mr. Robert H. Thomas

Actg. Manager, Quality Control and Technical Department

North Capital NH Streets

Washington, DC 20401

Phone: 202-512-0766

Fax: 202-512-0015

Email: rthomas@gpo.gov

Ms. Linda R. Horton

Director, International Policy

Food and Drug Administration, HHS

HF-23

5600 Fishers Lane Rm 15-74

Rockville, MD 20857

Phone: 301-827-3344

Fax: 301-443-6906

Email: Ihorton@oc.fda.gov

Kathleen Hastings

Office of International Policy

Food and Drug Administration, HHS

HF-23

5600 Fishers Lane Rm 15-74

Rockville, MD 20857

Phone: 301-827-3344

Fax: 301-443-6906

Email: khasting@oc.fda.gov

Mr. Xavier de Souza Briggs

Deputy Assistant Secretary for Research,

Evaluation and Monitoring

Office of Policy Development \& Research

451 7th Street, SW, Room 8146

Washington, DC 20410

Phone: $202-708-4230 \times 5716$

Fax: 202-708-3141

Email: xavier_briggs@hud.gov

Mr. Les Breden

Materials Engineer

451 7th Street, SW

Room 9152

Washington, DC 20410

Phone: 202-708-6423

Fax: 202-708-4213

Email: leslie h.breden@hud.gov

Dr. Warren Friedman

Research Manager

Office of Lead Hazard Control (LS)

451 7th Street, SW

Washington, DC 20410

Phone: 202-755-1785 x\#159

Fax: 202-755-1000

Email: Warren_Friedman@HUD.gov 
Interior, Department of the (DOI)

International Trade Commission (ITC)

Justice, Department of (DOJ)

Labor, Department of (DOL)

National Aeronautics and Space Administration (NASA)

Alternate:
Mr. Claude J. Christensen

Chief, IRM Program Planning, Review, and Standards Division

1849 C Street, NW

Mail Stop ? 5312

Washington, DC 20240

Phone: 202-208-3028

Fax: 202-501-2360

Email: claude christensen@ios.doi.gov

Mr. Stephen A. McLaughlin

Acting Director, Office of Administration 500 E Street, SW

Room 212

Washington, DC 20436

Phone: 202-205-3131

Fax: 202-205-2034

Dr. M. Wayne Shiveley Information Management and Security Staff 1001 G Street NW, Suite 850

Washington, DC 20530

Phone: 202-305-4107

Fax: 202-616-5455

Email: shivelew@usdoi.gov

Mr. Roland G. Droitsch Deputy Assistant Secretary for Policy Room S 2312

200 Constitution Avenue, NW

Washington, DC 20210

Phone: 202-219-9058

Fax: 202-219-9216

Email: droitsch-roland@dol.gov

Mr. Daniel R. Mulville

Mail Code AE

NASA Headquarters

300 E Street, SW

Washington, DC 20546-1823

Phone: 202-358-1823

Fax: 202-358-3296

Email: daniel.mulville@hq.nasa.com

Mr. Richard H. Weinstein Mail Code AE

NASA Headquarters

300 E Street, SW

Washington DC 20546-1823

Phone: 202-358-0538

Fax: 202-358-3296

Email: richard.weinstein@hq.nasa.gov 
National Archives and Records Administration (NARA)

\section{National Communications System (NCS)}

National Science Foundation (NSF)

Nuclear Regulatory Commission (NRC)

Alternate:

Office of Management and Budget (OMB) Liaison
Ms. Mary Ann Hadyka

National Archives and Records Administration Policy and Communication Staff

8601 Adelphi Road

Suite 4100

College Park, MD 20740-6001

Phone: 301-713-7360 ext. 222

Fax: 301-713-7270

Email: maryann.hadyka@arch2.nara.gov

Mr. Gary Fereno

Chief, Technology and Standards Division

Office of the Manager

701 South Court House Road

Arlington, VA 22 204-2198

Phone: 703-607-6200

Fax: 703-607-4830

Email: ferenog@ncs.gov

Dr. William S. Butcher Senior Engineering Advisor Engineering Education and Centers Division 4201 Wilson Boulevard, Suite 585

Arlington, VA 22230

Phone: 703-306-1380

Fax: 703-306-0289

Email: wbutcher@nsf.gov

Mr. John W. Craig

Director, Division of Regulatory Applications Office of Nuclear Regulatory Research Mail Stop T-9-F-33

Washington, DC 20555

Phone: 301-415-6207

Fax: 301-415-5385

Email: JWC1@nrc.gov

Gilbert C. Millman

Program Manager C \& S

Office of Nuclear Regulatory Research

Mail Stop T-10-D20

Washington, DC 20555

Phone: 301-415-5843

Fax: 301-415-5151

Email: gcm@nrc.gov

Ms. Virginia A. Huth

Policy Analyst, Information Policy Branch Office of Information and Regulatory Affairs NEOB, Room 10236

Washington, DC 20503

Phone: 202-395-3785

Fax: 202-395-5167

Email: HUTH_V@A1.EOP.GOV 


\section{Postal Service, U.S.}

State, Department of (STATE)

Transportation, Department of (DOT)

\section{Treasury, Department of (Treasurv)}

Meeting Correspondence to:

U. S. Trade Representative (USTR)
Mr. Bruce McConnell

Chief, Information Policy Branch

Office of Information and Regulatory Affairs

NEOB, Room 10236

Washington, DC 20503

Phone: 202-395-3785

Fax: 202-395-5167

Email: bruce.mcconnell@al.eop.gov

Mr. Myles A. Jackson

Manager, Configuration Management

Engineering Research and Development

Merrifield, VA 22082-8101

Phone: $703-280-7281$

Fax: 703-280-8414

Email: miackson@email.usps.gov

Ms. Marian Gordon

Director for Telecommunications and Information Standards

2201 C St. NW, Room 2529

Washington, DC 20520

Phone: 202-647-0197

Fax: 202-647-7407

Email: gordonmr@ms6820wpoa.us-state.gov

Mr. Frank Turpin

Director of International Harmonization

National Highway Traffic Safety

Administration

400 Seventh Street, SW

Suite 5220

Washington, DC 20590

Phone: 202-366-2114

Fax: 202-366-2106

Mr. James J. Flyzik

Deputy Assistant Secretary (Information Systems) \& Chief Information Officer

1500 Pennsylvania Avenue, NW

Room 2464

Washington, DC 20220

Phone: 202-622-1200

Fax: 202-622-2224

Email: jim.flyzik@cio.treas.gov

Mrs. Helen W. Whatley Office of Information Resources Management 1425 New York Avenue, NW

Washington DC 20220

Phone: 202-622-1541

Fax: 202-622-1595

Email: helen.whatley@clo.treas.gov

Ms. Suzanne Troje Director, Technical Trade Barriers $60017^{\text {th }}$ Street, NW

Washington, DC 20508

Phone: 202-395-9444

Fax: 202-395-5674 
Veterans Affairs, Department of (VA)

National Institute of Standards and Technology

National Institute of Standards and Technology

National Institute of Standards and Technology

National Institute of Standards and Technology

National Institute of Standards and Technology

National Institute of Standards and Technology
Mr. Gary J. Krump

Deputy Asst Secretary for Acquisition \& Materiel Management (90)

810 Vermont Avenue, NW

Washington, DC 20420

Phone: 202-273-6029

Fax: 202-273-6163

Email: krugar@mail.va.gov

Maureen Breitenberg

100 Bureau Drive STOP 2100

Gaithersburg, MD 20899-2100

Phone: 301-975-4031

Email: maureen.breitenberg@nist.gov

James Cigler

100 Bureau Drive STOP 2140

Gaithersburg, MD 20899-2140

Phone: 301-975-4171

Email: james.cigler@nist.gov

Patrick Cooke

100 Bureau Drive STOP 2150

Gaithersburg, MD 20899-2150

Phone: 301-975-4033

Fax: 301-926-1559

Email: patrick.cooke@nist.gov

Christine DeVaux

100 Bureau Drive STOP 2110

Gaithersburg, MD 20899-2110

Phone: 301-975-5503

Email: christine.devaux@nist.gov

Krista Johnsen-Leuteritz

100 Bureau Drive STOP 2100

Gaithersburg, MD 20899-2100

Phone: 301-975-5104

Email: krista.leuteritz@nist.gov

JoAnne Overman

100 Bureau Drive STOP 2150

Gaithersburg, MD 20899-2150

Phone: 301-975-4037

Email: joanne.overman@nist.gov 
APPENDIX E:

\section{LIST OF NIST PUBLICATIONS RELATED TO P. L. 104-113}




\title{
Publications on Standards And Conformity Assessment Activities
}

\author{
Office of Standards Services \\ National Institute of Standards and Technology \\ Gaithersburg, Maryland 20899
}

The ABC's of Standards-Related Activities in the United States (NBSIR 87-3576) - This report is an introduction to voluntary standardization, product certification and laboratory accreditation for readers not fully familiar with these topics. It stresses some of the more important aspects of these fields; furnishes the reader with both historical and current information on these topics; describes the importance and impact of the development and use of standards; and serves as background for using available documents and services.

The ABC'S of Certification Activities in the United States (NBSIR 88-3821) - This report, a sequel to NBSIR 87-3576, The ABC'S of Standards-Related Activities in the United States, provides an introduction to certification for readers not entirely familiar with this topic. It highlights some of the more important aspects of this field, furnishes the reader with information necessary to make informed purchases, and serves as background for using available documents and services.

$\underline{A B C}$ 's of the U.S. Conformity Assessment System (NISTIR 6014) - This report is designed to provide the reader with an introduction to conformity assessment and information on how the various conformity assessment activities are interlinked. It highlights some of the field's more important aspects and serves as background for using available documents and services.

Laboratory Accreditation in the United States (NISTIR 4576) - This report, a companion to NBSIR 87-3576 The ABC'S of Standards-Related Activities in the United States and NBSIR 883821 The ABC'S of Certification Activities in the United States, is designed to provide information on laboratory accreditation to readers who are new to this field. It discusses some of the more significant facets of this topic, provides information necessary to make informed decisions on the selection and use of laboratories, and serves as background for using other available documents and services.

Questions and Answers on Quality, the ISO 9000 Standard Series, Quality System Registration. and Related Issues (NISTIR 4721) - This report provides information on the development, content and application of the ISO 9000 standards to readers who are unfamiliar with these aspects of the standards. It attempts to answer some of the most commonly asked questions on quality; quality systems; the content, application and revision of the ISO 9000 standards; quality system approval/registration; European Community requirements for quality system approval/ registration; and sources for additional help. 
More Questions and Answers on the ISO 9000 Standard Series and Related Issues (NISTIR 5122) - This report, a sequel to NISTIR 4721, provides additional information on the ISO 9000 standards and related issues to readers unfamiliar with some of the new developments in this area. It attempts to answer additional questions on ISO 9000 standards related issues which NIST has received since the publication of NISTIR 4721 and identifies sources for further help in this area.

The U.S. Certification System from a Government Perspective (NISTIR 6077) - This report is designed to provide the reader with an introduction to the U.S. certification system from a governmental perspective. It highlights some of the relationships that exist between Federal and state agencies and the private sector and discusses some of the history and philosophy behind the U.S. system.

The National Technology Transfer and Advancement Act - Plan for Implementation (NISTIR 5967) - The National Technology Transfer and Advancement Act (P.L. 104-113) gives NIST responsibility to coordinate standards and conformity assessment activities with other Federal agencies, state and local governments, and with the private sector. Congress required NIST to submit a plan for implementing the coordination activities. Specific activities in strategic standards management, responsiveness to international trade concerns, greater use of voluntary standards, and conformity assessment procedures are described. Responsibilities of governments, standards developers, and private sector interests are outlined, as are a number of specific tasks.

Report on the Open Forum on Establishment of the National Council for Laboratory Accreditation (NACLA) at the National Institute of Standards and Technology January 7, 1997 (NISTIR 6008) - The forum was jointly sponsored by NIST, ACIL (formerly the American Council of Independent Laboratories), and the American National Standards Institute (ANSI). It was attended by more than 300 representatives from private industry and the government. The purpose of the Forum was to discuss a proposal to establish the National Council for Laboratory Accreditation (NACLA), which would be a cooperative partnership between the public and private sectors designed to provide a national infrastructure for laboratory accreditation in the United States.

Examination of Laboratory Accreditation Programs in the United States and the Potential Role for a National Laboratory Accreditation System (NIST GCR 97-714) - This report presents an initial study of existing U.S. laboratory accreditation programs, with a focus on government programs, particularly at the Federal level. The study was conducted in two phases: Phase I established categories of existing laboratory accreditation programs in the Federal government, at the state and local level, and in the private sector. Phase II compared technical standards used by five Federal government laboratory accreditation programs with general standards for laboratory accreditation established by ISO. 
Proceedings of the Open Forum on Laboratory Accreditation at the National Institute of Standards and Technology October 13,1995 (NIST SP 902) - The American National Standards Institute and ACIL requested that NIST work with them in an informal Laboratory Accreditation working group (LAWG) to evaluate the current situation in laboratory accreditation in the United States. This group sponsored a forum to hear reports from various sectors and to arrive at some consensus on the need to improve the current situation and infrastructure for laboratory accreditation in the United States.

Survey on the Implementation of ISO/IEC Guide 25 by National Laboratory Accreditation Programs (NISTIR 5473) - ISO/IEC Guide 25, General Requirements for the Competence of Calibration and Testing Laboratories, has been used by many laboratory accreditation programs worldwide to establish accreditation requirements designed to promote confidence in the calibrations and testing results of laboratories. National delegations to the International Laboratory Accreditation Conference (ILAC) were surveyed to collect information on the implementation and supplementation of the requirements of ISO/IEC Guide 25 within the context of their countries' laboratory accreditation programs. This report summarizes the results of that survey and includes a bibliographic list of publications concerned with ISO/IEC Guide 25 implementation complied from the information by the national delegations.

Directory of International and Regional Organizations Conducting Standards-Related Activities (NIST SP 767) - This directory contains information on 338 international and regional organizations which conduct standardization, certification, laboratory accreditation, or other standards-related activities. It describes their work in these areas, as well as the scope of each organization, national affiliations of members, U.S. participants, restrictions on membership, and the availability of any standards in English.

Directory of European Regional Standards-Related Organizations (NIST SP 795) - This directory identifies more than 150 European regional organizations - both governmental and private - that engage in standards development, certification, laboratory accreditation, and other standardsrelated activities, such as quality assurance. Entries describe the type and purpose of each organization; acronyms; national affiliations of members; the nature of the standards-related activity; and other related information.

Standards Activities of Organizations in the United States (NIST SP 806, 1996 Edition) - The directory identifies and describes activities of over 700 U.S. public and private sector organizations which develop, publish, and revise standards; participate in this process; or identify standards and make them available through information centers or distribution channels. The revision covers activities related to both mandatory and voluntary U.S. standards. It also contains a subject index and related listings that cover acronyms and initials, defunct bodies and organizations with name changes. 
Directory of Federal Government Certification Programs (NBS SP 739) - This directory presents information on U.S. Government certification programs for products and services. Entries describe the scope and nature of each certification program, testing and inspection practices, standards used, methods of identification and enforcement, reciprocal recognition or acceptance of certification, and other relevant details.

Directory of U.S. Private Sector Certification Programs (NIST SP 903) - This publication presents information on 178 private sector groups in the United States which engage in product certification activities. Entries describe the type and purpose of each organization, the nature of the activity, a pictorial representation of the organization's mark (if available), products certified, standards used, certification requirements, any accreditation or recognition by a U.S. or foreign private sector or government agency, availability of services, methods of cost determination, and other relevant details.

Directory of Federal Government Laboratory Accreditation/Designation Programs (NIST SP 808) - This directory provides updated information on 31 Federal government laboratory accreditation and similar type programs conducted by the Federal government. These programs, which include some type of assessment regarding laboratory capability, designate sets of laboratories or other entities to conduct testing to assist Federal agencies in carrying out their responsibilities. The directory also lists 13 other federal agency programs of possible interest, including programs involving very limited laboratory assessment and programs still under development.

Directory of State and Local Government Laboratory Accreditation/Designation Programs (NIST SP 815) - This directory provides updated information on 21 state and 11 local government laboratory accreditation and similar type programs. These programs, which include some type of assessment regarding laboratory capability, designate private sector laboratories or other entities to conduct testing to assist state and local government agencies in carrying out their responsibilities. Entries describe the scope and nature of each program, laboratory assessment criteria and procedures used in the program, products and fields of testing covered, program authority, and other relevant details.

Directory of Professional/Trade Organization Laboratory Accreditation/Designation Programs (NIST SP 831) - This directory is a guide to laboratory accreditation and similar types of programs conducted by professional and trade organizations. These programs accredit or designate laboratories or other entities to assist private sector professional societies, trade associations, related certification bodies, their membership, as well as government agencies, in carrying out their responsibilities. This accreditation or designation is based on an assessment of the capability of the laboratory to conduct the testing. However, the nature of the assessment varies considerably by organization and program.

ISO Environmental Management Standardization Efforts (NISTIR 5638-1) - This report describes the development of planned "environmental management" standards by the 
International Organization for Standardization (ISO). These standards address management systems and the environmental aspects of products in the areas of life cycle assessment and labeling. The report outlines the current status of the ISO standards and also covers developments relating to third party certification of environmental management systems.

Standards Setting in the European Union - Standards Organizations and Officials in EU Standards Activities (NIST SP 891, 1997 Edition) - The guide is designed to help U.S. manufacturers, exporters, and other interested persons in locating contact points for important information on the development of standards and conformity assessment issues. The report includes a history of the role of standards in the European Union (EU) and the latest information on the EU's harmonization directives for implementing the "New Approach" and the "Global Approach" for harmonizing technical regulations and standards to reduce barriers to trade.

Profiles of National Standards-Related Activities (NIST SP 912) - This directory describes the metrology, standardization, testing and quality (MSTQ) activities of more than 70 countries. Each entry includes basic data on the country's economy and trade; agencies and institutions responsible for metrology and calibration, standards development, testing, product certification, quality and environmental system registration and accreditation; and key contacts and information sources. Entries are formatted to facilitate access to specific information. An introductory section provides general information on development of the directory and an overview of world-wide MSTQ activities.

TBT Agreement Activities of the National Institute of Standards and Technology - This annual report describes the World Trade Organization (WTO) Agreement on Technical Barriers to Trade (TBT) activities conducted by NIST. NIST receives notifications of proposed foreign technical regulations related to trade, responds to inquiries on proposed technical regulations, participates in various bilateral and multilateral standards-related trade discussions, and respond to inquiries on the existence, source and availability of standards and standards-related information.

Using Voluntary Standards in the Federal Government (NISTIR 6086) - This report is a compilation of presentations given at a NIST-sponsored conference held on September 8, 1997, to foster better understanding among Federal agencies of the private sector standardization process. The conference took place as part of a major effort by NIST to implement the National Technology Transfer and Advancement Act which gives NIST responsibility to coordinate standards and conformity assessment activities with other Federal agencies, state and local governments, and with the private sector.

Environmental Management Systems Voluntary Project Evaluation Guidance (NISTIR 6120) The intent of this document is to provide a framework for the collection of information of value to regulatory agencies and others interested in determining the impact in several key areas of environmental management systems based on ISO 14001. 
National Voluntary Laboratory Accreditation Program (NVLAP) Directory (SP 810, 1998 Edition) - This annual directory lists laboratories that have been found to be competent to perform certain tests or calibrations as specified. These laboratories are allowed to use the NVLAP logo on their test or calibration certificates or reports, which implies that the processes used to achieve the tests or calibrations have been evaluated by NVLAP as being technically adequate when performed under the conditions specified in the laboratories' quality manuals and associated documentation. 
$+$ 